\title{
A study of The use of Manuka Honey and Methylglyoxal to Impart Antimicrobial Activity to Wool Textiles and Polymers
}

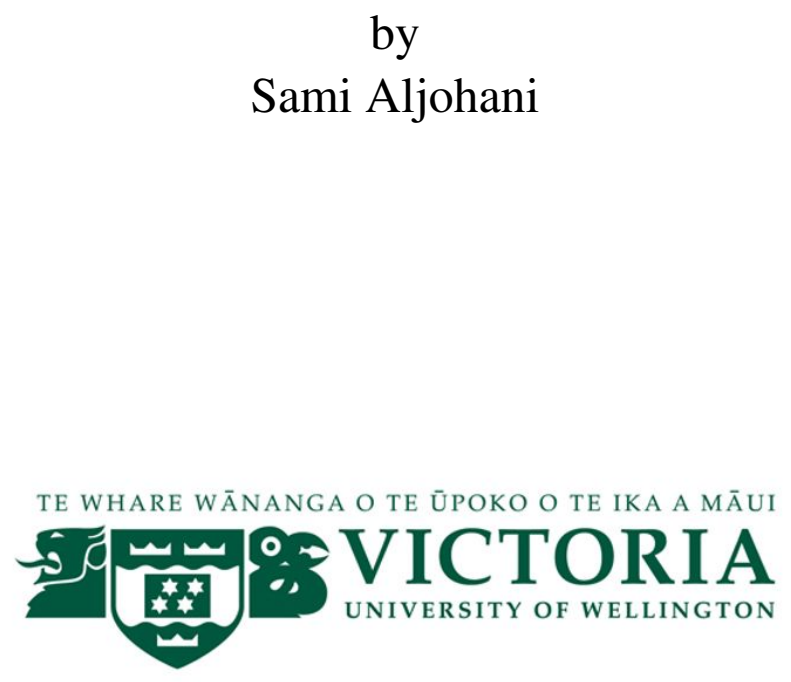

A thesis

submitted to Victoria University of Wellington in fulfilment of the requirements for the degree of Master of Science in Chemistry.

Victoria University of Wellington 2018 


\section{Abstract}

Methylglyoxal (MGO), which is an ingredient in New Zealand Manuka honey (MH) possesses unique antimicrobial properties against a broad range of bacteria. MGO has been determined to have a low minimum inhibitory concentration against bacteria. This provides a new opportunity to develop the use of this compound as a natural antimicrobial agent to impart such antimicrobial properties to wool textiles. This is the focus and detailed research work of this thesis. Also, its application to paper and polymer surfaces has been investigated briefly.

Due to their protein-based structure and porosity, woollen textiles provide a hospitable host for the growth of microorganisms. This microbial growth on such textiles can pose an undesirable health risk to humans and can negatively affect textile sales. the textile market. Similarly, microbial growth on other substrates such as walls, floors and various equipment can also pose health risks. There are a number of antimicrobial treatments on the market, but with the move to more natural-based antimicrobial agents, there is an opportunity to capture the natural antimicrobial properties of $\mathrm{MH}$ and particularly the active ingredient MGO, as a natural antimicrobial agent in wool textiles and paper and polymer substrates.

This research developed a novel approach and methodology to incorporate $\mathrm{MH}$ and also MGO itself as an isolated component and antimicrobial agent of $\mathrm{MH}$, into the wool fibres and chemically bonding it to the fibre proteins. This approach commenced with determining the extent of uptake of $\mathrm{MH}$, based on its MGO concentration, and MGO itself into wool fibres. The extent of MH and MGO uptake has been determined with High-Performance Liquid Chromatography (HPLC). This uptake was studied over a range of $\mathrm{MH}$ and $\mathrm{MGO}$ concentrations and temperatures using loose top wool, yarn and finished wool fabric. An increase in temperature from room temperature up to 80 ${ }^{\circ} \mathrm{C}$ resulted in significantly higher amounts of MGO and $\mathrm{MH}$ being absorbed by the wool. Also, higher concentrations of the initial MGO and MH solutions accelerated the uptake rates and resulted in higher uptake amounts. The relatively slow diffusion rate of MGO into the wool necessarily required a long period of time, up to 14 days, for the particular uptake to generally reach the saturation level. The maximum amounts of $\mathrm{MH}$ and MGO that were incorporated into wool fibres in this study were $21.2 \mathrm{mg} \mathrm{g}^{-1}$ and $299 \mathrm{mg} \mathrm{g}^{-1}$ wool, respectively.

The chemical interactions between MGO and MGO in MH with the wool fibres have been characterised by Fourier-Transform Infrared (FTIR) spectroscopy, Differential Scanning Calorimetry (DSC) and Thermogravimetric Analysis (TGA). FTIR spectra 
showed that the MGO absorption by the wool changed the intensity of particular peaks between 2,000 and $700 \mathrm{~cm}^{-1}$ characteristic of the wool proteins, and the NH stretching peaks of the wool at $3,270 \mathrm{~cm}^{-1}$. The TGA and DSC analyses showed a thermal stability of the wool after MGO absorption and the likely formation of new bonds, probably H-bonds, between the MGO and the wool. Confirming these findings, the MGOWool and $\mathrm{MH}-$ Wool showed a resistance against MGO leaching on washing with water, where less than $1 \%$ (relative) of MGO leached out. These results suggest the MGO is likely chemically bound to the wool fibres through hydrogen bonding.

The MGO-Wool and also MGO-paper composites produced in a similar way with MGO-Wool, exhibited antimicrobial activities against Gram-positive Staphylococcus aureus (S. aureus) and Gram-negative Escherichia coli (E. coli). The MGO-Wool showed bacteriostatic properties for all composites even after three months of being synthesised. This opens up potential applications for the use of MH and MGO in antimicrobial woollen apparel, medical textiles and bandages.

In addition, MGO was incorporated into samples of an acrylic polymer NeoCryl ${ }^{\circledR}$ XK98 and a polyurethane, Kamthane K-5000, polymer resin, respectively. The interaction of MGO with the respective polymer chains resulted in similar hydrogen bonding between MGO and the polymers. At high MGO concentrations this bonding was confirmed by the presence of a new endothermic peak in the DSC pattern. The addition of MGO also modified the polymer surface and resulted in a more hydrophobic surface with an increased water droplet contact angle of $87.5^{\circ}$. The new polymer composites were successfully tested against $S$. aureus and $E$. coli microbes and were shown to exhibit antimicrobial properties. 


\section{Acknowledgements}

My words started diminished in front of the caring, love support that my family have offered whether back home or in New Zealand. My parent's prayers and thoughts have been of help to me over the course of my life.

"Welcome aboard Sami ... you've done a great job", I heard these words on the day I started and on submission of my thesis. Between these two moments, I could not have asked for better support, patience and advice I have received from him throughout my time as his student. I would like to express my sincere gratitude to my supervisor Professor Jim Johnston. This work would not have been completed without his guidance.

I would like to thank all the research group, especially to Dr Matthew Cairns for his valuable discussions, advice and helping me run the HPLC. Also, a big thank to Matilda Hayward for her insights and proofreading. To the entire research group Dr Thomas Borrmann, Dr Eldon Tate, Dr Michelle Cook, Emma Wrigglesworth, Michael Schweig, Peter Shaw for your support, friendships and for creating such a friendly work environment.

I would like to thank Dr David Ackerley and his research group especially Dr Alistair Brown for letting me use their laboratory and helping me run the antimicrobial tests.

I would like to express my gratitude to my country the Kingdom of Saudi Arabia for sponsoring my study and giving me this opportunity.

It is a pleasure to thank my friends Omar Alsqar, Muhammad Ali Hashmi, Mohammad Alzeer, Mohammed Nofal and many others who made my stay in Wellington memorable. I am also indebted to Zoe Bouchu who has been on my side, encouraging me through my research, the time and effort to proofread my thesis.

Sami Aljohani 


\section{Contents}

$\begin{array}{ll}\text { Abstract } & \text { ii }\end{array}$

Acknowledgements $\quad$ iv

Table of Contents $\quad$ v

List of Figures

List of Schemes $\quad$ xiv

$\begin{array}{ll}\text { List of Tables } & \text { xv }\end{array}$

Glossary $\quad$ xvi

1 Introduction 1

$1.1 \quad$ Natural Products $\ldots \ldots \ldots \ldots$

1.1 .1 History . . . . . . . . . . . . . . . . 2

1.1 .2 Plants ......................... 4

1.1.3 Drug Precursors from Plant Secondary Metabolites . . . . . . . 5

1.1.3.1 Prototype drugs from Plant Secondary Metabolites . . 6

1.1.4 Natural Antimicrobial Products from Plant Kingdom . . . . . 7

1.1.5 Antimicrobial Mechanism of Plant Compounds . . . . . . . 8

1.1.6 Antibiotic Resistant Bacteria _. . . . . . . . . . . . 9 
1.2 Honey ................................. 9

1.2.1 Introduction . . . . . . . . . . . . . 9

1.2 .2 History . . . . . . . . . . . . . . . . 10

1.2.3 Chemistry of Honey . . . . . . . . . . . . . . . . . 11

1.2.3.1 Carbohydrates ............... 11

1.2.3.2 Proteins ................. 12

1.2.3.3 Vitamins ................ 12

1.2.3.4 Minerals . . . . . . . . . . . . . . 12

1.2.3.5 Phenolic Compounds . . . . . . . . . . . 13

1.2.3.6 Aroma Compounds . . . . . . . . . . . . . 14

1.2.3.7 Organic Acids and other Compounds . . . . . . . . . 14

1.2.4 Antioxidant Properties of Honey . . . . . . . . . . . . . . 15

1.2.5 Antimicrobial Activity of Honey . . . . . . . . . . . . . . 17

1.2.5.1 Non-peroxide Antimicrobial Components (Methylglyoxal $\ldots \ldots \ldots \ldots$. . . . . . . . . . 17

1.2.5.2 Sugars .................... 18

1.2.5.3 Hydrogen Peroxide . . . . . . . . . . . . . 18

1.2.5.4 Bee Defensin-1 . . . . . . . . . . . . . 19

1.2.5.5 Low pH Level . . . . . . . . . . . . . . . . . 19

1.3 Manuka Honey . . . . . . . . . . . . . . . . . . . . 20

1.3.1 Determining MGO Concentration in $\mathrm{MH} \ldots \ldots 22$

1.3.2 Wound Dressing Application . . . . . . . . . . . . . 23

1.4 Wool . . . . . . . . . . . . . . . . . . . . 26

1.4.1 Chemical Structure of Wool . . . . . . . . . . . . . 27

1.4.2 Morphological Structure of Wool . . . . . . . . . . . . . 29 
1.5 Polymer Resins . . . . . . . . . . . . . . . . . . 31

1.5.1 Characterisation of Polymer Resins . . . . . . . . . . 31

1.5.2 Polymers with Antimicrobial Activity . . . . . . . . . . 32

1.5.3 Acrylic Polymers . . . . . . . . . . . . . . . . 32

1.5.3.1 Poly(methyl methacrylate) (PMMA) . . . . . . . 33

1.5.4 Polyurethanes . . . . . . . . . . . . . . . 33

1.6 Project Scope . . . . . . . . . . . . . . . . . . . . . 35

2 Methodology $\quad 37$

2.1 Materials and Chemicals . . . . . . . . . . . . 37

2.2 Quantification of Methylglyoxal Content in Manuka Honey . . . . . . . 38

2.3 Procedure for determining amount of Manuka honey and Methylglyoxal Uptake . . . . . . . . . . . . . . . . . . . . . 38

2.3.1 Degradation of Methylglyoxal . . . . . . . . . . . . 39

2.3.2 Preparation of NeoCryl ${ }^{\circledR}$ XK-98 and Kamthane 5000 with Methylglyoxal . . . . . . . . . . . . . . 4 40

2.3.3 Methylglyoxal Leaching Test from Wool or Polymer Treated with Methylglyoxal . . . . . . . . . . . . . . 40 40

2.3.4 Dynasylan ${ }^{\circledR}$ Treatment . . . . . . . . . . . . . . 41

2.4 Characterisation Techniques . . . . . . . . . . . . 41

2.4.1 Analytical RP-HPLC Method Development . . . . . . . . . . 41

2.4.2 Nuclear Magnetic Resonance Spectroscopy (NMR) . . . . . . . 44

2.4.3 Fourier Transform Infrared Spectroscopy (FTIR) . . . . . . . . 44

2.4.4 Thermogravimetric Analysis (TGA) . . . . . . . . . . . . 45

2.4.5 Differential Scanning Calorimetry (DSC) . . . . . . . . . 45

2.4.6 Contact Angle (CA) Measurement . . . . . . . . . . . . . . . 46

2.4.7 Antimicrobial Test Protocol . . . . . . . . . . . . . 46 
3.1 Characterisation of Methylglyoxal by NMR . . . . . . . . . . . . . 48

3.2 The Uptake of Manuka Honey and Methylglyoxal by Wool . . . . . . . 49

3.2.1 Measuring the Uptake of Manuka Honey and Methylglyoxal at Room Temperature . . . . . . . . . . . . . . 50

3.2.2 Measuring the Uptake of Manuka Honey and Methylglyoxal at

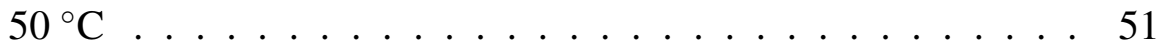

3.2.2.1 The Uptake of Manuka Honey and Methylglyoxal at $50{ }^{\circ} \mathrm{C}$ by Different Types of Wool . . . . . . . . . 55

3.2.3 Measuring the Uptake of Manuka Honey and Methylglyoxal at $70{ }^{\circ} \mathrm{C} \ldots \ldots \ldots \ldots \ldots \ldots$

3.2.4 Measuring the Uptake of Manuka Honey and Methylglyoxal at $80{ }^{\circ} \mathrm{C} \ldots \ldots \ldots \ldots \ldots \ldots \ldots$

3.2.5 The Methylglyoxal Uptake Using Glass Ampoules . . . . . . . 64

3.2.5.1 The Methylglyoxal Uptake at $80{ }^{\circ} \mathrm{C}$ In Glass Ampoules 65

3.2.5.2 The Methylglyoxal Uptake at $70{ }^{\circ} \mathrm{C}$ In Glass Ampoules 68

3.2.5.3 The Methylglyoxal and Manuka Honey Uptake at 50

${ }^{\circ} \mathrm{C}$ in Glass Ampoules . . . . . . . . . . . . . 72

3.2.5.4 Determining the Methylglyoxal Uptake at a Larger Scale of Wool . . . . . . . . . . . . . 74

3.3 Summary of the Temperature Influence on the Methylglyoxal and Manuka Honey Uptake by Wool . . . . . . . . . . . . . . . . . 76

3.4 Degradation of Methylglyoxal . . . . . . . . . . . . 78

3.5 Leaching Test of Methylglyoxal _. . . . . . . . . . . . . . 80

3.6 FT-IR Spectroscopy of Methylglyoxal and Wool Composites . . . . . . 80

3.7 Thermogravimetric Analysis (TGA) of Wool Composites . . . . . . . 85

3.8 Differential Scanning Calorimetry (DSC) Analysis of Wool Composites 87

3.9 Contact Angle Measurement of Wool Treatment . . . . . . . . . . 88

3.10 Antimicrobial Performance of MGO-Textile Composites . . . . . . . . 89 
3.11 Future Work . . . . . . . . . . . . . . . . . . 96

4 Polymeric Materials with Methylglyoxal $\quad 97$

4.1 Preparation of Polymeric Materials with Methylglyoxal _ . . . . . . 97

4.1 .1 NeoCryl $^{\circledR}$ XK-98 . . . . . . . . . . . . . . . . . . 97

4.1.2 Fourier Transform Infrared Spectroscopy (FTIR) Analysis of Methylglyoxal with Poly(methyl methacrylate) . . . . . . . 99

4.1.3 Differential Scanning Calorimetry Analysis of NeoCryl ${ }^{\circledR}$ XK98 Polymer with Methylglyoxal . . . . . . . . . . . 101

4.1.4 The Contact Angles of NeoCryl ${ }^{\circledR}$ XK-98 with Methylglyoxal . 102

4.1.5 Leaching Test of Methylglyoxal from Methylglyoxal-NeoCryl composites . . . . . . . . . . . . . 104

4.1.6 Antimicrobial Performance of Methylglyoxal-NeoCryl composites . . . . . . . . . . . . . . . 104

4.2 Kamthane K-5000 (Polyurethane) . . . . . . . . . . . . . 106

4.2.1 Fourier Transform Infrared Spectroscopy (FTIR) Analysis of Methylglyoxal with Polyurethane . . . . . . . . . . 107

4.2.2 Differential Scanning Calorimetry Analysis of Kamthane K5000 polymer with Methylglyoxal . . . . . . . . . . 109

4.2.3 Antimicrobial Performance of Methylglyoxal-Kamthane Composites .................... 110

4.3 Future Work . . . . . . . . . . . . . . . . . . 111

5 Conclusion

5.1 The Uptake of Manuka Honey and Methylglyoxal by the Wool . . . . 112

5.1.1 The Characterisation Techniques of MGO-Wool and MH-Wool 113

5.1.2 The Antimicrobial Properties of Coated MGO Samples . . . . . 114

5.2 Methylglyoxal with Polymeric Materials . . . . . . . . . . . . . . 114

5.2.1 The Characterisation Techniques of MGO-Polymer . . . . . . 115 
5.2.2 The Antimicrobial Properties of Methylglyoxal with Polymeric Materials ................... 115

Bibliography 


\section{List of Figures}

1.1 Examples of non-flavonoids' and flavonoids' structures present in honey 13

1.2 Structures of some antioxidant phenolic compounds in honey . . . . . . 16

1.3 An illustration of chain interactions in wool fibres, which provide the strength, stability and chemical and physical properties. . . . . . . . 28

1.4 The morphological structure of merino wool fibre. (Note: permission to reproduce this image has been granted by CSIRO Publishing) . . . . 30

1.5 An illustration of the gaps between cuticle cells allowing diffusion of small molecules. The Figure was designed based on data found in the literature. . . . . . . . . . . . . . . 30

2.1 Calibration Curves of MGO at high and low concentrations. Error bars (standard deviation) between duplicate are too small to show on the graph but the actual values are shown in Table 2.1. . . . . . . . . . . . 43

3.1 The ${ }^{1} \mathrm{H}$ NMR of $40 \%$ Methylglyoxal . . . . . . . . . . . . . . . . 49

3.2 The uptake of $50 \mathrm{mg} \mathrm{L}^{-1} \mathrm{MGO}$ by top wool over 7 days at $50{ }^{\circ} \mathrm{C} \ldots$. . 53

3.3 The uptake of $3.5 \mathrm{mg} \mathrm{L}^{-1} \mathrm{MGO}$ in $\mathrm{MH}$ by top wool at $50{ }^{\circ} \mathrm{C}$ over 7 days. 53

3.4 The uptake of $5 \mathrm{mg} \mathrm{L}^{-1} \mathrm{MGO}$ and $3.11 \mathrm{mg} \mathrm{L}^{-1} \mathrm{MGO}$ in MH by all types of wool at $50{ }^{\circ} \mathrm{C} \ldots \ldots \ldots \ldots$

3.5 The uptake of $50 \mathrm{mg} \mathrm{L}^{-1} \mathrm{MGO}$ and $27.14 \mathrm{mg} \mathrm{L}^{-1} \mathrm{MGO}$ in $\mathrm{MH}$ by all types of wool at $50{ }^{\circ} \mathrm{C} \ldots \ldots \ldots \ldots$

3.6 The uptake of $250 \mathrm{mg} \mathrm{L}^{-1} \mathrm{MGO}$ and $115 \mathrm{mg} \mathrm{L}^{-1} \mathrm{MGO}$ in $\mathrm{MH}$ by all types of wool at $50{ }^{\circ} \mathrm{C} \ldots \ldots \ldots \ldots$

3.7 The MGO uptake of 250 and $115 \mathrm{mg} \mathrm{L}^{-1} \mathrm{MGO}$ and MGO in MH respectively by top, yarn and fabric wool at $70{ }^{\circ} \mathrm{C} \ldots \ldots 63$ 
3.8 The uptake rates of 1.2 and $0.7 \mathrm{~g} \mathrm{~L}^{-1} \mathrm{MGO}$ by fabric wool at $80{ }^{\circ} \mathrm{C}$

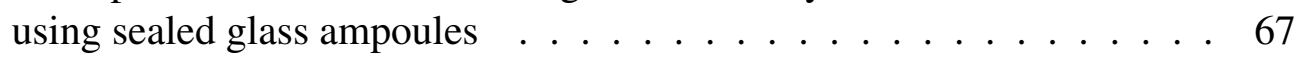

3.9 The uptake rates of 1.2 and $0.7 \mathrm{~g} \mathrm{~L}^{-1} \mathrm{MGO}$ by fabric wool at $70{ }^{\circ} \mathrm{C}$ using sealed glass ampoules . . . . . . . . . . . . . . 69

3.10 The uptakes of various MGO concentrations by fabric wool at $70{ }^{\circ} \mathrm{C}$ using sealed glass ampoules ............... . . 71

3.11 The effect of MGO concentrations on the colour of wool after 15 days treatment at $70{ }^{\circ} \mathrm{C}$. The wool tends to become darker when HPLC results show a large amount of MGO absorbed by wool . . . . . . . . 77

3.12 The effects of temperature on the amount of MGO absorbed by wool . 78

3.13 The effects of high temperatures on the MGO diffusion rates into wool fibres. The intercellular diffusion occurs between the gaps between cuticle cells into cell membrane complex. . . . . . . . . . 78

3.14 The FT-IR spectra of $40 \%$ MGO . . . . . . . . . . . . . . . . 82

3.15 Spectra of untreated wool(red colour) and MGO-Wool spectra (blue colour). ...................... 83

3.16 Scale up spectra of untreated wool(red colour) and MGO-Wool spectra (blue colour) in order to distinguish the MGO interactions with the wool. 85

3.17 TGA traces for non-treated wool, MGO-Wool $\left(1 \mathrm{~g} \mathrm{~L}^{-1} \mathrm{MGO}\right.$ at $\left.70{ }^{\circ} \mathrm{C}\right)$ and MGO-Wool (5 mg L ${ }^{-1} \mathrm{MGO}$ at $70{ }^{\circ} \mathrm{C}$ ) with 12.1, 7.2 and $13.6 \%$ mass loss respectively. . . . . . . . . . . . . . . . 86

3.18 DSC curves of (A) non-treated wool and (B) MGO-Wool composites (from the uptake of $1 \mathrm{~g} \mathrm{~L}^{-1} \mathrm{MGO}$ at $70{ }^{\circ} \mathrm{C}$ over 15 days) with holding time at $240{ }^{\circ} \mathrm{C}$ for ten minutes. . . . . . . . . . . . . . . 88

3.19 The zone of inhibition of paper coated with MGO solutions at: 1, 1') $\left.\left.\left.0.5 \mathrm{~g} \mathrm{~L}^{-1} \mathrm{MGO} 2,2^{\prime}\right) 1 \mathrm{~g} \mathrm{~L}^{-1} \mathrm{MGO} 3,3^{\prime}\right) 2 \mathrm{~g} \mathrm{~L}^{-1} \mathrm{MGO} 4,4^{\prime}\right) 0.25 \mathrm{~g}$ $\mathrm{L}^{-1} \mathrm{MGO}$ against S.aureus and E.coli. Note: arrows show the zone of inhibition.

3.20 Paper coated with MGO solutions for ten minutes at: 5, 9) $2 \mathrm{~g} \mathrm{~L}^{-1}$ MGO 6, 10) $0.5 \mathrm{~g} \mathrm{~L}^{-1}$ MGO 7, 11) $0.25 \mathrm{~g} \mathrm{~L}^{-1}$ MGO 8, 12) $0.005 \mathrm{~g}$ $\mathrm{L}^{-1} \mathrm{MGO}$ against S.aureus and E.coli. The samples differed in their activity after being washed with water as follows: 5', 9') $2 \mathrm{~g} \mathrm{~L}^{-1} \mathrm{MGO}$ 6', 10') $0.5 \mathrm{~g} \mathrm{~L}^{-1} \mathrm{MGO}$ 7', 11') $0.25 \mathrm{~g} \mathrm{~L}^{-1} \mathrm{MGO} 8^{\prime}$, 12') $0.005 \mathrm{~g}$ $\mathrm{L}^{-1} \mathrm{MGO}$, suggesting that MGO is likely to be washed off the surface. Note: arrows show the zone of inhibition. 
3.21 Zone of inhibition of treated fabric wool by various MGO concentrations against S.aureus and E.coli. The samples 13, 13', 14 and 14' were tested for their antibacterial activity after one day of finishing the uptake. The last two samples were tested after 70 days of the uptake and being kept at room temperature . . . . . . . . . . . . . . . . . . . 94

4.1 The effects of increasing MGO concentrations on the NeoCryl's colour. The colour of NeoCryl changes from colouress, yellow-brown to a brown colour with increasing the amount of MGO. . . . . . . . . . . . . 99

4.2 The FTIR spectra of NeoCryl ${ }^{\circledR}$ XK-98 (red colour) and treatment NeoCryl ${ }^{\circledR}$ XK-98 with 20\% MGO (blue colour) at ratio 9:1 NeoCryl:MGO . . . . 101

4.3 DSC curves of (A) non-treated NeoCryl (B) MGO-NeoCryl composites ( $\left.1 \mathrm{~g} \mathrm{~L}^{-1} \mathrm{MGO}\right)$ with holding time at $240{ }^{\circ} \mathrm{C}$ for ten minutes. . . . . . . 102

4.4 NeoCryl ${ }^{\circledR}$ XK-98 with MGO: A) Blank B) 1:10 (mL) 3\% MGO:NeoCryl C) 1:10 (mL) 10\% MGO:NeoCryl D) 1:10 (mL) 5\% MGO:NeoCryl E) 0.1:6 (g) MGO:NeoCryl F) 0.07:6 (g) MGO:NeoCryl G) 0.05:6 (g) MGO:NeoCryl against S.aureus and E.coli. Note: arrows show the zone of inhibition. . . . . . . . . . . . . . . 106

4.5 The FTIR spectra of untreated Kamthane K-5000 (black colour line) and treatment Kamthane K-5000 with 6\% MGO (red colour line) at a ratio of 9:1 Kamthane:MGO . . . . . . . . . . . . . . . . 108

4.6 Zoomed FTIR spectra of untreated Kamthane K-5000 (black colour line) and treatment Kamthane K-5000 with 6\% MGO (red colour line) at ratio 9:1 Kamthane:MGO . . . . . . . . . . . . . . . 108

4.7 The DSC analysis of $9 \mathrm{~mL}$ Kamthane with $1 \mathrm{~mL}$ water (red curve) and $9 \mathrm{~mL}$ Kamthane with $1 \mathrm{~mL} 6 \%$ MGO (black curve). . . . . . . . . . . . 109

4.8 The zone of inhibition test of blank Kamthane and MGO-Kamthane (A) Blank Kamthane (B) 0.05:9 (g) MGO:Kamthane (C) 0.03:9 (g) MGO:Kamthane (D) 0.02:9 (g) MGO:Kamthane. . . . . . . . . . . . . 110 


\section{List of Schemes}

1.1 The semi-synthetic approach of paclitaxel from 10-deacetylbaccatin III . 6

1.2 Oseltamivir phosphate semisynthesis from (-)-shikimic acid . . . . . . 6

1.3 1,2-Dicarbonyl compounds reported in honey . . . . . . . . . . . 20

1.4 The reaction of MGO with water, resulting in hydration of carbonyl

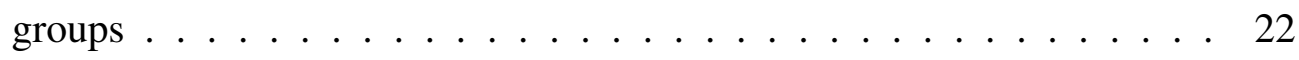

1.5 MGO derivatisation with OPD forming 2-MQ . . . . . . . . . . . 22

1.6 Some common acrylic acids and PMMA structures. . . . . . . . . . . 33

1.7 Polyurethane structure and its formation. . . . . . . . . . . . . . 34

3.1 Possible forms that present in MGO solution . . . . . . . . . . . . . . 48 


\section{List of Tables}

1.1 Average chemical composition of honey . . . . . . . . . . . . . 11

1.2 GO and MGO contents in a commercial honey sample and 6 Manuka honey samples (data given in $\mathrm{mg} \mathrm{kg}^{-1}$ and the variation is a result of triplicate analysis). .................. 23

1.3 Average chemical composition of wool fibres . . . . . . . . . . 27

2.1 Calibration Curve of MGO . . . . . . . . . . . . . . . 44

3.1 The percentage and weight uptakes of $3.5 \mathrm{mg} \mathrm{L}^{-1} \mathrm{MGO}$ in $\mathrm{MH}$ and 50 $\mathrm{mg} \mathrm{L}{ }^{-1} \mathrm{MGO}$ at $50{ }^{\circ} \mathrm{C} \ldots \ldots \ldots . \ldots . \ldots 54$

3.2 Illustration of the three types of wool being treated with MGO solutions alone or as a component of $\mathrm{MH}$ at various concentrations at $50^{\circ} \mathrm{C} \ldots 56$

3.3 The uptake percentage of 5,50 and $250 \mathrm{mg} \mathrm{L}^{-1} \mathrm{MGO}$ by top, fabric and yarn wool at $50{ }^{\circ} \mathrm{C} \ldots \ldots \ldots . \ldots . \ldots 58$

3.4 The uptake of 3.11, 27.14 and $115.2 \mathrm{mg} \mathrm{L}^{-1} \mathrm{MGO}$ in $\mathrm{MH}$ by top, yarn and fabric wool at $50{ }^{\circ} \mathrm{C} \ldots \ldots . \ldots . \ldots 59$

3.5 Illustration of the three types of wool being treated with MGO solutions alone or as a component of $\mathrm{MH}$ at various concentrations at $70{ }^{\circ} \mathrm{C} \ldots 61$

3.6 The uptake of 5, 50 and $250 \mathrm{mg} \mathrm{L}^{-1} \mathrm{MGO}$ by fabric, top and yarn wool

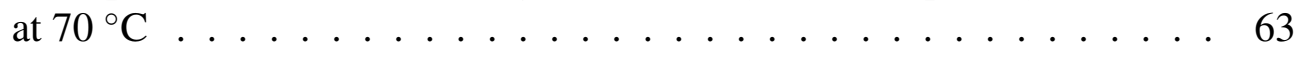

3.7 The uptake of 3.1, 27.1 and $115.2 \mathrm{mg} \mathrm{L}^{-1} \mathrm{MGO}$ in $\mathrm{MH}$ by fabric, top and yarn wool at $70{ }^{\circ} \mathrm{C} \ldots \ldots \ldots \ldots$

3.8 Preparation of the uptake of $\mathrm{MGO}$ at $80{ }^{\circ} \mathrm{C}$ with sealed glasses . . . . . 66

3.9 The MGO uptake at $80{ }^{\circ} \mathrm{C}$ by fabric wool. . . . . . . . . . . . . 67

3.10 Preparation of $\mathrm{MGO}$ uptake at $70^{\circ} \mathrm{C}$ with sealed glass ampoules . . . 68 
3.11 The MGO uptake percentage at $70{ }^{\circ} \mathrm{C}$ using sealed ampoules $\ldots \ldots$. . . 69

3.12 Replicates for the $\mathrm{MGO}$ uptake at $70{ }^{\circ} \mathrm{C} \ldots \ldots . \ldots 70$

3.13 The preparation methods of the MGO and $\mathrm{MH}$ solutions to determine the uptake at $50{ }^{\circ} \mathrm{C}$ using sealed glass ampoules . . . . . . . . . 73

3.14 The uptake percentage and weight of MGO and MGO in MH by wool at $50{ }^{\circ} \mathrm{C}$ using sealed glass ampoules . . . . . . . . . . . 74

3.15 An illustration of the MGO uptakes per wool weight at $70{ }^{\circ} \mathrm{C}$ (MGO wool $^{-1} \mathrm{~g} \mathrm{~g}^{-1}$ ). The scale up process validates the consistent absorption of MGO per a particular wool weight at every concentration of MGO. The table is showing the MGO absorption $(\mathrm{g})$ per wool $(\mathrm{g})\left(\mathrm{g} \mathrm{g}^{-1}\right) \ldots$. 75

3.16 The MGO leached from the MGO-Wool and MH-wool composites. MGO uptake was determined first then the same samples were tested for leaching test. . . . . . . . . . . . . . . . . . 81

3.17 The contact angle of blank wool and treated wool with MGO at MGO concentrations of 0.25 and $1 \mathrm{~g} \mathrm{~L}^{-1} \ldots \ldots \ldots$. . . . . . . 89

3.18 Effect of MGO concentrations on the growth of both $S$. aureus and $E$. coli for MGO-Wool composites after determining the uptake of MGO. . 95

4.1 The contact angle of NeoCryl and MGO-NeoCryl composites treated with Dynasylan ${ }^{\circledR}$ F8815. . . . . . . . . . . . . . . . . . . 103 


\section{Glossary}

\begin{tabular}{ll} 
CA & Contact Angle \\
3-DG & 3-Deoxyglucosulose \\
DHA & Dihydroxyacetone \\
E. coli & Escherichia coli \\
FT-IR & Fourier Transform Infra-red spectroscopy \\
GO & Glyoxal \\
HPLC & High-performance Liquid Chromatography \\
HTS & High Throughput \\
H2 & Hydrogen peroxide \\
K-5000 & Kamthane K-5000 \\
MGO & Methylglyoxal \\
MGO-Wool & Methylglyoxal-Wool \\
MGO-NeoCryl & Methylglyoxal-NeoCryl ${ }^{\circledR}$ XK-98 \\
MGO-K5000 & Methylglyoxal-Kamthane K-5000 \\
MH & Manuka Honey \\
MIC & Minimum inhibitory concentration \\
NeoCryl & NeoCryl ${ }^{\circledR}$ XK-98 \\
NMR & Nuclear magnetic resonance \\
NZ & New Zealand \\
PMMA & Poly(methyl methacrylate) \\
ppm & Parts per million \\
PSM & Plant Secondary Metabolite \\
PU & Polyurethane \\
S. aureus & Staphylococcus aureus \\
UMF & Unique Manuka Factor \\
UV & Ultra violet \\
VUW & Victoria university of Wellington \\
wt & Weight \\
\hline &
\end{tabular}




\section{Chapter 1}

\section{Introduction}

\subsection{Natural Products}

Natural Products, known as secondary metabolites which are small molecules with useful biological activity, have been the most effective source of potential drugs in pharmacology. Natural products provide unique structural diversity compared to synthetic drugs, which make them favourable for discovering novel low molecular weight lead compounds. Recent studies show that more than $75 \%$ of current medicines are natural products (NPs) or inspired by them ${ }^{1}$. In addition, between 1981 and 2007, approximately half of antibacterials and anticancer drugs were designed based on NP, and this percentage is even higher in case of anti-cancer and anti-infective agents. The classification sources of these chemicals are plants, microbes, animals, synthetic NPs and semi-synthetic NPs. As an example of its application, Cinchona bark provides the most economically practical source of quinine, which cures malaria, and a variety of other alkaloids $^{2,3}$. 


\subsubsection{History}

The development of small molecule agents for medical treatment has played a critical role in pharmacology for thousands of years. In fact, the use of natural products started from the early days of human civilisation, which was the primary source of basic medical needs. Today, a wide range of diseases are treated with medicines that are derived from nature, where plant products are the leading providers. The discovery of drugs began as an unexpected consequence in experimentation, trials, and observation of both human and animal reactions toward plant products ${ }^{4-6}$.

Even though each civilisation might develop its own medicines, there are numerous similarities in utilising a specific plant for treatment of certain diseases, which might require sharing the medical knowledge with other civilisations. Traditional Chinese Medicine has been extensively documented over the centuries from about 3500 B.C., which established using herbs for treatment of injuries, fevers, and other ailments. Moreover, ancient Egyptian history, from approximately 3000 B.C, has recorded many recipes for medicinal use based mainly on herbal products such as castor oil, garlic and other plants ${ }^{7,8}$.

Likewise through history, Chinese, Egyptians, Indian, and Babylonians contributed to the development of herbal drugs in Western societies. The Greeks and Romans shaped this knowledge, which is the forerunner of modern health care systems, such as hospitals and medical instruments used in surgery. The Roman physicians advanced pharmacies and medicines with complex prescriptions and formula that used a variety of compounds sourced from plants. The Arabs from the 5th to 12th centuries benefited from the geographic location of this medical knowledge, then expanded it to include their own resources ${ }^{9-12}$.

This rich traditional background of documented medicines, based mainly on nature, led the interest to discover and utilise NPs in medicines. During the 18th and 19th centuries, plants and marine organisms were studied to determine any potential thera- 
peutic sources of drugs. Therefore, since 1981, approximately half of the drugs in the market were inspired by their product derivatives. The chemistry of NPs has advanced research more specifically for drug developments. In general, the target of discovering a bioactive component could be narrowed to a specific principle in a plant to target only the particular disease ${ }^{8,13}$. This means isolation and characterisation of active agents in plants were the major challenges for chemists and apothecaries at that time. However, it was not until the early 19th century that Friedrich Setürner isolated morphine in a pure state from opium ${ }^{8,14}$ This discovery led to the isolation of other alkaloids and the establishment of extraction and identification methods.

These new methods of drug discovery, in contrast to tradition, begin with identifying a novel medicine with the knowledge of the biological target. An example, a small organic molecule activates or inhibits a biomolecule function. Scientists use varieties of techniques including computer modelling technology in the production of synthetic drugs to improve the selectivity to bind tightly to its target and stability. Therefore, synthetic drugs became more accessible in laboratory developments due to computeraided drug design ${ }^{2,15}$.

Computer-aided drug design utilises a computational approach to predict the nature and strength of binding to a target of interest. This involves studying the intermolecular interaction and binding affinity between the small molecule and the target and analysing their structures. Ideally, computerised and synthetic methods advance drug discovery. In this way, a new interesting compound could be synthesised through the prediction of its conformation and molecular mechanism using theory. High throughput screening methods (HTS), in particular, raises the production and the discovery of more synthetic drugs due to their high performance. It was believed that natural products are incompatible with drug design based on high-throughput screening for pharmaceutical manufacture. This belief was associated with the expectation of providing all the chemical needs of combinatorial chemistry. Although these design techniques are efficient, other concepts must be examined for a safe and efficient drug, such as bioavailability, 
metabolic half-life, side-effects and other. In other words, computerised and synthetic methods advance drug discovery, but there are disadvantages including difficulties of handling, side-effects, limited yield, low purity, poor solubility and limited accessible sources. Studies have indicated natural products and mimicking their properties would see significant improvements for therapeutic benefits, which have potential in disease treatment ${ }^{1,4,9,11,15}$.

Natural products exhibit a tremendous chemical diversity such as functional group and stereochemistry, which have a high efficiency in binding selectivity even against complex targets ${ }^{2,15}$ NPs and semisynthetic derivatives also have additional advantages over entirely synthetic drugs in molecular size, less hydrophobicity, great dimensional complexity and aromatic rings. These features in NPs could be incorporated into drugs synthetically, which could improve the drug design and reliability of NPs. Understanding these valuable bioactive agents, quality control, and cost-effective of NPs leads the focus of pharmaceutical industry to discover, develop, and focus intensively on this source. Not surprisingly, the annual sales of drugs in the market support the case of NPs ${ }^{1}$.

Given the current technological advances in HTS, a new field of drug discovery could lead the researchers to identify many more novel compounds in nature. This challenging goal is particularly important as a low percentage of the plant's biodiversity has, so far, been analysed for their biological activity. The discovery of such natural therapeutics is promising ${ }^{1}$.

\subsubsection{Plants}

The plant kingdom supplies most active ingredients where over $75 \%$ of inhabitants rely on traditional medicines worldwide for primary healthcare ${ }^{11}$. Although approximately 250,000 species of plants have been examined for their biological activity, this presents less than $11 \%$ of earth's plants, which indicates an invaluable source of future 
medicines. The pharmacological advantages of plants result from the direct use of plant secondary metabolites (PSMs) or as a chemical probe.

\subsubsection{Drug Precursors from Plant Secondary Metabolites}

All NPs begin as simple or complex mixtures with other compounds in nature, which requires their isolation and purification. Some of these molecules can be utilised as drug precursors (semisynthetic process), which are modified chemically to reach the target compounds. This protocol provides sufficient supply of a particular medicine. The reasons for this semisynthetic modification of plant derivatives, which are not necessarily pharmacologically active, are the low yield of specific compounds in nature and economic viability of total synthesis (e.g. complex structures, chiral centres, aromatic rings) for drug companies ${ }^{7,16}$.

For instance, the cancer drug paclitaxel was isolated in the early 1970s from Taxus brevifolia, the Pacific Yew tree, with a maximum yield of $0.4 \%$, which was not sufficient for the market. This low yield would prevent large-scale manufactacture of the medicine unless an alternative method of extraction was found ${ }^{17}$. Although total synthesis seems an alternative method for a similar study case ${ }^{18}$, it is unattractive economically for the mass scale production of paclitaxel. In 1988, Pierre Potier's group reported the possibility of isolating large quantities of 10-deacetylbaccatin from needles of the European Yew. Chemical modification of its structure led to an ample supply of paclitaxel by a short semisynthetic method ${ }^{19,20}$ (Scheme 1.1).

A second example is oseltamivir phosphate (Tamiflu), which treats and prevents influenza A and B. The first report and traditional protocol of Tamiflu synthesis begins from (-)-shikimic acid for industrial scale (Scheme 1.2) ${ }^{7,21}$. However, the shortage of natural resources limit synthetic strategies, which leads to finding a readily available starting material. Therefore, several methods have been explored to achieve sufficient production of Tamiflu by genetically engineered Escherichia coli strains ${ }^{7}$ and total syn- 

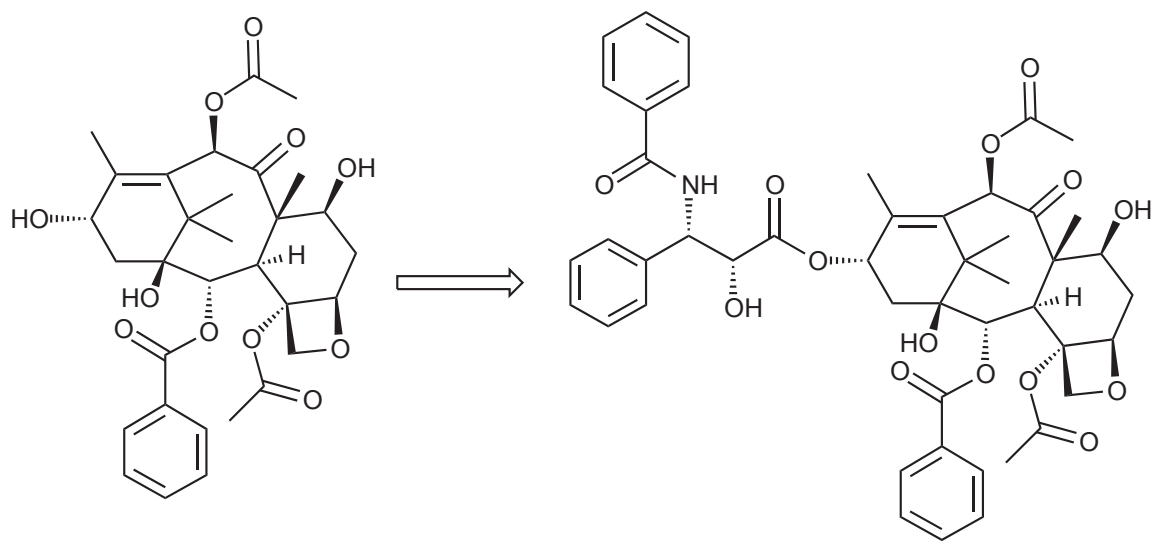

10-deacetylbaccatin III

Paclitaxel

Scheme 1.1: The semi-synthetic approach of paclitaxel from 10deacetylbaccatin III<smiles>CCOC(=O)C1=C[C@H](OC(CC)CC)[C@H](NC(C)=O)[C@H](N)C1</smiles>

Oseltamivir phosphate<smiles>O=C(O)C1=C[C@H](O)[C@H](O)[C@H](O)C1</smiles>

(-)-shikimic acid

Scheme 1.2: Oseltamivir phosphate semisynthesis from (-)-shikimic acid

thesis from aziridine as the fundamental synthon ${ }^{21}$.

These examples illustrate the requirement for the chemical modification of small-molecule drugs as a starting material in order to synthesise the drug in question. This approach is due to the limited supply in nature, high selectivity, sufficient yield and low-cost production.

\subsubsection{Prototype drugs from Plant Secondary Metabolites}

A prototype drug is the lead agent in drug family from different living organisms, from which PSMs contribute $23 \%$ of this chemical application. Many compounds isolated from nature have novel pharmacological properties but are too toxic or insoluble for clinical use. Due to their unique biological activity, there is a need to develop their 
derivatives, which organic and medicinal chemists pursue. An example of this prototype is the guanidine, which is naturally isolated from Galega officinalis L, but cannot be utilised purely due to its toxicity. However, several derivatives have been reported in the literature reviews and dimethyl-biguanide was synthesised for treatment of diabetes type II from guanidine as the vital prototype ${ }^{22}$.

Marine organic compounds, mainly terrestrial, contribute to drug discovery as a source of compounds in a natural form or a key of synthetic modification. PSMs, as mentioned, have properties that are beneficial for the treatment of human diseases such as cancer ${ }^{20}$, inflammation, bacterial infections ${ }^{23}$ and other diseases ${ }^{7}$. However, numerous secondary metabolites have reported significant antimicrobial activity, which can be isolated from organisms and microorganisms ${ }^{7,9}$. The scientific communities have paid much attention to the potential antimicrobial activities of natural products. The following sections will highlight the antimicrobial activity of natural products and their influence on the market.

\subsubsection{Natural Antimicrobial Products from Plant Kingdom}

Modern medicine is increasingly receptive to antimicrobial and other drugs derived from plants. PMSs provide various benefits for better control of infections due to their unique antimicrobial properties. Many plants display inhibition against multiple bacteria including Gram-positive (most common) and Gram-negative. Therefore, they can contribute to drug development in two ways: firstly, as the base of a new medicine development; secondly, as a phytomedicine for the treatment of disease. Studies show that a few antibiotics, derived from plants, have launched in the market since $1990 \mathrm{~s}^{24}$.

Several compounds present in plants have been reported with antimicrobial activity, such as thiosulfinates, phenolics and flavonoids. Natural phenolic compounds are considered as the main component in plants providing their antimicrobial activity such as phenolic derivatives including phenolic aldehydes, phenolic ketones and isoflavonoids. On the other hand, several nonphenolic compounds have been reported to have activity 
against a variety of Gram-positive and Gram-negative bacteria from coriander, rosemary and other plants.

\subsubsection{Antimicrobial Mechanism of Plant Compounds}

Phenol compounds are the leading bioactive component in the plant, and their antimicrobial mechanisms depend on their concentration. Phenols affect microbial cell permeability because of the ability to cause protein denaturation and affect enzyme activity at both high and low concentrations respectively. It is reported that high antimicrobial activity is attributed to the formation of active phenoxy radicals due to alkyl substitution in phenol nucleus. The mechanism by which phenolic compounds act against bacteria is highly complex ${ }^{6,7}$.

Plant antimicrobial peptides are potential antibiotics with novel therapeutic mechanisms. The peptides are easily controlled due to the positive charge, which attracts them to heavily negatively charged bacterial cell membranes. Other beneficial features of peptides are flexibility, hydrophobicity in order to interact with bacterial membranes and ease of structural modification due to a long chain of amino groups. This peptide mechanism is involved in disrupting cell membranes by the inhibition of proteins, binding to DNA and RNA or targeting intracellular organelles ${ }^{6,25}$.

A similar and important peptide group is the defensin peptides produced by insects (i.e. honey bees), which have a broad spectrum activity against bacteria and fungi. The defensins of honey provide anti-infection properties, which inhibit pathogens of the honey bee by the destruction of the cytoplasmic membrane. Therefore, these different families of antimicrobial peptides are considered promising antibiotic agents due to their non-specific molecular targets and fast destruction of a bacteria membrane ${ }^{6,7,25}$. 


\subsubsection{Antibiotic Resistant Bacteria}

Since the discovery of antibiotic agents, resistance against these agents has been observed, which negatively impact infection treatment and the drug market. In 1945, Alexander Fleming who discovered penicillin reported the first microbial resistance to penicillin ${ }^{26}$. Some bacteria have developed resistance to a drug that is used to treat them. These bacteria, after an overexposure to a certain antibiotic, resist some antimicrobial agents by changing their outer structure or by altering the antibiotic, rendering it harmless. In general, the microbes are educated to resist by breeding out their vulnerability to the antibiotic agents. In addition, numerous classes of bacteria are able to resist the most accessible antibiotic source, which raises concerns for antibiotic development $^{16,26,27}$.

There is an urgent need for a better understanding of antibiotic resistance and a new approach to drug design. It is apparent that there is ample scope for innovation based on natural product chemistry. Natural products and their derivatives have played important roles in the past, and they are in privileged positions to address the present bacterial resistance issue. Nature serves as a pointer for a novel and unexplored small molecule targets, and this type of approach is finding significant commercial application.

\subsection{Honey}

\subsubsection{Introduction}

Honey is known as a natural supersaturated sugar solution that is produced by honeybees from the nectar of plants or other plant secretions that bees collect and then use. The honey's composition, aroma, flavour and colour depend on four factors: flowers, climate, geographic location and honeybee species. Moreover, the production, packaging and storage process affect the honey factors. Honey, in general, is classified based 
on the source of the blossom and honeydew honey. For instance, Manuka Honey is named after the plant it was made from, which will be addressed below ${ }^{28,29}$.

\subsubsection{History}

Before the relatively recent scientific interest and analysis of honey, it had been known for its therapeutic effects. Until the beginning of $20^{\text {th }}$ century, it has been used to treat and prevent infection, mainly, as wound care practice. Then, the use of synthetic drugs expanded and became demanding with the new technology. However, honey was mentioned as a remedy by different civilisations including the ancient Egyptians, Chinese, Greeks and Romans. During that time, the use of honey as a medicine was not based on the knowledge of having antimicrobial properties and contents. As a result of the discovery of antibiotics, there was a discontinuity of the medical application and utilisation of honey in modern Western medicine. An extensive use of antibiotics led to such antibiotic resistance by bacteria and becoming a worldwide issue. This was due to the misuse of antibiotics, and the adaption of resistance by bacteria with some antibiotics, followed by a resistance which prompts the potential of natural products to address antibiotic opposition. As a result, an opportunity emerged for honey to be re-established as a broad spectrum antimicrobial agent that is non-toxic, for medical applications ${ }^{30}$.

For chemical and biological interests, honey was examined for its antimicrobial activity in 1892 for the first time ${ }^{31}$. In 1919, Sackett claimed that limited dilution of honey appears to increase the antimicrobial properties ${ }^{32}$. Dold reported in 1937 further investigation of honey composites, which resulted in introducing the term inhibine for the honey antimicrobial activity. Several studies have focused on testing the honey behaviour against a wide spectrum of microorganisms. Also, different kinds of honey have been investigated for their antimicrobial activity against different bacteria in order to discover the most active composition ${ }^{9,30}$. 
Most recent publications illustrate that honey inhibits approximately 60 species of bacteria including anaerobes, aerobes, gram-positive, and gram-negative. Also, it shows antifungal activity against different types of Aspergillus, Penicillium and yeasts ${ }^{33}$.Honey has a unique chemical composition, which is related to its antimicrobial properties. The following section will discuss the unique chemical composition of honey.

\subsubsection{Chemistry of Honey}

Honey contains approximately 200 components, mainly comprising of different carbohydrates, water, aromatic substance, vitamins, amino acids, organic acids, flavonoids, minerals and other phenolic compounds. In order to understand each component present in honey and their behaviour, which influences the antimicrobial activity, the topics listed below discuss each compound class of honey ${ }^{28,29}$. The antimicrobial compounds, in particular methylglyoxal in New Zealand Manuka honey, is the main focus of this research study, which will be covered in detail in Section 1.2.5.1 and Section 1.3.

\begin{tabular}{|c|c|}
\hline Honey Composition & Average percentage \\
\hline Water & $17.9 \%$ \\
\hline D-Fructose & $39.44 \%$ \\
\hline D-Glucose & $28.15 \%$ \\
\hline Sucrose & $3.19 \%$ \\
\hline Minerals & $0.36 \%$ \\
\hline Protein & $1.13 \%$ \\
\hline Phenolic compounds & $0.1 \%$ \\
\hline Vitamins, enzymes, aromas & $<1 \%$ \\
\hline
\end{tabular}

Table 1.1: Average chemical composition of honey

\subsubsection{Carbohydrates}

Honey is mostly a concentrated aqueous solution of a sugar mixture, which represents $80-83 \%(\mathrm{w} / \mathrm{v})$ of the total honey ${ }^{12}$. The carbohydrates present in honey consist most of the honey properties such as energy value and viscosity. Those sugars are mostly represented by the monosaccharides, glucose and fructose, where other oligosaccharides 
have also been reported. Components of honey, and mainly the sugar, may vary or get affected due to the temperature in the hive or storage ${ }^{28}$.

\subsubsection{Proteins}

The average of protein content depends greatly on the influence of plants and to a significant part from the species of the honeybees. The total amount of proteins is relatively small in honey, which vary between $0.1 \%$ and $3.3 \%$ (Apis cerana up to $3.3 \%$, Apis mellifera up to $1.6 \%$ ), representing $1.13 \%(\mathrm{w} / \mathrm{w})$ of the total honey. The richest source of amino acids in honey and pollen is proline, beside other essential amino acids such as asparagine, arginine, cysteine, histidine, lysine and valine. Proline originated from honeybees during the conversion of nectar into honey and represents between 50-85\% of amino acid in honey. Proline content varies between different honey sources and its level indicates the total amount of amino acid in a particular honey. Also, it counts as an additional measurement for the honey's quality and maturity ${ }^{34}$.

\subsubsection{Vitamins}

Vitamins present in the honey are small but at detectable quantities and are mostly water soluble. In 1940s, a chemical method was introduced to determine ascorbic acid and then other vitamins were discovered in honey ${ }^{35}$. The vitamins present in honey are riboflavin (vitamin B2), nicotinic (vitamin B3), ascorbic acid (vitamin C), and folic acid (vitamin B9). The low $\mathrm{pH}$ of honey provides an excellent environment for the formation and presence of those vitamins in honey ${ }^{28,35}$.

\subsubsection{Minerals}

Several groups of chemicals have been determined in honey including minerals, which are paramount for the human diet. The average content of a mineral species varies 
according to how light in colour the honey is and ranges between $0.04 \mathrm{wt} \%$ and $0.2 \mathrm{wt} \%$ for light and dark honey, respectively. This percentage reflects the type of soil that the plant and nectar live on that honeybees collect their food from. The mineral elements present in honey are mainly calcium, potassium, magnesium, manganese, iodine, zinc, silver and chromium ${ }^{28}$.

\subsubsection{Phenolic Compounds}

Phenolic compounds are considered as one of the largest classes of plant secondary metabolites, which are biosynthesised predominantly by plants for protection, then transferred to honey through the nectar. The phenolic compounds in honey present as two groups: non-flavonoids (phenolic acids) and flavonoids (e.g. flavones, flavanones, isoflavones and chalcones) ${ }^{12,28,36}$. Those compounds contain various aromatic rings with one or more hydroxyl groups, which vary in a simple or a complex phenolic compounds (Figure 1.1). Phenolic compounds, as with other organic compounds, can be degraded by environmental conditions, which creates instability, under alkaline condition and have high sensitivities to oxidation in honey ${ }^{12,28}$.

Phenolic acid

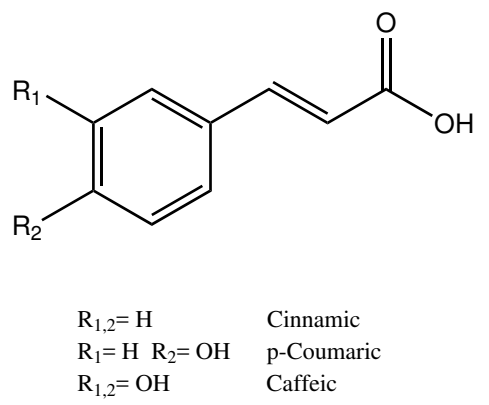

Flavonoids

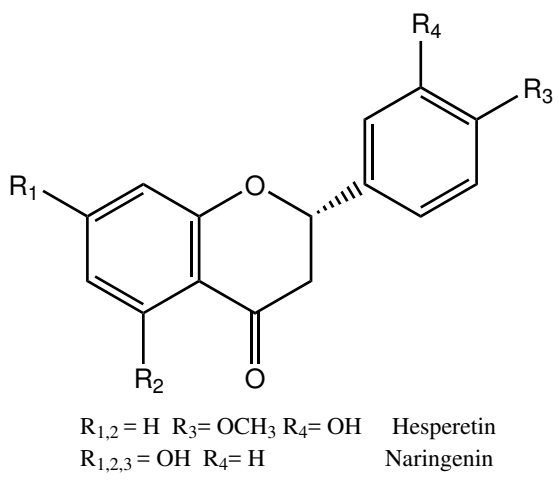

Figure 1.1: Examples of non-flavonoids' and flavonoids' structures present in honey 


\subsubsection{Aroma Compounds}

Volatile compounds are found in honey and are responsible for its both aroma and flavour qualities. The honey flavour is a combination of different volatile compounds that differs for several factors such the nectar, plants, honeybee, processing conditions, geographical location, presence of microorganisms and storage. Although some volatile compounds of certain regional plants can be transferred to honeys by bees, honeybees either convert the constituents of a plant or produce other compounds with aroma properties. More than 400 compounds have been reported with volatile fractions in honey. Their chemical groups include: hydrocarbons, aldehydes, ketones, fatty acids, carboxylic acids esters, benzene (include its derivatives), sulphurous compounds, alcohols and cyclic compounds. Carboxylic acid carbon chains interrupt the honey flavour based on their length ${ }^{37-39}$. For instance acetic acid provides a spicy aroma and flavour, but butanoic acid has a rancid aroma ${ }^{12}$. These volatile compounds could be used to identify a particular type of honey due to the influence of region, plants, and other factors on their components and flavour. For instance, the levels of benzaldehyde and furfural could be related to clover, wildflower and thistle honeys ${ }^{37-39}$.

\subsubsection{Organic Acids and other Compounds}

Organic acids contribute important properties to the honey. Although they are present in small quantities $(0.57 \%)^{28}$, they are responsible for antibacterial and antioxidant activities. These acids characterise the honey attributes such as colour, flavour, acidity, $\mathrm{pH}$ and electrical conductivity. In general, honeybees use enzymatic methods to produce these organic acids from sugars after being collected from the nectar. The organic acid level can be used to identify the honey's botanical and/or geographical origin based on citric, formic, gluconic, malic, pyruvic and other acids ${ }^{40}$.

A lower level of Hydrogen peroxide is an essential and typical component of different honeys that is related to the antibacterial activity. Hydrogen peroxide is produced by 
the oxidation of glucose in honey. It has been reported that hydrogen peroxide is an effective antimicrobial agent when present at a particular concentration, but exceeding this level would lead to oxygen radicals and subsequent damage in tissues ${ }^{41}$. The hydrogen peroxide content in honey varies because of the region and chemical composition of honey. Moreover, light, heat and enzymatic catalysis are likely to decrease the hydrogen peroxide level in honey ${ }^{41}$.

\subsubsection{Antioxidant Properties of Honey}

Honey is used for medical needs due to its unique properties, but recently its antioxidant properties have gained much attention. A regular process of metabolism generates reactive oxygen species (ROS) and other free radicals, but excess production leads to oxidative damage resulting in diseases such as cancer and coronary, and neurological degeneration. There are several mechanisms to counteract this issue by antioxidants, which are naturally synthesised in the body, or externally supplied ${ }^{42}$.

Studies illustrate that foods, including honey, are rich sources of antioxidants resulting in protection from ROS and free radicals enhancing the human health. Honey is reported to have a strong antioxidant capacity (antioxidant activity) that could prevent several diseases, for instance, tissue inflammation, cancer, diabetes, allergies and other ailments. These antioxidant agents stimulate biomolecules in the body and result in an antioxidant response in cells ${ }^{43,44}$. Numerous compounds correspond to this activity such as sugar, proteins, amino acids, organic acids and others. However, the primary antioxidant compounds in honey are phenolic flavonoids and non-flavonoids. The antioxidant phenolic compounds that have been reported in honey are: (i) flavonoids: chrysin (1), kaemferol (2), quercetin (3), lutelin (4), apigenin, hesperetin, pinocembrin (5), pinobanksin (6), galangin, and (ii) non-flavonoids: naringenin (7), genistein (8), caffeic (9), benzoic (10), chlorogenic, cinnamic, ferulic (12), galic acid, p-coumaric acids, ellagic (11), and syringic acid (set numbers are shown in Figure 1.2) ${ }^{45,46}$. 
<smiles>[R8]c1cc([R3])c2c(=O)c([R5])c(-c3ccc([R6])c(Br)c3)oc2c1</smiles>

(1) $\mathrm{R}_{1,2,3}=\mathrm{H} \quad \mathrm{R}_{4,5}=\mathrm{OH}$

(2) $\mathrm{R}_{1}=\mathrm{H} \mathrm{R}_{2,3,4,5}=\mathrm{OH}$

(3) $\mathrm{R}=\mathrm{OH}$

(4) $\mathrm{R}_{3}=\mathrm{H} \mathrm{R}_{1,2,4,5}=\mathrm{OH}$<smiles>O=c1c(-c2ccc(O)cc2)coc2cc(O)cc(O)c12</smiles>

(8)<smiles>[R7][C@H]1C(=O)c2c(O)cc(O)cc2O[C@H]1c1ccc(Br)cc1</smiles>

(5) $\mathrm{R}_{1,2}=\mathrm{H}$

(6) $\mathrm{R}_{1}=\mathrm{H} \mathrm{R}_{2}=\mathrm{OH}$

(7) $\mathrm{R}_{1}=\mathrm{OH} \mathrm{R}=\mathrm{H}$<smiles>O=C(O)/C=C/c1ccc(O)c(O)c1</smiles>

(9)<smiles>O=C(O)c1ccccc1</smiles>

(10)<smiles>O=c1oc2c(O)c(O)cc3c(=O)oc4c(O)c(O)cc1c4c23</smiles>

(11)<smiles>COc1cc(/C=C/C(=O)O)ccc1O</smiles>

(12)

Figure 1.2: Structures of some antioxidant phenolic compounds in honey

Moreover, recent research showed that the honey antioxidant compounds are bioavailable for humans ${ }^{47}$. In 2003, Schramm reported that honey fed at $1.5 \mathrm{~g} \mathrm{~kg}^{-1}$ of body weight assists the rise of antioxidant capacity in the human body, which supports the bioavailability of the antioxidant compounds. In addition, this observation indicates the valuable use of phenolic antioxidants in honey to boost the oxidative defence in the human body ${ }^{47}$.

The antioxidant activity of honey could be influenced mostly by the region of the honey beside minor effects of processing, storage and handling. The level of honey antioxidant activity strongly correlates with phenolic content in honey and the honey's colour. Darker honeys show higher concentrated phenolic compounds than lighter honeys, resulting in a high antioxidant content ${ }^{10}$. 


\subsubsection{Antimicrobial Activity of Honey}

The treatment of bacterial infections faces increasing challenges as a result of bacterial resistance to current antimicrobial agents. This is leading to the development of alternative antibacterial and antifungal agents. Therefore, studies have been focused on discovering natural products, which exhibit antibacterial properties. Honey owes a significant amount of its medical uses its antimicrobial activity. In this regard, different microbial species have been reported to be susceptible to the antimicrobial activity of honey including Gram-positive (i.e. Bacillus subtilis, Staphylococcus aureus (S. aureus) and Paenibacillus larvae) and Gram-negative (i.e. Pseudomonas aeruginosa, and Escherichia coli (E. coli)) ${ }^{33}$. Roshan (2017) examined 10 different Australian and other commercial honeys against $S$. aureus, S. epidermidis, E. faecalis, A. baumannii, E. coli, S. Typhimurim and P. aeruginosa. The results showed that all honeys displayed antimicrobial activity and inhibited the bacterial growth, which varied for the type of bacteria $^{48}$. This finding is supported by different studies proving the antimicrobial property of honey in general ${ }^{33}$.

The antibacterial activity of honey is due to two distinct factors: enzymatic production of hydrogen peroxide and non-peroxide honeys. Studies show that the antibacterial property of honey is derived from the effects of hydrogen peroxide, methylglyoxal (present in non-peroxide honeys), bee defensin-1 (antimicrobial peptide), low pH and high sugar content ${ }^{49}$.

\subsubsection{Non-peroxide Antimicrobial Components (Methylglyoxal)}

The antimicrobial action of honey is mainly due to the presence of $\mathrm{H}_{2} \mathrm{O}_{2}$, but a variety of honey is known for non-peroxide antibacterial activity. Manuka honey (MH) has been identified for its unique non-peroxide antimicrobial components, which relates to honey from the native New Zealand Manuka tree (Leptospermum scoparium). Recently researchers have reported a high level of the antimicrobial compound methyl- 
glyoxal (MGO) in MH (see Section 1.6). Various foods have shown a range of MGO concentrations $^{50}$, but $\mathrm{MH}$ has been reported as containing the highest concentration of $\mathrm{MGO}^{51}$. There is a correlation between the MGO level and the ability of honey to inhibit S. aureus growth ${ }^{50}$. Dilution of MH to low MGO concentrations confirms the activity for $\mathrm{MH}$ nonperoxide antimicrobial components. The activity of $\mathrm{MH}$ and MGO against a broad spectrum of bacteria has been the subject of further investigation ${ }^{52-55}$. MGO is the main focus of this research study and it will be discussed in Section 1.3.

\subsubsection{Sugars}

Honey contains a high concentration of sugars, which represent approximately $80 \%$ of honey. The combination of high sugar concentration and low levels of water (13\%) prevents the microorganisms from damaging the honey. Although dilution of honey between $29 \%$ and $40 \%$ might result in microbial growth, the sugar level in the honey is sufficient to maintain antibacterial activity. For example, $S$. aureus is prevented at low sugar concentration of $29 \%(\mathrm{v} / \mathrm{v})^{56}$. In addition, the antimicrobial activity of honey is still retained at a higher dilution, but it is as a result of compounds other than sugars ${ }^{57}$.

\subsubsection{Hydrogen Peroxide}

Hydrogen peroxide $\left(\mathrm{H}_{2} \mathrm{O}_{2}\right)$ was first identified in the 1960 s as a significant antimicrobial component in honey. During the production of honey, honeybees use the enzyme, glucose oxidase which breaks down glucose sugars to generate $\mathrm{H}_{2} \mathrm{O}_{2}$. The importance

of $\mathrm{H}_{2} \mathrm{O}_{2}$ is to prevent honey spoilage during its production when the level of sugar is below the effective level of inhibition microbial growth. Hydrogen peroxide works as an antimicrobial agent at a high concentration $(0.8$ to $8 \mathrm{M})$ against Staphylococcus, Streptococcus, Pseudomonas-species, and Bacillus. However, at higher concentration, $\mathrm{H}_{2} \mathrm{O}_{2}$ leads to cellular and protein damage in tissue due to the occurrence of oxygen radicals $56,58,59$ 
Several studies show that a fast wound healing process occurs when honey is utilised as a dressing, which is due to $\mathrm{H}_{2} \mathrm{O}_{2}$ involvement. $\mathrm{H}_{2} \mathrm{O}_{2}$ is produced as a part of the inflammatory response to infection, which stimulates repairing the damage. The $\mathrm{H}_{2} \mathrm{O}_{2}$ in honey might affect also the growth and survival of microorganisms. However, honey antioxidants such as ascorbic acid, polyphenols and catalases might lower the oxidative stress of cells and protect them ${ }^{58}$.

The contribution of $\mathrm{H}_{2} \mathrm{O}_{2}$ to the antimicrobial property of honey were detected by neutralising effects of this compound using catalase reduction of $\mathrm{H}_{2} \mathrm{O}_{2}$ to water and $\mathrm{O}_{2}$. The neutralisation resulted in reduction of the total antimicrobial activity of the honey ${ }^{56}$.

\subsubsection{Bee Defensin-1}

The peptide defensin-1 has been identified for having antibiotic effectiveness in Revamil branded honey. In 1994, this peptide was discovered in the honeybee ${ }^{60}$ and later in the honey. Bee defensin-1 shows a significant activity toward Gram-positive bacteria only including $B$. subtilis, $S$, aureus and Paenibacillus larvae. Investigations have identified a few honeys having bee defensin- 1 . However, the contribution of this peptide was examined by neutralising bee defensin- 1 with other bioactive compounds, which resulted in a reduction of antimicrobial property of honey ${ }^{56}$.

\subsubsection{Low pH Level}

The low $\mathrm{pH}$ of honey plays a role in its antimicrobial activity of honey. This low $\mathrm{pH}$ is associated with the high concentration of $\mathrm{H}_{2} \mathrm{O}_{2}$ and gluconic acid. As has been mentioned above, honey has many acids such as phenolic and aromatic acids. The level of acids in the honey increases because of heat and storage conditions (e.g. temperature $)^{48,61,62}$. 


\subsection{Manuka Honey}

Manuka honey has been identified as unique therapeutic honey that is derived from Leptospermum scoparium, which is the native New Zealand Manuka tree. This honey shows inhibition towards a broad range of microorganisms, which is recognised for its a potential medical application for wound dressing and healing process. Several studies indicate different kinds of honey possess an antimicrobial activity after the neutralising of hydrogen peroxide due to non-peroxide compounds. In 1990, a group of Waikato University researchers identified some antibacterial constituents of $\mathrm{MH}$ and significant antimicrobial activity was observed $^{52}$. In 2004, Weigel et al. pioneered the measurement of 1,2-dicarbonyl compounds: glyoxal (GO) (A), methylglyoxal (MGO) (B) and 3-deoxyglucosulose (3-DG) (C) in MH honey (Scheme 1.3) ${ }^{63}$.

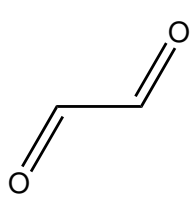

(A)<smiles>CC(=O)C=O</smiles>

(B)

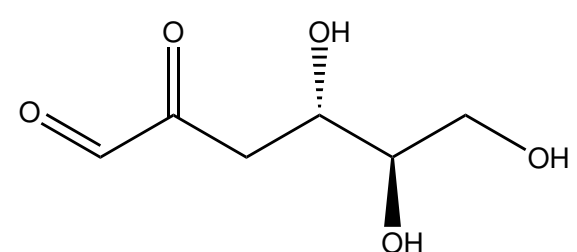

(C)

Scheme 1.3: 1,2-Dicarbonyl compounds reported in honey

The contents of both MG and MGO are generally low in different kinds of honey (up to $5 \mathrm{mg} \mathrm{kg}^{-1}$ ). However, Manuka honey exclusively has high concentrations of MGO (up to $800 \mathrm{mg} \mathrm{kg}^{-1}$ ), giving a clear indication of MGO's contribution to the antimicrobial activity of Manuka honey. The amount of MGO correlates with MH's antimicrobial property, which is utilised as a label for the bioactivity of the honey. A commercial measure, known as Unique Manuka Factor (UMF), references the microbial activity of $\mathrm{MH}$ based on the concentration of MGO in $\mathrm{MH}^{53}$.

The formation of MGO in MH has been identified as originating from dihydroxyacetone , 1,3-dihydroxy propanone, (DHA) from the nectar of MH flowers. Fresh MH contains a low concentration of MGO and a high concentration of DHA. Adams et al. reported 
that the DHA is non-enzymatically transferred to MGO, which occurs during honey storage due to the temperature conditions, resulting in a high level of MGO and a low level of DHA. The group added DHA to clover honey, which led to a similar high level of MGO to that found in MH. These results supported the evidence of non-enzymatic conversion of DHA to MGO at high levels in the nectar. However, the origin of DHA in the nectar of $\mathrm{MH}$ remains unclear ${ }^{54}$.

1,2-Dicarbonyl compounds are formed as a result of the Maillard reaction or in a caramelised mixture from reducing carbohydrates. Some studies have investigated these dicarbonyl compounds present in $\mathrm{MH}$ and their responsibility for the non-peroxide activity. The three compounds 3-DG, MGO and GO were evaluated using agar diffusion to examine their antimicrobial activity by E. Mavric et al. ${ }^{53}$. All three compounds have shown inhibition effects against $E$. coli and $S$. aureus, however, the most significant antimicrobial impacts were only associated with MGO. The minimum concentration needed to inhibit the bacterial growth (MIC) for MGO was $1.1 \mathrm{mM}$ for both bacteria types. The MIC value represents the minimum concentration of a specific compound, where the inhibition effects could be detected .The MICs of GO were 4.3 and $6.9 \mathrm{mM}$ for $S$. aureus and E. coli respectively, where 3-DG showed no inhibition effects for bacterial growth up to $60 \mathrm{mM}^{53}$. This low MIC of MGO led to interest in using MGO in new application developments.

To determine the chemical substances of $\mathrm{MH}$ and their antimicrobial activity, a high dilution of many honey samples (up to 80\%) showed an absence of antibacterial effects. However, $\mathrm{MH}$ was diluted to concentrations where $\mathrm{MGO}$ was between 1.1 to $1.8 \mathrm{mM}$ (30\% honey dilution) and exhibited antimicrobial effects, which are similar to the determined MIC of the standard solution of MGO. A diluted forest honey (20\%) had no antibacterial effects, while the addition of $1.9 \mathrm{mM}$ of $\mathrm{MGO}$ to this sample resulted in a clear inhibition zone that corresponded to the addition of MGO. These findings suggest that MGO is directly responsible for the unique antibacterial activity of $\mathrm{MH}^{53,54}$. 


\subsubsection{Determining MGO Concentration in MH}

The quantitative measurement of MGO requires an understanding of its behaviour in a solution, although MGO is reactive in water and undergoes a spontaneous reaction with water as shown in Scheme 1.4 and less than $1 \%$ remains unreacted ${ }^{64}$. Also, a significant amount of MGO can transform into monomeric mono- and dihydrate forms, and their equilibria is strongly influenced by solvent and temperature ${ }^{65}$. One of the important challenge MGO has is having a low molecular mass and lack of an ultraviolet absorbance, which creates difficulties for analytical detection systems. Alternatively, MGO detection often employs derivatisation with ortho-phenylenediamine (OPD), which forms 2-methylquinoxaline (Scheme 1.5) that can be detected by UV-Vis spectrophotometry.

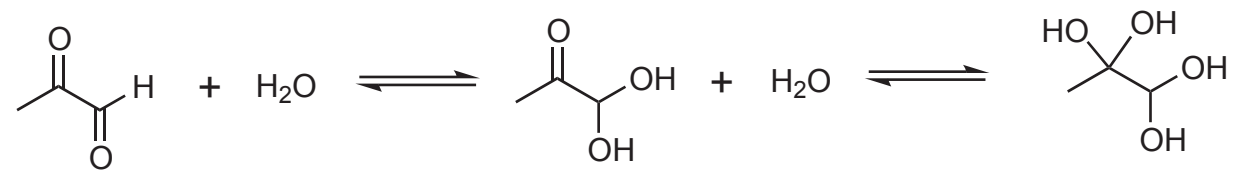

Scheme 1.4: The reaction of MGO with water, resulting in hydration of carbonyl groups

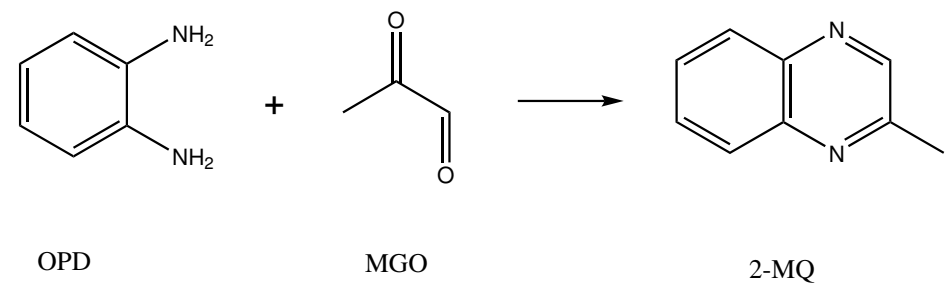

Scheme 1.5: MGO derivatisation with OPD forming 2-MQ

This method led to analysis of the three 1,2-dicarbonly compounds: 3-DG, GO and MGO through derivatisation with OPD using RP-HPLC in different commercially available honey samples according to Weigel et $\mathrm{al}^{63}$. For the first time, in 2008 a large number of commercially available honey samples were analysed using this method to determine the level of 1,2-dicarbonyl compounds. The study supported the low content of GO and MGO in honey samples except MH from NZ. In MH samples, the UV detection with with HPLC showed prominent peaks that have identical retention time as MGO in its OPD form. In addition, the correlation of UMF-value with the content of 
MGO was reported ${ }^{53}$. The MGO concentrations in different commercial honey samples including MH were identified, and they ranged between 38 to $761 \mathrm{mg} \mathrm{kg}^{-1}$ for $\mathrm{MH}$ only (Table 1.2) ${ }^{53}$.

Table 1.2: GO and MGO contents in a commercial honey sample and 6 Manuka honey samples (data given in $\mathrm{mg} \mathrm{kg}^{-1}$ and the variation is a result of triplicate analysis).

\begin{tabular}{l|ll}
\hline Sample & GO & MGO \\
\hline Commercial honey & 1.7 & 3.1 \\
Manuka 1 & $0.7 \pm 0.2$ & $38.4 \pm 5.0$ \\
Manuka 2 & $3.0 \pm 1.0$ & $347 \pm 20$ \\
Manuka 3 & $3.9 \pm 1.0$ & $411 \pm 24$ \\
Manuka 4 (UMF 10) & $1.2 \pm 0.5$ & $416 \pm 35$ \\
Manuka 5 (UMF 20) & $4.2 \pm 1.1$ & $743 \pm 40$ \\
Manuka 6 (UMF 25) & $7.0 \pm 1.0$ & $761 \pm 25$ \\
\hline
\end{tabular}

\subsubsection{Wound Dressing Application}

The healing process rebuilds the shape of an injured tissue and prevents micro-organism growth and damage. The practice of treating a wound to heal has probably been known since ancient times. Initially, wound infections are the primary issue in healthcare management because infections are likely to lead to the formation of inflammatory exudate, or delays to the healing. The skin, in this case, plays an important role in protection from microorganism growth. This means the skin must be covered with an ideal dressing immediately after any damage. The optimal dressing creates a moist environment at the wound interface, absorbs excess exudates, allows gaseous exchange, and becomes a barrier to microorganisms. Also, it should be non-toxic, antimicrobial, biocompatible and easily removed. These requirements are primarily related to the materials that are used to fabricate the wound dressing using antimicrobial agents with natural or synthetic fibres ${ }^{66-68}$.

Several studies have reported chemical modifications of wool fibres to achieve particular properties for various end-use applications. Natural textile fibres provide suitable envi- 
ronment properties for a microbial contamination because of their large surface area and hydrophilic properties. This ideal environment for microbial growth leads to damage of textile and affects users, so increasing the potential risk of infection and transmission of diseases. In order to meet the high demand for natural textile applications (e.g. wound healing) with antimicrobial properties, chemical modification is required ${ }^{68-70}$.

Studies show different applications have utilised bacteriostatic agents into textile fibres including triclosan ${ }^{71}$, chitosan ${ }^{72}$, aromatic halogen compounds, phenols ${ }^{73}$, and silver nanoparticles ${ }^{74}$. These applications were made with the view to prevent microbial attack on wool and could extend their useful life. However, a few drawbacks of these applications including their side effects, toxicity, cost-effectiveness and availability raises the need for an alternative green approach. Honey provides a range of natural antimicrobial features, which makes it desirable for wound healing and dressing by incorporating the honey properties into wool fabrics ${ }^{75}$.

Honey has been used as a therapy treatment through various civilisations but only in 1992 was it used clinically in the treatment of some disease including ulcers and other surface infections related to burns and wounds ${ }^{30,76}$. The physical and chemical properties of honey positively influence the wound healing process and environment; this is mainly because of the honey's acidity and levels of sugar and hydrogen peroxide. The incorporation of the antimicrobial property of honey into wound dressings is aimed at preventing microbial growth in the moist wound environment with no tissue damage being caused by the honey itself. Although a large number of reports and advantages support using honey in wound dressing, honey in general varies significantly in its antibacterial activity ${ }^{61,66,77}$. Therefore, many studies have focused on finding a type of honey with a high antibacterial activity, with $\mathrm{MH}$ being the leading example here.

Non-peroxide compounds, mainly MGO, present in MH provide unique antibacterial functions. Clinical studies show an increase in successfully treating infections and improving the healing process when $\mathrm{MH}$ is used in a therapeutic dressing ${ }^{78}$. This suggest that MGO in MH has a potential use as wound healing due to its antimicrobial activity. 
Also, a few clinical studies reported its activity toward cancer cells, antiviral and antimalarial properties. MGO can modify DNA (e.g. leukaemia and prostate cancer cells) and cell components (e.g. proteins, nucleic acids and free amino acids). The wound healing process is improved by MGO activating macrophages and lymphocytes, which improve the healing process. The MIC $(1.05 \mathrm{mM})$ of $\mathrm{MGO}$ has attracted attention for application development because of its ability to prevent bacterial growth, and its anti-proliferative effects on tumour cells. These MGO properties have been reported in different applications such as a liquid treatment form ${ }^{53,79}$, poly(vinyl alcohol) fibres ${ }^{80}$ and as a polymer-based complex ${ }^{81}$.

To date, the incorporation of MGO and MH into wool and other textile fibres has not been previously studied in terms of characterising the uptake of MH or MGO by wool. In August 2017, a group at the University of Leeds studied the antibacterial activity of MGO and MH at equivalent MGO concentrations by simply coating them onto fabrics by a commonly used padding process ${ }^{82}$. In this study, the MGO and MH were reported for the first time in terms of concentration per unit area of fabric and the MIC of MGO-wool $^{82}$. It is important to know how much of the bioactive compound MGO is required to coat a fabric for medical (wound dressing) and apparel uses. However, in this method, the textile was immersed into $\mathrm{MH}$ and MGO solutions for a short period of time (ten minutes) and then dried and tested for their antimicrobial properties. This coating simply sits on the fibre surface and there is unlikely to be any durable bonding of the MH or MGO with the textile fibres ${ }^{82}$. Hence, the MH or MGO would readily wash off because they are not likely to be attached to the surface. A rigorous determination of the actual extent of uptake of MH or MGO has not been reported.

As a result, there is a need to quantitatively determine the uptake of MG and MGO by the wool fibre and to incorporate them into the fibre and hence the fabrics by chemical bonding in order to achieve an effective antibacterial textile based on a natural product. This particular goal begins with achieving an understanding of the nature of textile fibres and their chemical structure. Furthermore, a polymer-based MGO complex is 
another potential application, which could be used to generate an antimicrobial surface coating based on this natural active species.

\subsection{Wool}

Textiles can be classified into synthetic and natural fibres, which vary in physical and chemical properties. In general, fibres can be considered to comprise large and small molecules, which are linked together forming chain structures typical of polymers. Synthetic fibres (e.g. polyester and nylon) are made from chemical polymerisation and are not biodegradable products. Natural fibres are defined as a substance that are produced by animals (e.g. wool, silk) or plants (e.g. cotton). They are increasingly becoming more preferable as their properties are favoured those of synthetic fibres, such as biodegradability its low weight, recyclability and high strength and stiffness ${ }^{83}$. However, as they are essentially protein or cellulose based fibre, natural textiles provide a hospitable environment for the growth of microorganisms, which can result in damage to the fibres and a potential risk for users. This issue requires an antimicrobial $\mathrm{f}$ coating in textile to address the problem ${ }^{83}$

Recent studies show an increase in the total global natural fibres market, with a value of US\$ 531.3 million in $2016^{83}$. This translates into an increase in the number of applications of natural fibres. New Zealand (NZ) is one of the largest exporters of crossbred and merino wool, which is the preferred natural fibre in certain carpet, textile and apparel products ${ }^{84}$. This provides an opportunity for NZ to add further value to NZ merino and crossbred wool through the development of natural fibre products based on capturing the natural antimicrobial properties of MGO and $\mathrm{MH}$. 


\subsubsection{Chemical Structure of Wool}

Wool fibres comprise long strands of molecules forming a linear, stringlike structure. The chemical nature of wool fibres varies among animals, mostly consist of protein chains comprising the elements carbon, oxygen, hydrogen, nitrogen, sulfur, and some other inorganic components as shown in Table 1.3. All 20 amino acid types are found in wool, which can be characterised according to hydrophilic, hydrophobic or nature: acidic (e.g. asparagine and aspartic acid), basic (e.g. arginine histidine and lysine). These amino acids form strong polypeptides that generate the strength, flexibility and low solubility of wool ${ }^{85,86}$.

Table 1.3: Average chemical composition of wool fibres

\begin{tabular}{|l|l|}
\hline Elements of Wool & Weight (\%) \\
\hline Carbon & $50-52$ \\
\hline Oxygen & $22-25$ \\
\hline Hydrogen & $6.5-7.5$ \\
\hline Nitrogen & $16-17$ \\
\hline Sulfur & $3-4$ \\
\hline Others & $<1$ \\
\hline
\end{tabular}

In wool, these polypeptide-chains are cross linked together forming portions by inter and intra-chain reactions as shown in Figure 1.3. The disulfide bond is the primary cross-linker in wool, which is responsible for its insolubility. The presence of high content of oppositely charged side-chains provides other cross linking types: salt bridge (involve exchanging protons mostly between carboxyl and amino groups) and isodipeptide (forming between amino groups). In addition, hydrogen bonding, noticeably stabilises the fibre especially between amide, hydrogen donating and accepting groups. Overall, these different types of cross-linkages in the wool chains provide the resiliency of the fibre and a better understanding for chemical finishing of fibres. The different chemical components create a complicated structure of wool with a complex morphology that provides wool fibres with greater chemical stability and additional strength ${ }^{85,87}$. 


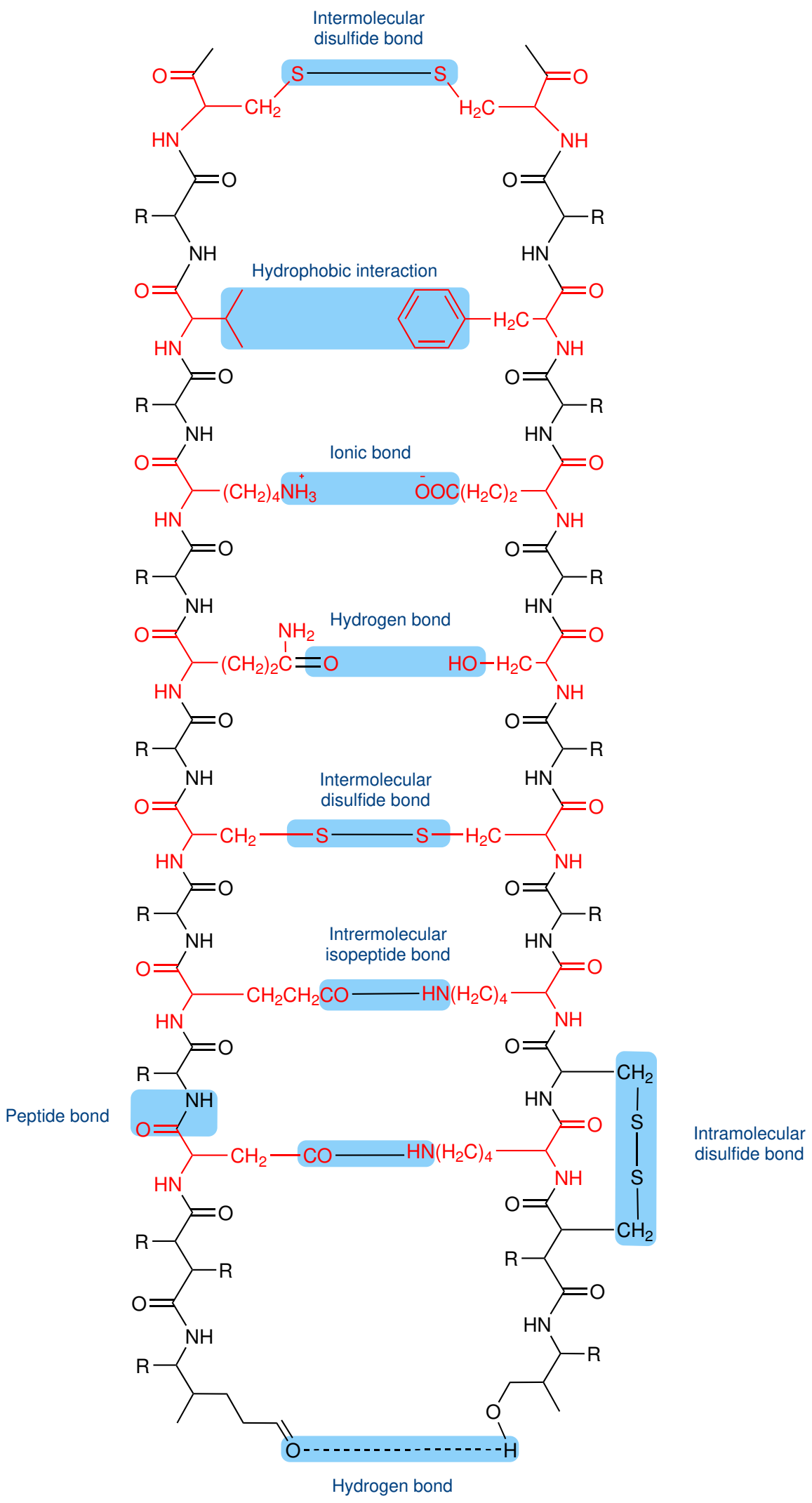

Figure 1.3: An illustration of chain interactions in wool fibres, which provide the strength, stability and chemical and physical properties. 


\subsubsection{Morphological Structure of Wool}

Among other types of fibres, wool has a complex structure and multiple layers, which influence the actual properties of fibres. The morphological structure of wool is represented in Figure 1.4, showing the core layers of the fibre. The three primary layer of fibre are the external cuticle (5-10 wt\%), the internal cortex cells, ortho- $(60-90 \mathrm{wt} \%)$ and para-cortex cells (40-10 wt $\%)$, and the cell membrane complex $(3 \mathrm{wt} \%)^{87}$.

The cuticle cell is a thin sheet that covers and protects the inner regions of the wool with a thickness of $0.5-0.8 \mu \mathrm{m}$. It contains a surface covalently bound fatty acid that is bound to it by a thioester linkage; this creates a high resistance to oxidising agents and alkalis. Fine wool fibres are covered by a single layer and multiple layers are present on more durable cross bred wool fibre. Studies show that the cuticle consists of various layers (multi-functional as a sandwich system) including endocuticle, exocuticle and epicuticle. This functionality protects the wool and acts as a natural diffusion barrier toward hydrophilic substance such as some dyes. Figure 1.5 shows the gap between cuticle cells provides cavities, which allows small molecules to diffuse through (e.g. dyes). The low concentration of disulphide cross-links and the total amount of acidic, basic and polar amino acids present in the endocuticle increases the swelling capacity and enable chemical attack on the endocuticle ${ }^{86,88,89}$.

The cortex is the central part of wool fibre and consists of long and twisted spindle shaped cells. In merino wool, both cortex cells (ortho-cortex, the outer layer, and paracortex, the inner layer) are shaped bilaterally with a helical borderline, resulting in a stable and robust crimp. The para-cortex contains a higher amount of cystine, forming di-sulphide cross-links, than in the ortho-cortex. This significant amount of sulphur in the para-cortex results in a highly cross-linked, strong layer and chemical stability ${ }^{86,88,89}$. In 1954 Mercer et al. ${ }^{90}$ discovered the reactivity of the cystine of keratin occurs in the ortho-cortex. These chemical differences between the two segments make the ortho-cortex more accessible to reagents, dyes and more reactive than the para- 
cortex. Moreover, the ortho-cortex contains a higher proportion of non-keratinous proteins including intermacrofibrillar material, which makes this segment more susceptible to acid hydrolysis and more wettable. These properties, beside a lower cross-link rate in the ortho-cortex, generate a swollen segment ${ }^{87,89}$.

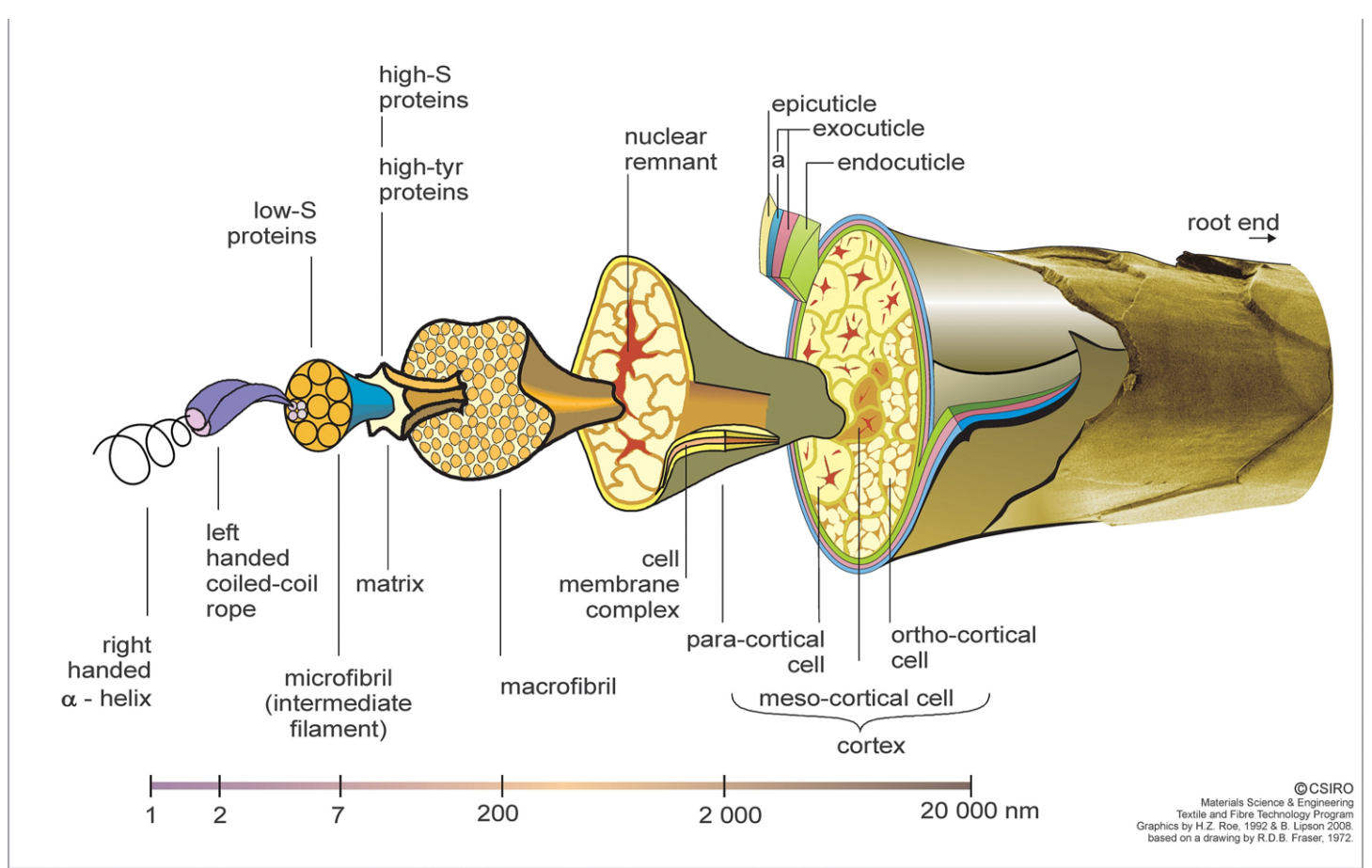

Figure 1.4: The morphological structure of merino wool fibre. (Note: permission to reproduce this image has been granted by CSIRO Publishing)

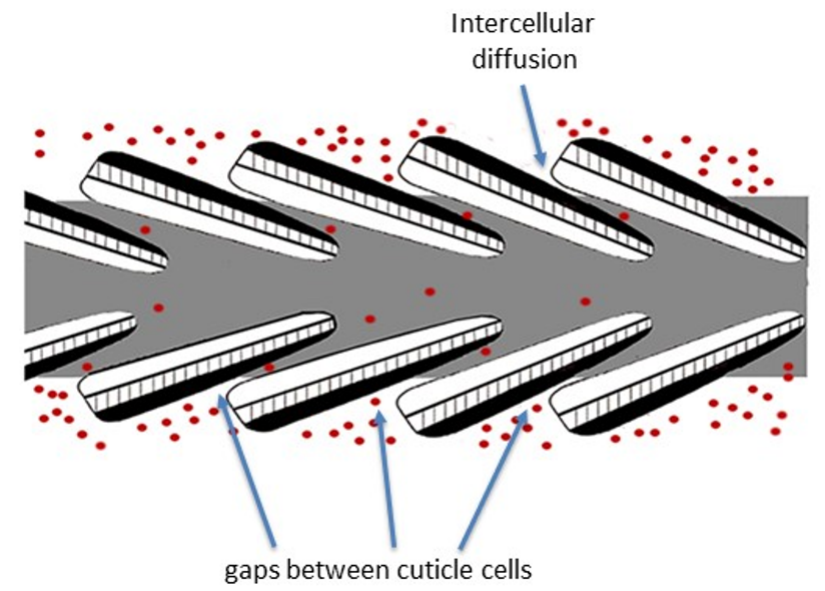

Figure 1.5: An illustration of the gaps between cuticle cells allowing diffusion of small molecules. The Figure was designed based on data found in the literature. 
The cell membrane complex (CMC) is a layer that surrounds the cuticle and cortical cells in keratinised wool fibre. The importance of the CMC is linking both cells of the cuticle and cortex, transporting dyes and chemicals into the fibre to characterise the surface properties. The space within the $\mathrm{CMC}$ is the route of diffusion of substances into cortex cells. Reactive chemicals and reducing agents attack the lipids of the CMC and are likely to damage and weaken the cortex cells (see Figures 1.4 and 1.5) (77,88. $^{8}$.

\subsection{Polymer Resins}

\subsubsection{Characterisation of Polymer Resins}

The second class of substrates that were used in this project are polymer resins. They can be divided into two groups based on their source, which are from natural products (e.g. chitosan and fibrin) or synthetically produced (e.g. acrylic resin and its derivatives such as polymethyl methacrylate (PMMA) and polyurethane(PU)). A wide range

of applications uses polymeric material in industrial products, packaging ${ }^{91}$, medicine ${ }^{92}$, coating, daily uses and other advanced applications ${ }^{91}$. Particular characteristics make these materials useful in applications for consumer and industrial products such as weight in comparison to strength, ease of processing and low cost. This work focused on adding antimicrobial properties to polymeric materials used in coating for functional applications $^{91,92}$.

Polymeric materials consist of a long chain of organic compounds known as macromolecules, arising from multiple monomer repeat units linked together. The commercial polymers have on average more than 1,000 monomer repeat units with a molecular weight between $10^{4}$ and $10^{7} \mathrm{~g} \mathrm{~mol}^{-1}$. The polymer type is defined based on consisting of either one monomer repeat unit, known as homopolymers or two or more types of monomer repeat units, known as copolymers ${ }^{93}$. 
Four different terminologies are used to define the polymeric materials:

1. Macromolecule: refers to a structure of covalently bonded monomers.

2. Polymer: refers to a naturally or synthetically produced polymeric material.

3. Plastic: refers to a synthetic material, but without considering its structure.

4. Polymeric Materials: refers to a combination of polymer and plastic materials $^{91,93}$.

\subsubsection{Polymers with Antimicrobial Activity}

The growth of microorganisms on the surface of the polymeric products is a growing concern. The use of polymeric materials with antimicrobial properties is important for research focus in consequent industrial applications. Several applications incorporate silver ${ }^{94}$, chitosan and triclosan by mixing these bioactive components with various polymers ${ }^{95}$. A potential application of this research is to use methylglyoxal (MGO) as a natural product in polymeric materials and to study if the polymer is able to release the MGO in a pathogenic environment. In a similar study, MGO was conjugated with polyamidoamine as a drug delivery system. This approach showed a slow release of MGO in cancer therapy, developing a potential use of MGO in polymer conjugates against a specific target ${ }^{81}$.

\subsubsection{Acrylic Polymers}

Acrylic resins are thermoplastic or thermosetting; thermoset is plastic that is derived from acrylate monomers (e.g. acrylic and methacrylic acids are shown in Figure 1.6). Two known functionalities are present in acrylic acid: vinyl and carboxylic acid, which facilitate polymerisation of the resin. This occurs through the reactive vinyl double 
bond, which forms homoplymer or polyacrylic acid (cross-linked polymer). These functionalities of the acrylic acid enable the subsequent fabrication of different products. Emulsion polymerisation can generate acrylic resins that further cross link on drying or coating to form surface coatings with water resistance and colour properties to a substrate ${ }^{93}$.

\subsubsection{Poly(methyl methacrylate) (PMMA)}

PMMA is the most common acrylic resin and is synthetically prepared from the ester methyl methacrylate. The polymerisation process for PMMA results in the formation of an emulsion of the poly-methyl methacrylate where the molecules cross link extensively. The structure of the PMMA unit can be seen in Scheme 1.6. The bulk of the methyl groups prevents the polymer chains from crystallising, which creates a tough and rigid resin. Its unique properties for the polymer market interests to developed applications of PMMA and it could be promising to incorporate an antimicrobial agent into the polymer ${ }^{93}$<smiles>C=CC(=O)O</smiles>

Acrylic Acid<smiles>C=C(C)C(=O)O</smiles>

Methacrylic Acid

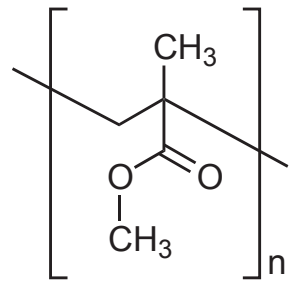

PMMA

Scheme 1.6: Some common acrylic acids and PMMA structures.

\subsubsection{Polyurethanes}

Polyurethane (PU) is a thermoplastic copolymer comprising diol and diisocyanate monomers, that polymerise to form amorphous or semicrystalline and crystalline polymer domains. The softness of the amorphous and semicrystalline segments lead to flexible polymers 
and a hard segment results in a rigid polymer. Preparation of polyurethane by polymerisation involves the reaction of a diisocyanate monomer with a diol as seen in Scheme 1.7. The functional groups of hard segments mostly hydrogen bond to each other in a linear chain where $\mathrm{N}-\mathrm{H}$ acts as a good donor and $\mathrm{C}=\mathrm{O}$ as acceptor resulting in a hydrogen bond between the two groups. This self-association is an additional driving force in the hard segment, but it is less noticeable in soft segments even with the presence of other acceptor groups such as an ether oxygen or ester carbonyl. The hydrogen bonding creates an important structural feature of polyurethanes and their properties ${ }^{91,96-99}$.

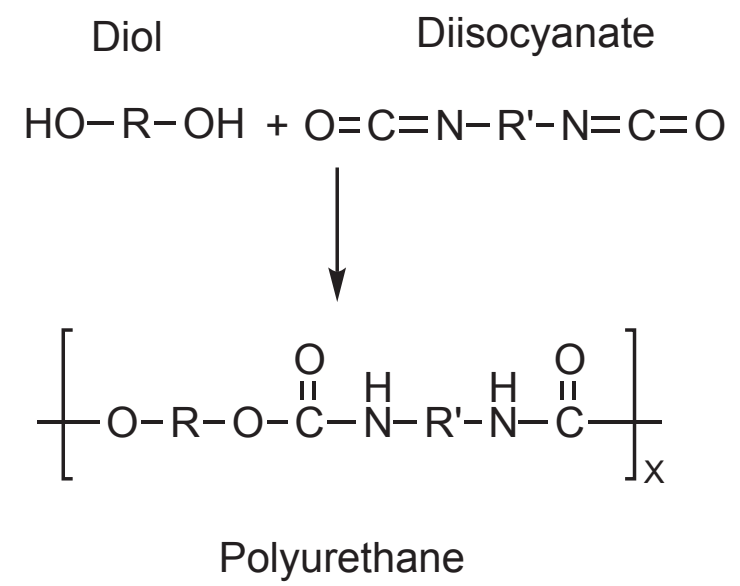

Scheme 1.7: Polyurethane structure and its formation. 


\subsection{Project Scope}

This research focused on capturing the antimicrobial properties of naturally occurring chemical compounds by incorporating them into wool fibres and fabrics, and a polymer coating, with a possible view to potential applications by the wool and polymer industry.

In this work, the novel use of New Zealand Manuka honey (MH) and particularly the active ingredient methylglyoxal (MGO) as a natural antimicrobial agent in wool fibres, fabrics and a polymer coating is presented, the various stages include:

1. Analytical method development for determining the MH and MGO uptake, and measuring this uptake at different temperatures, concentrations and times.

- In this method, High-Performance Liquid Chromatography (HPLC) was used to analyse MGO and MH solutions before and after the uptake by wool.

2. Characterisation of the MGO-wool and MH-wool composites:

- Fourier-Transform Infrared Spectroscopy (FTIR).

- Differential Scanning Calorimetry (DSC).

- Thermogravimetric Analysis (TGA).

3. Dynasylan ${ }^{\circledR}$ F8815 treatment of MGO-Wool composites.

- This treatment impacts hydrophobic surface properties to the wool and MGOWool composites.

- Then the contact angle of the wool and MGO-Wool composites was determined.

4. Zone of inhibition test for the antimicrobial activity of MH- and MGO-Wool composites.

- The purpose of this test is to determine the extent of antimicrobial activity for the MH- and MGO-Wool composites. 
In the second part, MGO was used in a polymer coating as follows:

1. Preparation of polymers with MGO.

- Polymer matrix composites including NeoCryl ${ }^{\circledR}$ XK-98, Poly(methyl methacrylate) (PMMA) and polyurethane were mixed with MGO.

2. The characterisation of the MGO-polymer composites by:

- Fourier-Transform Infrared Spectroscopy (FTIR).

- Differential Scanning Calorimetry (DSC).

- Nuclear Magnetic Resonance (NMR).

3. Zone of inhibition test for antimicrobial activity of the MGO-Polymer composites.

- The purpose of this test is to determine the extent of antimicrobial activity for the MGO-Polymer composites. 


\section{Chapter 2}

\section{Methodology}

\subsection{Materials and Chemicals}

The chemicals and materials used in this study for determining the Manuka Honey $(\mathrm{MH})$ and methylglyoxal (MGO) uptake and coating with MGO were:

1. $40 \%$ (w/v in water) MGO aqueous solution purchased from Apollo Scientific Limited.

2. Two batches $(250 \mathrm{~g})$ of commercially available Arataki Honey $\mathrm{UMF}^{\circledR} 10+$ Manuka Honey were purchased for determining the MGO level and the uptake.

3. The merino wool in both fabric and yarn forms were supplied by Dr Peter Ingham from AgResearch Ltd in Lincoln, New Zealand.

4. The merino loose top wool was purchased from Ashford Handicrafts Ltd, Ashburton, New Zealand. All merino wool forms were unheaded and undyed.

5. Antimicrobial silver fabric, used for antimicrobial testing, was provided by Prof Jim Johnston, Victoria University of Wellington, New Zealand. 
6. NeoCryl ${ }^{\circledR}$ XK-98, Poly(methyl methacrylate), a self-crosslinking acrylic emulsion polymer, and Kamthane K5000 latex paint base (polyurethane) were supplied by the Polymer Group Ltd in Auckland, New Zealand.

7. PMMA, powder, with an average M.W. of 15,000 was purchased from SigmaAldrich, New Zealand.

8. Dynasylan ${ }^{\circledR}$ F8815 was supplied by Evonik Industries.

\subsection{Quantification of Methylglyoxal Content in Manuka Honey}

Several studies have found that the level of MGO in MH is within the range of 38 to $761 \mathrm{mg} \mathrm{kg}^{-1}$ (as stated in Section 1.3.1). Thus, MH UMF10+ used in this study has an assumed MGO level of $450 \mathrm{mg} \mathrm{kg}^{-1}$ based on the study of E. Mavric et $\mathrm{al}^{53}$. A MH solution with MGO concentration of $200 \mathrm{mg} \mathrm{L}^{-1}$ was prepared using $44.4 \mathrm{~g} \mathrm{MH}$ and $66.6 \mathrm{~g}$ of water. The solution was then diluted to achieve the following concentrations; $175,150,100,75$ and $50 \mathrm{mg} \mathrm{L}^{-1}$ of $\mathrm{MH}$ based on MGO concentration. $1 \mathrm{~mL}$ of each stock solution was derivatised with orthophenylenediamine (OPD) for determining the MGO level using HPLC analysis (further details are stated in Section 2.4.1).

\subsection{Procedure for determining amount of Manuka honey and Methylglyoxal Uptake}

Wool fibres in loose top form, yarn and finished fabrics were weighed $(0.1 \mathrm{~g} \pm 0.02)$. They were then dipped into hot water at $60{ }^{\circ} \mathrm{C}$ for five minutes, or until wetted, to ensure the hydrophilicity of the surface does not slow down the absorption rate. Following that, each of the wetted wool samples were placed into $20 \mathrm{~mL}$ solutions of $\mathrm{MH}$ and 
MGO at various concentrations and temperatures. The samples were placed into a hot water shaking bath at $30 \mathrm{rpm}$ between 50 and $80{ }^{\circ} \mathrm{C}$. One vial was collected from the hot water bath after a certain time to determine the MGO level by HPLC (HPLC analysis of MGO is discussed in more detail in Section 2.4.1). The wool samples were removed from the treatment solutions, and $1 \mathrm{~mL}$ of each solution was collected in order to determine the MGO level. The wool samples were dried with paper towels, and then left at room temperature for 24 hours to dry. The uptake was measured by analysing the amount of MGO in the MH and MGO solutions, via HPLC, before and after the wool treatment. The difference in concentrations, in the first instance, is assumed to be due to MGO absorption by wool. To ascertain the validity of this approach, reference solutions $(20 \mathrm{~mL})$ were treated under the same conditions without wool, and the MGO and $\mathrm{MH}$ concentrations of $1 \mathrm{~mL}$ samples were collected and measured at the same time. Various characterisation methods (as detailed below) were used to determine the absorption amounts and its effects on the wool behaviour. The variables influencing the rate of $\mathrm{MH}$ and $\mathrm{MGO}$ uptake included concentration, temperature, time and procedure, and will be discussed in the results Chapter 3 .

\subsubsection{Degradation of Methylglyoxal}

The effect of the post-treatment storage conditions on the degradation of MGO solution was analysed. Two wool samples were treated with two solutions $(20 \mathrm{~mL})$ of $5 \mathrm{mg} \mathrm{L}^{-1}$ MGO and MGO in MH solutions, which contained $5 \mathrm{mg} \mathrm{L}^{-1} \mathrm{MGO}$ for 24 hours at $90{ }^{\circ} \mathrm{C}$. From each solution, $1 \mathrm{~mL}$ was collected after 24 hours and stored at $4{ }^{\circ} \mathrm{C}$ for a week before it was derivatised. Another $1 \mathrm{~mL}$ of both solutions were also collected at the same time, and were stored in the dark at room temperature for a week. Finally, all samples were derivatised with OPD and analysed to quantify if there was an effect of the storage condition on the concentration of MGO in solutions. 


\subsubsection{Preparation of NeoCryl ${ }^{\circledR}$ XK-98 and Kamthane 5000 with Methylglyoxal}

The preparation of NeoCryl ${ }^{\circledR}$ XK-98 and polyurethane (kamthane 5000) polymers containing MGO was achieved via two different process.

Firstly, the polymers were mixed with varying concentrations of liquid MGO, taking into consideration the absolute dilution rate of the polymers. Therefore, 9 and $6 \mathrm{~mL}$ of each polymer base was mixed with $1 \mathrm{~mL}$ of MGO at concentrations between 1-40\%. The polymer mixed via an overhead mixer at a speed of $40 \mathrm{rpm}$ and MGO was added dropwise. Then the polymer and MGO were mixed for 5 mins before being removed and placed on a shaking machine at $30 \mathrm{rpm}$ for 24 hours. $1 \mathrm{~mL}$ of each mixture (MGOPolymer) was dried on a glass microscope slide at room temperature and at $60{ }^{\circ} \mathrm{C}$ for 24 hours before any further analysis, which is presented in Chapter 4.

Second, $1 \mathrm{~mL}$ of MGO at concentrations between 1-10\% were dried by a rotary evaporation and then mixed with 9 and $6 \mathrm{~mL}$ of the polymer base whilst stirring at $250 \mathrm{rpm}$ for 24 hours. The mixture of MGO-Polymer was then dried on a glass microscope slide at room temperature for 24 hours or until dried.

\subsubsection{Methylglyoxal Leaching Test from Wool or Polymer Treated with Methylglyoxal}

The purpose of a leaching test was to determine if the MGO is chemically bonded to or firmly contained between the wool layers or cross-linked with the polymers. The wool treated with MGO was synthesised via the methods outlined previously in Section 2.3. For the leaching test, $0.1 \mathrm{~g}$ of two fabric wool samples, originally treated with 1 and $2 \mathrm{~g}$ $\mathrm{L}^{-1}$ MGO for 15 and 4 days respectively, was immersed in $20 \mathrm{~mL}$ distilled water at 70 ${ }^{\circ} \mathrm{C}$ in a hot water shaking bath for 5 days. The MGO concentrations in the water were 
quantitatively analysed by HPLC. Various other MGO-Wool samples (top, fabric and yarn wool) were analysed for MGO leaching at between 50 and $80{ }^{\circ} \mathrm{C}$.

The leaching test for the MGO-polymer base was accomplished for the MGO-NeoCryl mixture at ratio 1:9 v/v MGO:NeoCryl $(\mathrm{mL})$ with 6 and 7\% MGO. Each mixture (5 $\mathrm{mL}$ ) was dried on glass microscope slides at room temperature and then immersed into $100 \mathrm{~mL}$ of distilled water at $50{ }^{\circ} \mathrm{C}$ for 3 days. The amount of $\mathrm{MGO}$ in the water was analysed quantitatively by HPLC.

\subsubsection{Dynasylan ${ }^{\circledR}$ Treatment}

MGO-Wool and MGO-Polymer composites were treated with a hydrophobic surface agent Dynasylan ${ }^{\circledR}$. Dynasylan ${ }^{\circledR}$ lowers the surface energy of the substrates in order to achieve superhydrophobic surfaces of a material. The treated wool/polymer samples with MGO were soaked in a solution of Dynasylan ${ }^{\circledR}(2 \mathrm{wt} \%$ of wool or polymer) in water at room temperature under constant shaking for 16 hours. The samples were then dried at room temperature for 24 hours and the contact angle of a water droplet was measured to determine whether the hydrophobicity had been improved by the Dynasylan ${ }^{\circledR}$ treatment.

\subsection{Characterisation Techniques}

\subsubsection{Analytical RP-HPLC Method Development}

The MGO content was determined after derivatisation with orthophenylenediamine (OPD) using a modified method designed by Weigel et al. ${ }^{63}$. Aqueous solution $(1 \mathrm{~mL})$ of honey or MGO was mixed with $0.6 \mathrm{~mL}$ of $0.2 \%$ (w/v) OPD solution and were allowed to react at room temperature in the dark for 16 hours. Following that, pyrazine 
was added as an internal standard $\left(0.4 \mathrm{~mL}\right.$ of $\left.0.05 \mathrm{~g} \mathrm{~L}^{-1}\right)$ to account for instrumental variations in each analysis. The mixture was then filtered using a membrane filtration $(0.45 \mu \mathrm{m})$. Then, a $5 \mu \mathrm{L}$ sample of the derivatisation mixture was injected automatically into the HPLC instrument and the analysis was performed, two replicates, at a flow rate of $1 \mathrm{~mL} \mathrm{~min}{ }^{-1}$. Solvent A was microfiltered water with $0.025 \%(\mathrm{v} / \mathrm{v})$ formic acid, and solvent B was methanol HPLC grade containing $0.025 \%(\mathrm{v} / \mathrm{v})$ formic acid. The concentration gradient started with $36 \% \mathrm{MeOH}$ and was held for 2 minutes, followed by a linear increase to $80 \% \mathrm{MeOH}$ over 14 minutes, which was then held at this solvent ratio for 5 minutes before it was reduced back to the initial concentrations over 60 seconds, followed by an equilibration period of 8 minutes. The analytical column was a Waters BEH C18 2 x 250mm $1.7 \mu \mathrm{m} \mathrm{C18} \mathrm{column} \mathrm{with} \mathrm{an} \mathrm{oven} \mathrm{temperature} \mathrm{of} 35{ }^{\circ} \mathrm{C}$. Peaks were detected by measurement of UV absorbance at $312 \mathrm{~nm}$.

The quantification of HPLC peaks to determine the MGO concentrations was achieved by running calibration curves of known concentrations of MGO normalised to pyrazine then quantifying honey and MGO solutions accordingly (from the uptake). Table 2.1 and Figure 2.1 illustrate two linear $\left(\mathrm{R}^{2}=0.999\right)$ calibration curves for lower and higher concentrations of MGO and pyrazine. MGO solutions were prepared via dilution of $40 \% \mathrm{MGO}\left(400 \mathrm{~g} \mathrm{~L}^{-1}\right), 0.05 \mathrm{~g}$ of pyrazine into $1 \mathrm{~L}$ of water and $0.2 \mathrm{~g}$ of OPD into 100 $\mathrm{mL}$ vial with water. 

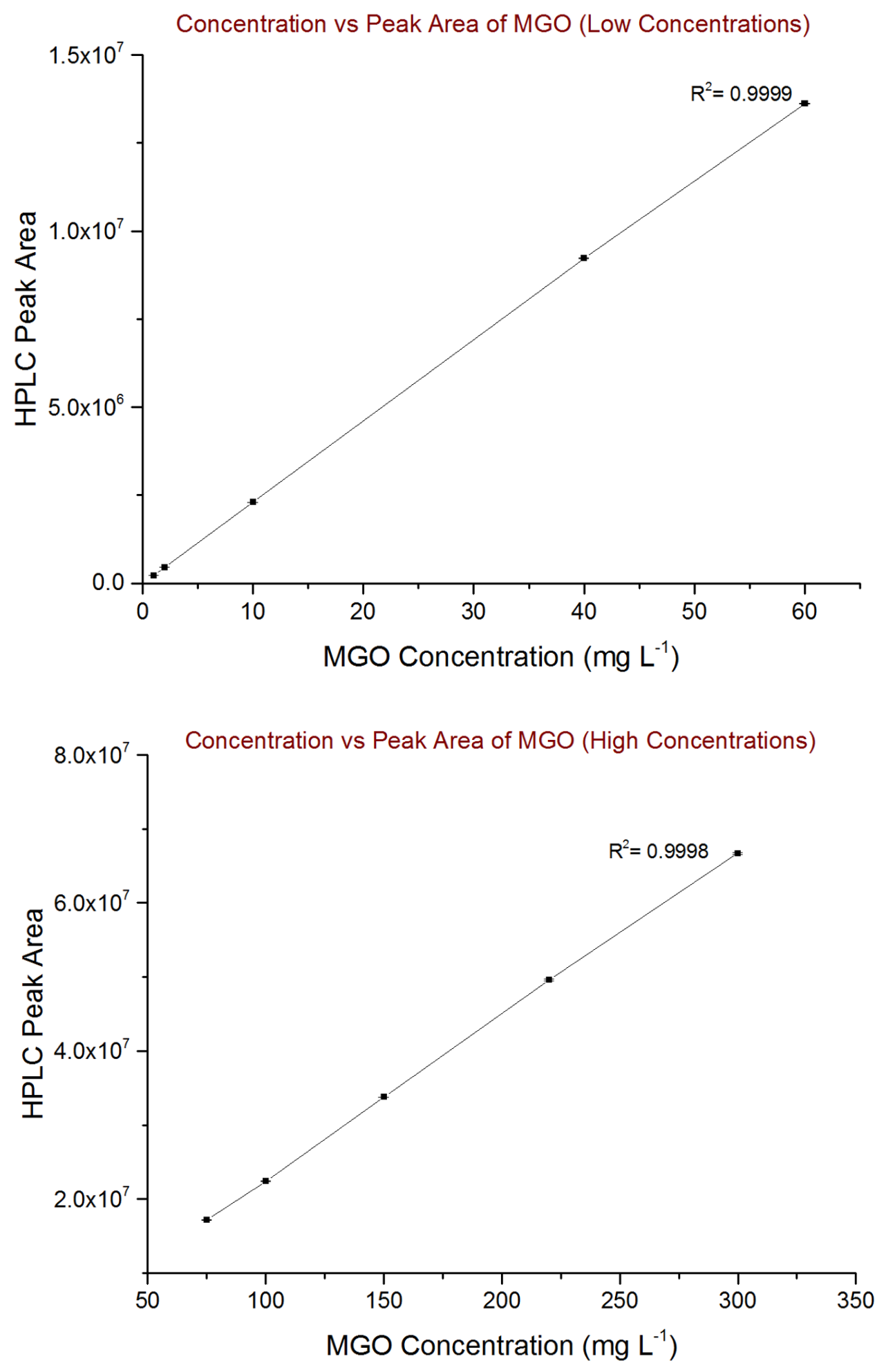

Figure 2.1: Calibration Curves of MGO at high and low concentrations. Error bars (standard deviation) between duplicate are too small to show on the graph but the actual values are shown in Table 2.1. 
Table 2.1: Calibration Curve of MGO

\begin{tabular}{|c|c|c|}
\hline \multicolumn{3}{|c|}{ Low MGO Concentration Curve } \\
\hline Concentration $\mathrm{mg} \mathrm{L}^{-1}$ & Peak Area & SD \\
\hline 1 & 225,361 & \pm 866 \\
\hline 2 & 452,793 & \pm 733 \\
\hline 10 & $2,300,135$ & \pm 46 \\
\hline 40 & $9,230,560$ & $\pm 12,832$ \\
\hline 60 & $13,621,499$ & $\pm 7,168$ \\
\hline High MGO Concentration Curve \\
\hline Concentration $\mathrm{mg} \mathrm{L}^{-1}$ & Peak Area & SD \\
\hline 75 & $17,191,288$ & $\pm 6,719$ \\
\hline 100 & $22,432,778$ & $\pm 17,994$ \\
\hline 150 & $33,769,587$ & $\pm 28,419$ \\
\hline 220 & $49,601,412$ & $\pm 106,277$ \\
\hline 300 & $66,710,548$ & $\pm 145,743$ \\
\hline
\end{tabular}

\subsubsection{Nuclear Magnetic Resonance Spectroscopy (NMR)}

NMR spectroscopy was used to characterise the hydrated forms of $40 \% \mathrm{MGO}$ in water. The measurements were carried out using a Varian AutoX $500 \mathrm{MHz}$ spectrometer. The ${ }^{1} \mathrm{H}$ NMR spectrum of MGO was recorded using $\mathrm{D}_{2} \mathrm{O}$. All chemical shifts are shown in parts per million (ppm).

\subsubsection{Fourier Transform Infrared Spectroscopy (FTIR)}

FTIR spectra of both liquid and solid samples were obtained to characterise the functional groups in the materials using a Bruker Tensor 27 IR spectrometer. An attenuated total reflectance (ATR) crystal from Pike Technologies was used for the analysis. 
Background correction was carried out with air before scanning samples eight times between 600 and 4,000 $\mathrm{cm}^{-1}$. A few drops of the liquid samples were placed onto the ATR crystal using a disk with a Teflon ring. Solid samples including fabric wool and dried polymer on micro-glass were placed onto the ATR crystal and pressed against the surface of the crystal with a high pressure clamp after removing the Teflon ring.

\subsubsection{Thermogravimetric Analysis (TGA)}

TGA measures the weight change of a material with respect to changes in temperature and time. Thus, the decomposition behaviour (thermal stability) was obtained using the thermogravimetric analyser Shimadzu TGA-50 (H). Wool samples were heated from $25^{\circ} \mathrm{C}$ to $200{ }^{\circ} \mathrm{C}$ at a heating rate of $10{ }^{\circ} \mathrm{C} \mathrm{min}-1$ and held at $200{ }^{\circ} \mathrm{C}$ for 5 mins.

For the analysis, nitrogen gas was used with a flow rate of $50 \mathrm{~mL} \min ^{-1}$. A known weight of wool was placed onto a small platinum pan for the analysis. All samples were kept in an oven at $\sim 35^{\circ} \mathrm{C}$ drying overnight before the TGA analysis, unless otherwise stated. An untreated wool sample was used as a standard for the TGA experiment.

\subsubsection{Differential Scanning Calorimetry (DSC)}

Differential scanning calorimetry was used to measure the heat absorbed or released from the treated wool or polymer with MGO, which was carried out using a DSC-60 from Shimadzu. The DSC analysis was carried out for the samples using a reference pan, empty pan or untreated material, in order to determine the heat absorbed or released associated with the MGO. Polymer samples weighed $45 \pm 4 \mathrm{mg}$ and wool samples 11.7 $\pm 4 \mathrm{mg}$ for both treated or untreated materials. (note: the nature of wool limited the experiments to achieve a standarised weight with the polymers samples. In this analysis, the temperature was increased from 30 to $250{ }^{\circ} \mathrm{C}$ at a rate of $5^{\circ} \mathrm{C} \mathrm{min}-1$ and held at 250 ${ }^{\circ} \mathrm{C}$ for 5 mins. DSC was conducted under a nitrogen atmosphere. (note: a few samples 
were held at $200{ }^{\circ} \mathrm{C}$ for 5 mins each).

\subsubsection{Contact Angle (CA) Measurement}

The treatment of wool with MGO and then Dynasylan ${ }^{\circledR}$ altered the wool surface, so it was important to determine the level of the hydrophobicity using contact angle measurements. The contact angle goniometer used in this analysis was designed and fabricated at the School of Chemical and Physical Science's workshop.

Images of a static drop resting on the surface of the substrate were recorded by a SD900 Panasonic video camera. For CA determination, a $10 \mu \mathrm{L}$ volume droplet of distilled water was placed manually by a syringe onto the surface of the sample. The camera then took a series of images at 350 frames per second at optical zoom (x4). Contrast and brightness were adjusted as necessary. Three images per droplet were taken and four droplets were placed randomly to measure the average CA of each surface.

All images were analysed by Image-J software (version $1.51 \mathrm{n}$ ) with plugin Drop Snake created by Stalder et al. ${ }^{100,101}$, which is based on the shapes of the metastable droplets. An average of four measurements of each image were obtained to determine the average CA.

\subsubsection{Antimicrobial Test Protocol}

A zone of inhibition protocol measures the ability of textiles and solids to inhibit microbial growth. The aim was to investigate whether the MGO exhibits antimicrobial activity after being incorporated in textiles and polymers. The tests were mostly done at the School of Biological Sciences at Victoria University of Wellington and a few tests were performed at Wellington Southern Community Laboratories.

Bacterial Culture from long-term storage (either Escherichia coli W3310 or Staphylo- 
coccus aureus) was streaked out onto Mueller-Hinton agar and incubated at $37^{\circ} \mathrm{C}$ for 12 - 16 hours. Then, a single colony was used to inoculate $5 \mathrm{~mL}$ of Mueller-Hinton broth and incubated at $37^{\circ} \mathrm{C}$ for 12 - 16 hours. Each bacterial culture was then diluted to an $\mathrm{OD}_{600}$ of 0.1 and $200 \mu \mathrm{L}$ was spread on a Mueller-Hinton agar plate. Following this, untreated and treated sample with MGO (e.g. Wool, filter paper disks and polymer) were then placed on top of the spread culture, and the plate was incubated at $37{ }^{\circ} \mathrm{C}$ for 12 - 16 hours. The zone of inhibition was then measured by photo capturing the plate and measuring with a ruler to determine the extent of this zone. 


\section{Chapter 3}

\section{Results and Discussion}

\subsection{Characterisation of Methylglyoxal by NMR}

MGO has been detected in direct (NMR) and indirect (using OPD) methods at high levels in active $\mathrm{MH}$. The antimicrobial activity of non-peroxide compounds in the honey were at a similar level to the MGO in MH. The NMR spectra of isolated MGO from MH honey have been reported having a mixture of (1) mono- and (2) dihydrate forms of MGO keto-aldehyde form (3) as shown in Scheme 3.1 ${ }^{65}$.<smiles>CC(=O)C(O)O</smiles>

1<smiles>CC(O)(O)C(O)O</smiles>

2<smiles>CC(=O)C=O</smiles>

3

Scheme 3.1: Possible forms that present in MGO solution

The ${ }^{1} \mathrm{H}$ NMR spectrum of $40 \%$ MGO in $\mathrm{D}_{2} \mathrm{O}$ is shown in Figure 3.1 . The ${ }^{1} \mathrm{H}$ NMR spectrum shows the presence of mono - (5.14 ppm (s, CH), $2.16 \mathrm{ppm}(\mathrm{s}, \mathrm{CH} 3))$ and dihydrate (4.24 ppm (s, CH) 1.23 ppm (s, CH3)) forms of MGO, which were compared with similar studies of $\mathrm{MGO}^{50}$. A number of signals are shown as a result of 
the polymerisation of MGO with water being in impurity. This confirms there are a variety of structures of MGO beside the keto-aldehyde form. Nemet et al. ${ }^{65}$ have reported the influence of solvent, temperature and the amount of water on the equilibrium forms. These findings were important to be taken in account for the characterisation of MGO-Wool and MGO-Polymer compisites. It suggests drying MGO before mixing with NeoCryl ${ }^{\circledR}$ XK-98 (PMMA) and Kamthane K-5000 (polyurethane) polymers could minimise the effect of solvents.

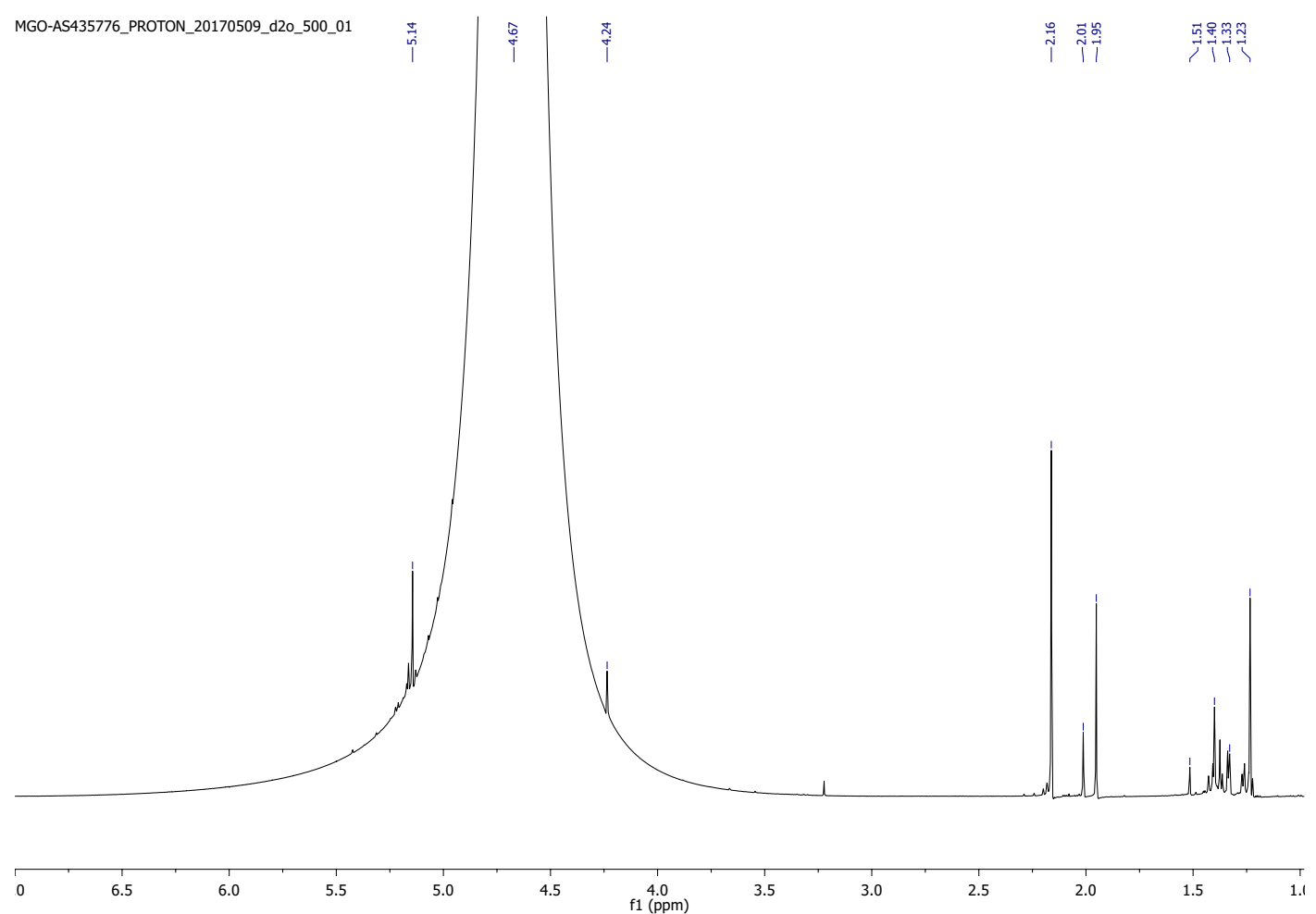

Figure 3.1: The ${ }^{1} \mathrm{H}$ NMR of $40 \%$ Methylglyoxal

\subsection{The Uptake of Manuka Honey and Methylglyoxal by Wool}

This study involved extensively investigating the uptake of MH and MGO by wool to determine the nature of the MH- and MGO-Wool composites. The challenges were finding a quantitative analytical method for determining MGO uptake and compatible 
methods (e.g. temperature, concentrations and treatment methods). Weigel's method ${ }^{63}$ of analysis of 1,2-dicarbonyl compounds including MGO using HPLC seemed an efficient way to quantify the MGO uptake. The uptake was performed by four general steps: (1) preparing a certain MGO concentration; (2) immersing wool samples into the MGO or MH solutions; (3) determining the optimum temperature and time, which could increase the absorption level and extent of absorption; (4) quantifying the MGO absorption into wool by determining the differences in MGO concentration in the solution after the uptake using HPLC. For quantitative analysis, a specific weight of wool was immersed into known volumes and concentrations of MGO in MH or MGO only for varying times, the wool was then removed and the solutions were analysed for any changes in MGO level by HPLC. The difference in the concentrations in the first instance were most likely due to the MGO absorbed by wool. This hypothesis of how $\mathrm{MH}$ and MGO absorption occurred is presented in the following sections.

\subsubsection{Measuring the Uptake of Manuka Honey and Methylglyoxal at Room Temperature}

Wool fibres in loose top form, yarn and finished fabrics were weighed out in amounts of $0.1 \mathrm{~g} \pm 0.02$ for this uptake work. Then they were dipped into hot water at $60{ }^{\circ} \mathrm{C}$ for five minutes or until fully wetted to ensure the hydrophilicity of the surface did not slow down the absorption rate. Following this, each one of four wetted wool samples was placed into sample vials containing $20 \mathrm{~mL}$ solutions of $0.04 \mathrm{mg} \mathrm{L}^{-1} \mathrm{MGO}$ or 5.6 $\mathrm{mg} \mathrm{L}^{-1}$ of MGO in MH, respectively. The samples were placed on a shaking machine at $30 \mathrm{rpm}$ for 16 hours. From each sample, one $\mathrm{mL}$ was collected after 16 hours to perform the derivatisation with OPD for HPLC analysis. The treated wools were dried at the room temperature for a further day.

The uptake for 16 hours at room temperature was not effective and showed negligible absorption. Less than $2 \%$ of MGO in MH was absorbed by wool under these condi- 
tions. Also, the wool treatment with MGO did not show any uptake at room temperature, which was likely due to the low concentration of the initial and final solution that were near the detection limit of HPLC. This suggested that an increase in the initial concentrations and the temperature in order to increase the uptake over a similar time frame should be used.

\subsubsection{Measuring the Uptake of Manuka Honey and Methylglyoxal at $50{ }^{\circ} \mathrm{C}$}

To determine the uptake at $50{ }^{\circ} \mathrm{C}$, similar methods to the uptake at room temperature were followed. The treatment started with preparing $5 \mathrm{mg} \mathrm{L}^{-1} \mathrm{MGO}$ and $4.5 \mathrm{mg} \mathrm{L}^{-1}$ MGO in MH solutions (20 mL each) and two top wool (2 samples X $0.1 \mathrm{~g}$ ) were immersed into the prepared solutions using only two vials of $20 \mathrm{~mL}$. Then the samples were placed into a dark hot shaking bath at $50{ }^{\circ} \mathrm{C}$ and shaking at $30 \mathrm{rpm}$. After that, $1 \mathrm{~mL}$ was collected from each vial at the times of $30,60,120,180,240,300,360$, 720 and 1,380 minutes. These were then analysed for their MGO level using the OPD derivatisation and HPLC as discussed previously determined.

There was a small amount of MGO lost from the MH and MGO solutions during the uptake. However, this reduction of MGO level from the solutions was very slow over the 16 hour time frame. An anomalous result of the MGO level was found by noticeable fluctuations in the MGO concentrations, which was largely in MGO level in MH. This anomalous result was likely due to using a single vial for several times to determine the uptake over a day. This seemed to be an effect of collecting $1 \mathrm{~mL}$ from the same vial during the uptake study, which means the volume was reduced over the time and changed the MGO level. Thus, a single vial of MGO and MH solutions with a wool sample was required for each day or each study of MH and MGO uptake. shows there was a significant amount of MGO lost from the MH and MGO solutions during the uptake. However, this reduction of MGO level from the solutions was very slow over 
the 16 hours time frame. Also, an anomalous result of the MGO level was found by noticeable fluctuations in the MGO concentrations, which was largely in MGO level in MH. Also, an experimental error can be seen when a single vial was used several times to determine the uptake over a day. This seemed to be an effect of collecting $1 \mathrm{~mL}$ from the same vial during the uptake study, which means the volume was reduced over the time and changed the MGO level.

In order to avoid any inaccuracy of measuring the uptake, a single vial (20 mL) was used for each MGO and MH analysis. Two solutions of $50 \mathrm{mg} \mathrm{L}^{-1} \mathrm{MGO}(31.25 \mu \mathrm{L}$ of $40 \% \mathrm{MGO}$ into $250 \mathrm{~mL}$ of total solution) and $3.5 \mathrm{mg} \mathrm{L}^{-1} \mathrm{MGO}$ in $\mathrm{MH}$ were prepared. Then, 7 fabric wool samples for each MH and MGO solution were prepared and each wool sample placed into a separate $20 \mathrm{~mL}$ solution of $\mathrm{MH}$ or MGO using $20 \mathrm{~mL}$ vials. These vials then were capped and put into a dark hot bath at $50{ }^{\circ} \mathrm{C}$ and shaking at 30 rpm. The aim was to investigate the uptake after 1 hour and 1, 2, 3, 4, 5, 6, and 7 days. At each time of the uptake period, a single vial was collected from the hot bath and was allowed to cool down to room temperature. Then $1 \mathrm{~mL}$ was taken from these vials for the HPLC analysis of MGO level in order to determine the MGO in MH and MGO uptake respectively. In addition, $20 \mathrm{~mL}$ of each $\mathrm{MH}$ and $\mathrm{MGO}$ solution were treated similarly without wool in the hot shaking bath for 7 days. This was to measure the behaviour and changing of the MGO concentrations under the exact conditions without any wool. From each stock solution, $1 \mathrm{~mL}$ was used as a standard solution and reference for the starting value of the solution used each particular treatment. The wool samples were allowed to dry at room temperature. 


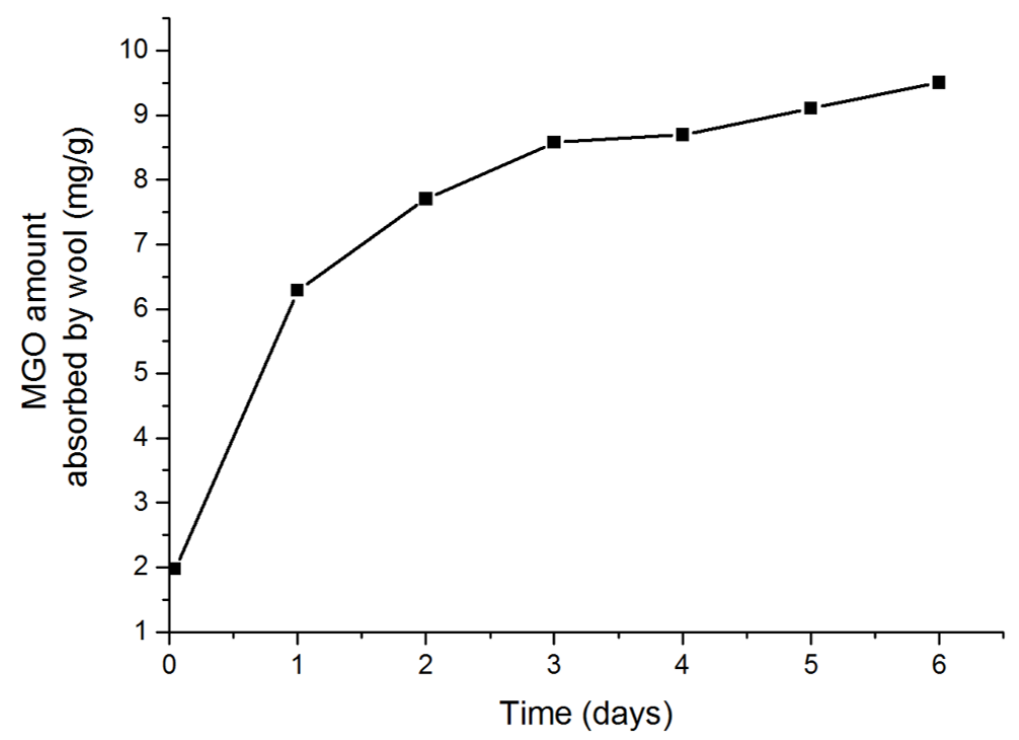

Figure 3.2: The uptake of $50 \mathrm{mg} \mathrm{L}^{-1} \mathrm{MGO}$ by top wool over 7 days at 50 ${ }^{\circ} \mathrm{C}$

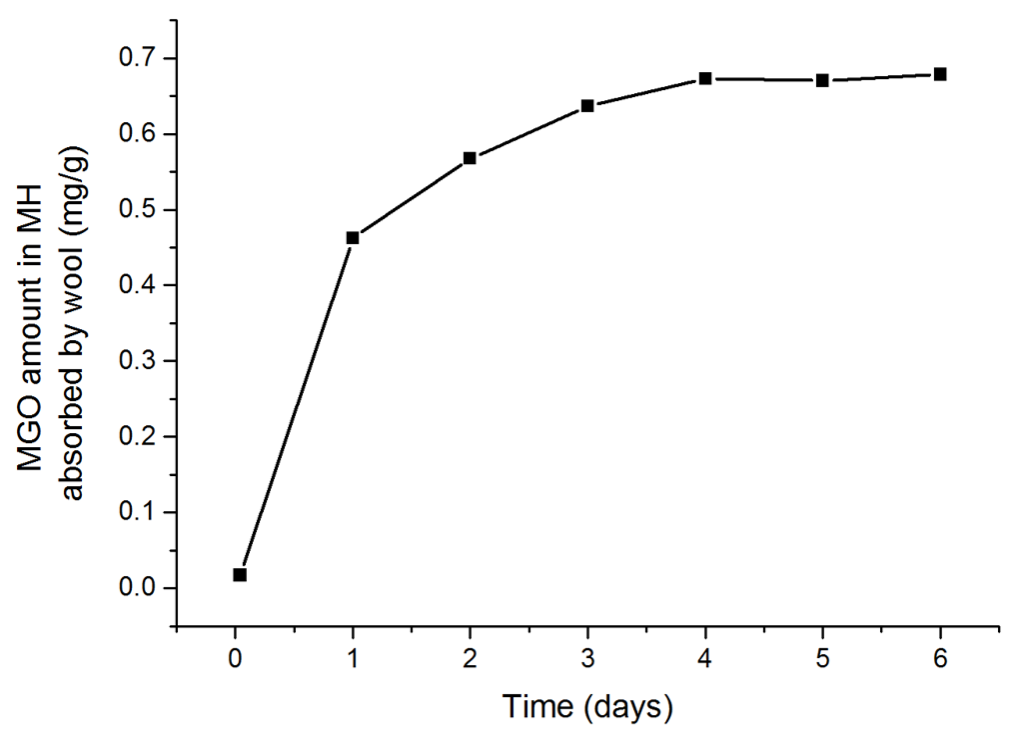

Figure 3.3: The uptake of $3.5 \mathrm{mg} \mathrm{L}^{-1} \mathrm{MGO}$ in $\mathrm{MH}$ by top wool at $50{ }^{\circ} \mathrm{C}$ over 7 days.

For MGO, Figure 3.2 and Table 3.1 show wool absorbed MGO at a faster rate within a day up to $63 \%$ of the initial concentration. The second day of the uptake resulted in $14 \%$ additional uptake but was not as significant as the effect of the first day of MGO uptake. Although the MGO uptake slowly increased between three and six days, the saturation level had still not been reached. The top wool absorbed a higher percentage of the MGO at this temperature. This suggests the uptake is diffusion related. 
Table 3.1: The percentage and weight uptakes of $3.5 \mathrm{mg} \mathrm{L}^{-1} \mathrm{MGO}$ in $\mathrm{MH}$ and $50 \mathrm{mg} \mathrm{L}^{-1} \mathrm{MGO}$ at $50{ }^{\circ} \mathrm{C}$

\begin{tabular}{|c|c|c|c|}
\hline Samples & Days & $\begin{array}{c}\text { Absorption of } 50 \mathrm{mg} \mathrm{L}^{-1} \mathrm{MGO} \\
\% \text { uptake } \\
\text { wt uptake } \mathrm{mg} \mathrm{g}^{-1}\end{array}$ & $\begin{array}{c}\text { Absorption of } 3.5 \mathrm{mg} \mathrm{L}^{-1} \mathrm{MGO} \text { in } \mathrm{MH} \\
\% \text { uptake } \\
\text { wt uptake } \mathrm{mg} \mathrm{g}^{-1}\end{array}$ \\
\hline \multirow[b]{2}{*}{1} & \multirow[b]{2}{*}{ (1 hour) } & $19.73 \%$ & $0.17 \%$ \\
\hline & & 1.97 & 0.017 \\
\hline \multirow[b]{2}{*}{2} & \multirow[b]{2}{*}{1} & $62.87 \%$ & $4.63 \%$ \\
\hline & & 6.29 & 0.463 \\
\hline \multirow[b]{2}{*}{3} & \multirow[b]{2}{*}{2} & $77.03 \%$ & $5.67 \%$ \\
\hline & & 7.7 & 0.57 \\
\hline \multirow[b]{2}{*}{4} & \multirow[b]{2}{*}{3} & $85.8 \%$ & $6.37 \%$ \\
\hline & & 8.6 & 0.64 \\
\hline \multirow[b]{2}{*}{5} & \multirow[b]{2}{*}{4} & $86.98 \%$ & $6.73 \%$ \\
\hline & & 8.7 & 0.67 \\
\hline \multirow[b]{2}{*}{6} & \multirow[b]{2}{*}{5} & $91.08 \%$ & $6.7 \%$ \\
\hline & & 9.1 & 0.67 \\
\hline \multirow{2}{*}{7} & \multirow{2}{*}{6} & $95.05 \%$ & $6.79 \%$ \\
\hline & & 9.5 & 0.68 \\
\hline
\end{tabular}

For MGO in MH, the HPLC analysis showed that the MGO concentration in the initial MH solution was $3.5 \mathrm{mg} \mathrm{L}^{-1}$ (it was intended to be $5 \mathrm{mg} \mathrm{L}^{-1}$ ). This might be due to an error of preparing the $\mathrm{MH}$ sample, which is addressed in a further uptake run. The uptake of MGO in MH was similar to MGO uptake where the absorption level depended on temperature and time of the uptake. In Figure 3.3, it can be seen that the amount of MGO absorbed mostly within 3 days of the uptake then remained steady. After 7 days the MGO absorption reached a peak at $6.79 \%\left(0.68 \mathrm{mg} \mathrm{g}^{-1}\right)$ absorption.

Also, Figure 3.3 and Table 3.1 show that the amount of MGO absorption in MH was generally lower than the absorption of aqueous MGO. The amount of MGO absorbed by wool from synthetic MGO was about 10 times higher than the MGO absorption from $\mathrm{MH}$. This is possible because the MGO is not the only absorbate from $\mathrm{MH}$ and the chemical compounds of MH (i.g. sugars) might be absorbed faster than MGO or blocking MGO diffusion into wool particularly at lower MGO concentration.

Table 3.1 suggests that wool absorbed more MGO as a pure liquid than in MH. However, both MH and MGO did not reach the saturation concentrations, which raised the need 
to increase the concentration of the initial solutions to see if a greater driving force for the uptake was possible. In addition, other types of wool (fabric and yarn) were subsequently studied for their respective absorption profiles.

\subsubsection{The Uptake of Manuka Honey and Methylglyoxal at $50{ }^{\circ} \mathrm{C}$ by Different Types of Wool}

Seven solutions of 5, 50, 250 and 1,000 $\mathrm{mg} \mathrm{L}^{-1} \mathrm{MGO}$ and 5, 50 and $250 \mathrm{mg} \mathrm{L}^{-1} \mathrm{MGO}$ in $\mathrm{MH}$ were prepared to determine the MGO uptake by top wool, fabric and yarn wool. All three types of wool were immersed with various concentrations of MGO in $\mathrm{MH}$ and MGO respectively as shown in Table 3.2. The uptake was determined after each day, over 7 days at $50{ }^{\circ} \mathrm{C}$ for the three types of wool with the method used here as previously discussed in Section 3.2.2. Also, $1 \mathrm{~mL}$ of $1 \mathrm{~g} \mathrm{~L}^{-1}$, including standard and the uptake solutions, was diluted to a total volume of $10 \mathrm{~mL}$ with water to be within the calibration range for the HPLC. The MH solutions required large amounts (up to $0.5 \mathrm{~kg}$ ) to prepare 50 and $250 \mathrm{mg} \mathrm{L}^{-1}$ of MGO in MH. Thus each $0.021 \mathrm{~g}$ of the top, yarn and fabric wool were immersed into $4.20 \mathrm{~mL}$ of 50 and $250 \mathrm{mg} \mathrm{L}^{-1} \mathrm{MGO}$ in $\mathrm{MH}$, which was equivalent to $1 \mathrm{~g}$ wool with $20 \mathrm{~mL}$ of 50 and $250 \mathrm{mg} \mathrm{L}^{-1} \mathrm{MGO}$ in $\mathrm{MH}$. 


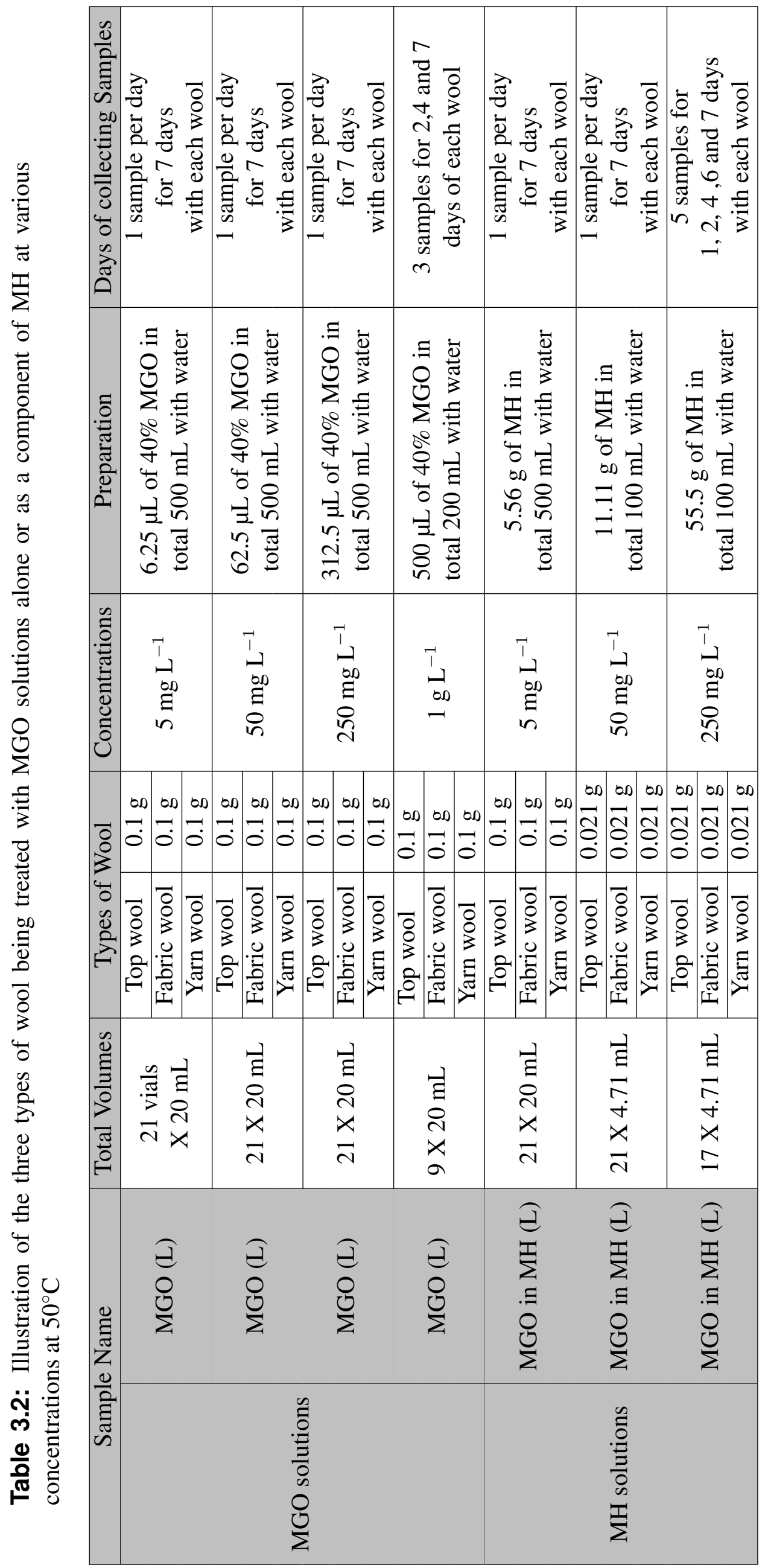




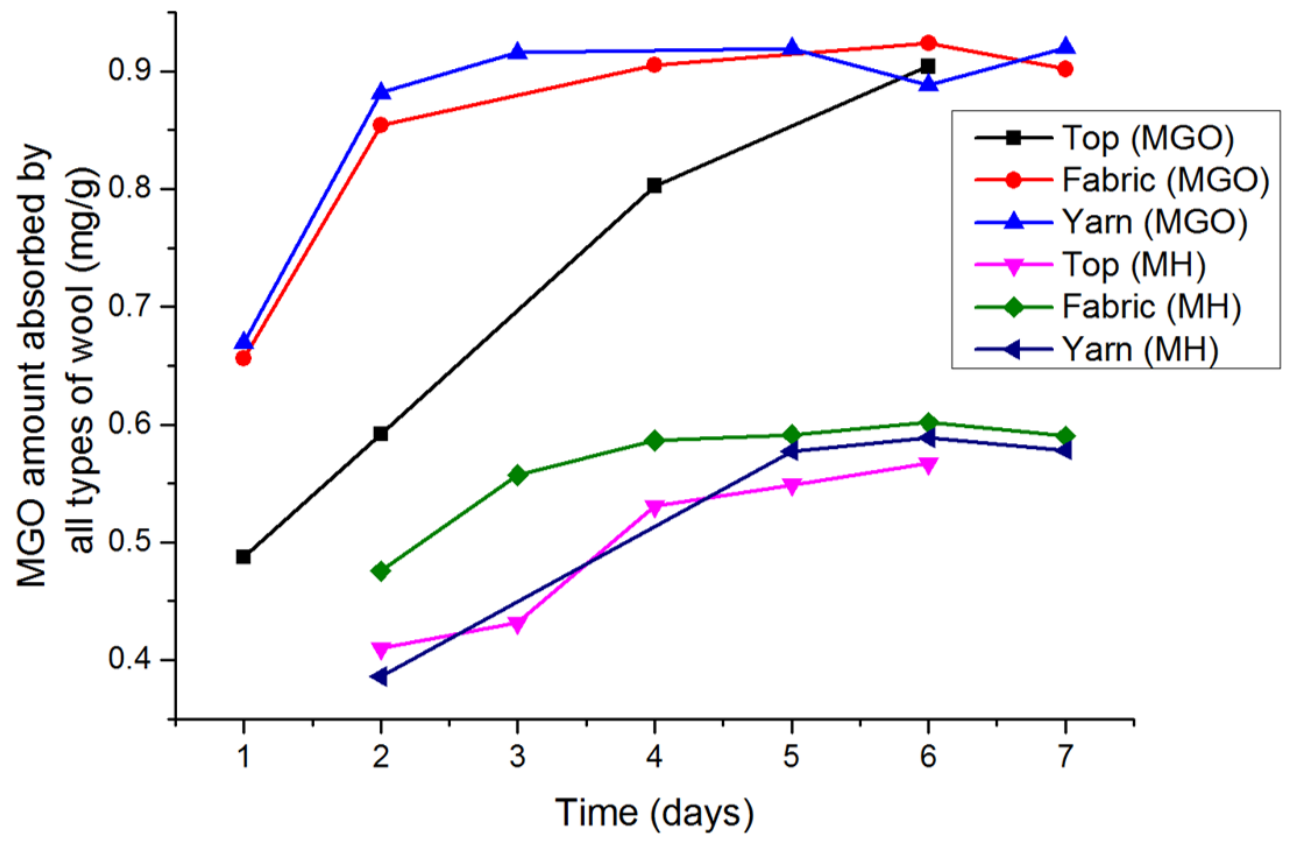

Figure 3.4: The uptake of $5 \mathrm{mg} \mathrm{L}^{-1} \mathrm{MGO}$ and $3.11 \mathrm{mg} \mathrm{L}^{-1} \mathrm{MGO}$ in $\mathrm{MH}$ by all types of wool at $50{ }^{\circ} \mathrm{C}$

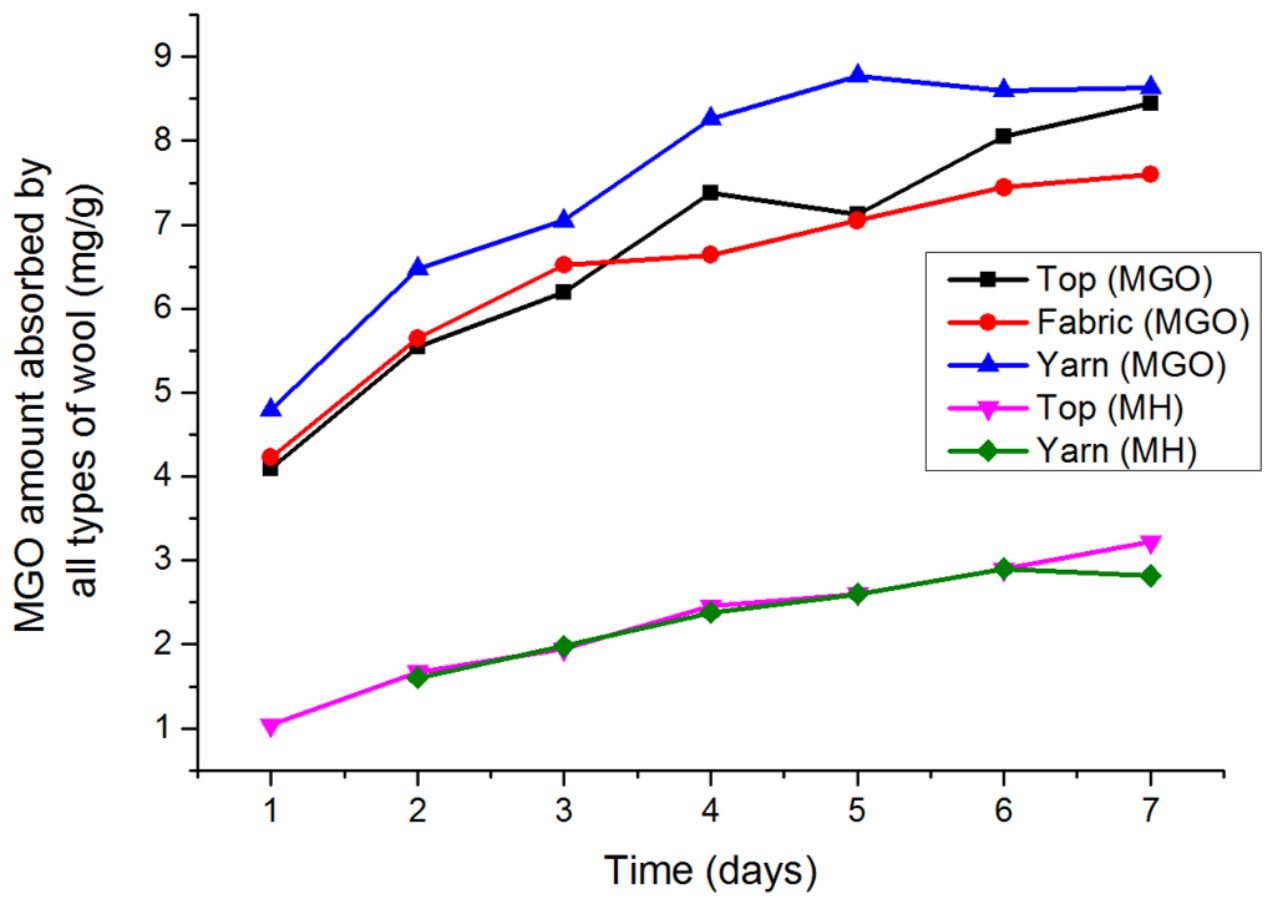

Figure 3.5: The uptake of $50 \mathrm{mg} \mathrm{L}^{-1} \mathrm{MGO}$ and $27.14 \mathrm{mg} \mathrm{L}^{-1} \mathrm{MGO}$ in $\mathrm{MH}$ by all types of wool at $50{ }^{\circ} \mathrm{C}$ 


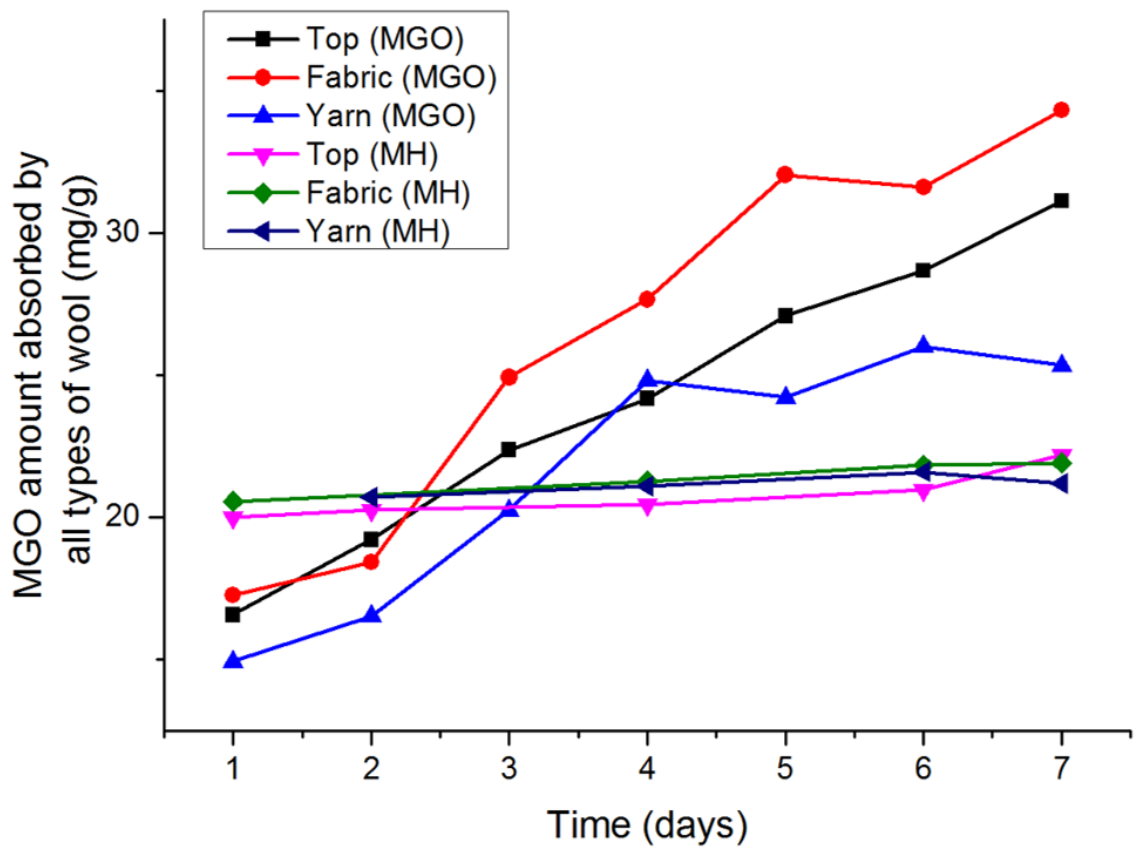

Figure 3.6: The uptake of $250 \mathrm{mg} \mathrm{L}^{-1} \mathrm{MGO}$ and $115 \mathrm{mg} \mathrm{L}^{-1} \mathrm{MGO}$ in $\mathrm{MH}$ by all types of wool at $50{ }^{\circ} \mathrm{C}$

Table 3.3: The uptake percentage of 5, 50 and $250 \mathrm{mg} \mathrm{L}^{-1}$ MGO by top, fabric and yarn wool at $50{ }^{\circ} \mathrm{C}$

\begin{tabular}{|c|c|c|c|c|c|c|c|c|c|}
\hline \multirow{4}{*}{ days } & \multicolumn{3}{|c|}{$5 \mathrm{mg} \mathrm{L}^{-1} \mathrm{MGO}$} & \multicolumn{3}{|c|}{$50 \mathrm{mg} \mathrm{L}^{-1} \mathrm{MGO}$} & \multicolumn{3}{|c|}{$250 \mathrm{mg} \mathrm{L}^{-1} \mathrm{MGO}$} \\
\hline & \multicolumn{3}{|c|}{$\%$ uptake } & \multicolumn{3}{|c|}{$\%$ uptake } & \multicolumn{3}{|c|}{$\%$ uptake } \\
\hline & \multicolumn{3}{|c|}{ wt uptake $m g \mathrm{~g}^{-1}$} & \multicolumn{3}{|c|}{ wt uptake $\mathrm{mg} \mathrm{g}^{-1}$} & \multicolumn{3}{|c|}{ wt uptake $\mathrm{mg} \mathrm{g}^{-1}$} \\
\hline & Top & Fabric & Yarn & Top & Fabric & Yarn & Top & Fabric & Yarn \\
\hline 0 & $0 \%$ & $0 \%$ & $0 \%$ & $0.0 \%$ & $0.0 \%$ & $0.0 \%$ & $0.0 \%$ & $0.0 \%$ & $0.0 \%$ \\
\hline \multirow{2}{*}{1} & $53.0 \%$ & $71.3 \%$ & $72.8 \%$ & $40.6 \%$ & $53.2 \%$ & $47.6 \%$ & $24.9 \%$ & $26.2 \%$ & $27.6 \%$ \\
\hline & 0.49 & 0.66 & 0.67 & 4.1 & 4.2 & 4.8 & 16.57 & 17.26 & 14.92 \\
\hline \multirow{2}{*}{2} & $64.3 \%$ & $92.8 \%$ & $95.9 \%$ & $55.0 \%$ & $71.1 \%$ & $64.3 \%$ & $30.1 \%$ & $28.6 \%$ & $30.6 \%$ \\
\hline & 0.59 & 0.85 & 0.88 & 5.5 & 5.6 & 6.5 & 19.21 & 18.42 & 16.52 \\
\hline \multirow{2}{*}{3} & - & - & $99.6 \%$ & $61.4 \%$ & $82.1 \%$ & $70.1 \%$ & $36.5 \%$ & $41.6 \%$ & $37.5 \%$ \\
\hline & - & - & 0.92 & 6.2 & 6.52 & 7 & 22.37 & 24.93 & 20.25 \\
\hline \multirow{2}{*}{4} & $87.3 \%$ & $98.4 \%$ & - & $73.2 \%$ & $83.6 \%$ & $82.1 \%$ & $40.1 \%$ & $47.0 \%$ & $45.9 \%$ \\
\hline & 0.8 & 0.91 & - & 7.4 & 6.6 & 8.3 & 24.18 & 27.66 & 24.81 \\
\hline \multirow{2}{*}{5} & - & - & $100.0 \%$ & $70.6 \%$ & $88.8 \%$ & $87.3 \%$ & $45.9 \%$ & $55.8 \%$ & - \\
\hline & - & - & 0.92 & 7.2 & 7.1 & 8.8 & 27.08 & 32.04 & - \\
\hline \multirow{2}{*}{6} & $98.3 \%$ & $100.4 \%$ & $96.6 \%$ & $79.9 \%$ & $93.8 \%$ & $85.5 \%$ & $49.1 \%$ & $54.9 \%$ & $48.1 \%$ \\
\hline & 0.9 & 0.91 & 0.92 & 8.1 & 7.4 & 8.6 & 28.68 & 31.60 & 26.00 \\
\hline \multirow{2}{*}{7} & - & $98.0 \%$ & $100.0 \%$ & $83.8 \%$ & $95.7 \%$ & $85.8 \%$ & $54 \%$ & $60.4 \%$ & $46.9 \%$ \\
\hline & - & 0.9 & 0.92 & 8.5 & 7.6 & 8.6 & 31.12 & 34.32 & 25.35 \\
\hline
\end{tabular}


Table 3.4: The uptake of 3.11, 27.14 and $115.2 \mathrm{mg} \mathrm{L}^{-1} \mathrm{MGO}$ in $\mathrm{MH}$ by top, yarn and fabric wool at $50{ }^{\circ} \mathrm{C}$

\begin{tabular}{|c|c|c|c|c|c|c|c|c|}
\hline \multirow{4}{*}{ days } & \multicolumn{3}{|c|}{$3.11 \mathrm{mg} \mathrm{L}^{-1} \mathrm{MH}$} & \multicolumn{2}{|c|}{$27.14 \mathrm{mg} \mathrm{L}^{-1} \mathrm{MH}$} & \multicolumn{3}{|c|}{$115.2 \mathrm{mg} \mathrm{L}^{-1} \mathrm{MH}$} \\
\hline & \multicolumn{3}{|c|}{$\%$ absorption } & \multicolumn{2}{|c|}{$\%$ absorption } & \multicolumn{3}{|c|}{$\%$ absorption } \\
\hline & \multicolumn{3}{|c|}{ wt uptake $\mathrm{mg} \mathrm{g}^{-1}$} & \multicolumn{2}{|c|}{ wt uptake $\mathrm{mg} \mathrm{g}^{-1}$} & \multicolumn{3}{|c|}{ wt uptake $m g \mathrm{~g}^{-1}$} \\
\hline & top & Fabric & Yarn & Top & Yarn & top & Fabric & Yarn \\
\hline 0 & $0 \%$ & $0 \%$ & $0 \%$ & $0.0 \%$ & $0.0 \%$ & $0.0 \%$ & $0.0 \%$ & - \\
\hline \multirow{2}{*}{1} & - & - & - & $19.2 \%$ & - & $86.8 \%$ & $89.2 \%$ & - \\
\hline & & & & 1.10 & - & 20.01 & 20.56 & - \\
\hline \multirow{2}{*}{2} & $66.1 \%$ & $76.7 \%$ & $62.3 \%$ & $30.8 \%$ & $89.9 \%$ & $87.9 \%$ & - & $89.9 \%$ \\
\hline & 0.41 & 0.48 & 0.39 & 1.67 & 1.60 & 20.25 & - & 20.72 \\
\hline \multirow{2}{*}{3} & $69.6 \%$ & $89.9 \%$ & - & $35.9 \%$ & - & - & - & - \\
\hline & 0.43 & 0.56 & & 1.95 & - & - & - & - \\
\hline \multirow{2}{*}{4} & $85.6 \%$ & $94.6 \%$ & - & $45.3 \%$ & $91.5 \%$ & $88.7 \%$ & $92.3 \%$ & $91.5 \%$ \\
\hline & 0.53 & 0.59 & - & 2.45 & 2.38 & 20.45 & 21.26 & 21.09 \\
\hline \multirow{2}{*}{5} & $88.5 \%$ & $95.4 \%$ & $93.2 \%$ & $48.0 \%$ & - & - & - & - \\
\hline & 0.55 & 0.59 & 0.58 & 2.60 & - & - & - & - \\
\hline \multirow{2}{*}{6} & $91.4 \%$ & $97.0 \%$ & $94.9 \%$ & $53.4 \%$ & $93.7 \%$ & $90.9 \%$ & $94.7 \%$ & $93.7 \%$ \\
\hline & 0.57 & 0.60 & 0.59 & 2.90 & 2.90 & 20.95 & 21.83 & 21.60 \\
\hline & - & $95.2 \%$ & $93.3 \%$ & $59.4 \%$ & $92.0 \%$ & $96.3 \%$ & $95.1 \%$ & $92 \%$ \\
\hline & - & 0.59 & 0.58 & 3.22 & 2.81 & 22.18 & 21.91 & 21.20 \\
\hline
\end{tabular}

Figure 3.4, Table 3.3 and Table 3.4 show that within 7 days of the uptake study from low solution concentration, the three types of wool absorbed 93-100\% (between 0.58 and $\left.0.92 \mathrm{mg} \mathrm{g}^{-1}\right)$ of MGO from MH (3.11 $\left.\mathrm{mg} \mathrm{L}^{-1} \mathrm{MGO}\right)$ and MGO $\left(5 \mathrm{mg} \mathrm{L}^{-1}\right)$ solutions respectively. The uptake of MGO by wool reached a maximum of $1 \mathrm{mg} \mathrm{g}^{-1}$ using MGO only and $0.6 \mathrm{mg} \mathrm{g}^{-1}$ using MH solution. Yarn and fabric wool had a slightly higher MGO uptake in comparison to top wool.

Figure 3.5, Figure 3.6, Table 3.3 and Table 3.4 show that the increase of initial MGO and $\mathrm{MH}$ concentrations boosted the weight absorptions of MGO by wool. The uptake percentages reduced from low solution concentration (100\% uptake, $0.9 \mathrm{mg} \mathrm{g}^{-1}$ ) to high solution concentration (46.9\% uptake, $25 \mathrm{mg} \mathrm{g}^{-1}$ ) MGO concentrations after 7 days. However, the amounts of MGO absorbed by the wool were much higher for the 
higher concentration solutions. The low percentage uptakes of 50 and $250 \mathrm{mg} \mathrm{L}^{-1}$ were likely due to reaching or being near to the saturation level. Thus, a further uptake study with longer uptake time and higher MGO concentration were needed to determine the saturation level.

The three types of wool slightly varied in the absorption amount of MGO. Fabric wool displayed moderate to high MGO uptake from MGO and MH solutions. However, top wool gradually absorbed MGO and increased significantly after each day of the uptake. The three figures showed top wool did not have a steady absorption level between 3 to 7 days in comparison to yarn and fabric. It appears that the top wool absorbed MGO slowly and required a large amount of MGO to reach the saturation level. It is likely that this loose top wool has a larger accessible surface area so it did not reach the saturation level.

Table 3.3 and Table 3.4 confirmed that wool absorbed more MGO from the pure MGO starting solution, than from MH solutions as was stated previously in Section 3.2.2. However, $\mathrm{MH}$ at $115 \mathrm{mg} \mathrm{L}^{-1} \mathrm{MGO}$ concentration showed a similar uptake level as from MGO solution within the first three days. This MGO uptake from MH is questionable as the MGO levels in standard and uptake solutions were quite similar. Also, $\mathrm{MH}$ at this MGO concentration and higher temperature did not display a similar MGO uptake. This suggests that a further study is required here to resolve the issue.

\subsubsection{Measuring the Uptake of Manuka Honey and Methylglyoxal at $70{ }^{\circ} \mathrm{C}$}

The uptake of the loose top, yarn and fabric wool forms obtained with various MGO concentrations at $70{ }^{\circ} \mathrm{C}$ are shown in Table 3.5. The method used here was provided in Section (3.2.2). $20 \mathrm{~mL}$ vials were used in this experiment with plastic lids and an additional covering over the lids with aluminium foil was used to minimise any evaporation of the uptake solutions of dissolved MGO and $\mathrm{MH}$ components at this temperature. 


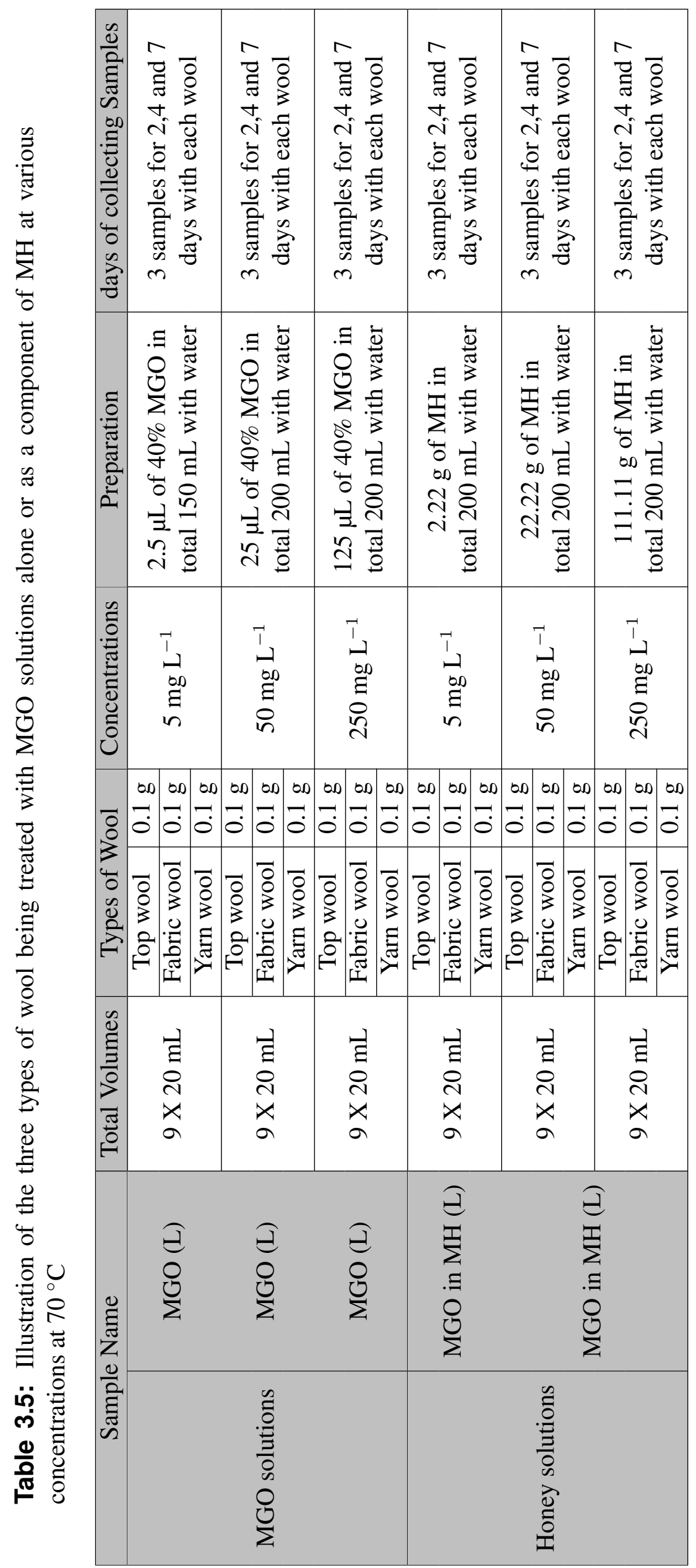


The uptake at $70{ }^{\circ} \mathrm{C}$ resulted in a high absorption of MGO and $\mathrm{MH}$ at all starting concentrations. Wool reached a maximum MGO uptake of $60.4 \%\left(34.3 \mathrm{mg} \mathrm{g}^{-1}\right)$ with 250 mg L ${ }^{-1}$ MGO at $50{ }^{\circ} \mathrm{C}$ (Table 3.4), but at $70{ }^{\circ} \mathrm{C}$ (Table 3.6), wool absorbed up to 97\% (52.7 $\mathrm{mg} \mathrm{g}^{-1}$ ) of this concentration as seen in Table 3.6. The high MGO uptake imparted a light brown colour to the wool at $50{ }^{\circ} \mathrm{C}$, but an increase in temperature displayed higher absorption amount of MGO and a darker brown colour to the wool. A control wool sample with no MGO was placed into water at 50 and $70{ }^{\circ} \mathrm{C}$ for 14 days, but there was no colour change of wool was absorbed. This confirms that the colour change was related to the amount of MGO absorbed by wool at different temperature.

An increase in temperature led to a large reduction in MGO levels in all solutions, which showed a higher uptake of both $\mathrm{MGO}$ and $\mathrm{MH}$ at $70{ }^{\circ} \mathrm{C}$ compared to the uptake at room temperature and $50{ }^{\circ} \mathrm{C}$. All three wool samples absorbed a higher amount of MGO in synthetic MGO solutions than in MH (see Figure 3.7, Table 3.6 and Table 3.7). For all types of wool, a noticeable increase in the uptake amounts from all MGO concentrations in $\mathrm{MH}$ at $70{ }^{\circ} \mathrm{C}$ (Table 3.7) compared to the uptake amounts at $50{ }^{\circ} \mathrm{C}$ (Table 3.4) was observed.

The wool absorbed up to $100 \%$ of $5\left(0.9 \mathrm{mg} \mathrm{g}^{-1}\right.$ uptake) and 50 (10 $\mathrm{mg} \mathrm{g}^{-1}$ uptake) $\mathrm{mgL}^{-1} \mathrm{MGO}$ at $70^{\circ} \mathrm{C}$ within 4 days of the study, where this percentage was not reached at $50{ }^{\circ} \mathrm{C}$ before 6 days. On the other hand, wool absorbed only $60 \%\left(34 \mathrm{mg} \mathrm{g}^{-1}\right)$ of 250 $\mathrm{mg} \mathrm{L}{ }^{-1} \mathrm{MGO}$ at $50{ }^{\circ} \mathrm{C}$, and an increase in temperature to $70{ }^{\circ} \mathrm{C}$ increased the uptake to $97 \%\left(53 \mathrm{mg} \mathrm{g}^{-1}\right.$ ) from the same solution concentration. Thus, the uptake is dependent on temperature and the exposure time, which enhanced the total amount of MGO and MGO in MH absorbed by wool. 
Table 3.6: The uptake of 5, 50 and $250 \mathrm{mg} \mathrm{L}^{-1}$ MGO by fabric, top and yarn wool at $70{ }^{\circ} \mathrm{C}$

\begin{tabular}{|c|c|c|c|c|c|c|c|c|}
\hline \multirow{4}{*}{ days } & \multicolumn{3}{|c|}{$5 \mathrm{mg} \mathrm{L}^{-1} \mathrm{MGO}$} & \multicolumn{2}{|c|}{$50 \mathrm{mg} \mathrm{L}^{-1} \mathrm{MGO}$} & \multicolumn{3}{|c|}{$250 \mathrm{mg} \mathrm{L}^{-1} \mathrm{MGO}$} \\
\hline & \multicolumn{3}{|c|}{$\%$ uptake } & \multicolumn{2}{|c|}{$\%$ uptake } & \multicolumn{3}{|c|}{$\%$ uptake } \\
\hline & \multicolumn{3}{|c|}{ wt uptake $\mathrm{mg} \mathrm{g}^{-1}$} & \multicolumn{2}{|c|}{ wt uptake $m g g^{-1}$} & \multicolumn{3}{|c|}{ wt uptake $m g \mathrm{~g}^{-1}$} \\
\hline & Top & Fabric & Yarn & Top & Fabric & Top & Fabric & Yarn \\
\hline 0 & $0 \%$ & & & $0.0 \%$ & $0.0 \%$ & $0.0 \%$ & $0.0 \%$ & $0.0 \%$ \\
\hline & $100 \%$ & $99.4 \%$ & 97.8 & $98.3 \%$ & $99.7 \%$ & $77.7 \%$ & $74.9 \%$ & $80.3 \%$ \\
\hline & 0.92 & 0.91 & 0.90 & 9.91 & 10.05 & 42.08 & 40.53 & 43.49 \\
\hline \multirow[b]{2}{*}{4} & $99.6 \%$ & $99.2 \%$ & $96.5 \%$ & $99.5 \%$ & $99.9 \%$ & $85.7 \%$ & - & $93.4 \%$ \\
\hline & 0.92 & 0.91 & 0.89 & 10.08 & 10.10 & 46.37 & - & 50.55 \\
\hline \multirow[b]{2}{*}{1} & $100 \%$ & - & $99.1 \%$ & $100 \%$ & - & $96.4 \%$ & - & $97.4 \%$ \\
\hline & 0.93 & - & 0.91 & 10.11 & - & 52.20 & - & 52.72 \\
\hline
\end{tabular}

Table 3.7: The uptake of 3.1, 27.1 and $115.2 \mathrm{mg} \mathrm{L}^{-1} \mathrm{MGO}$ in $\mathrm{MH}$ by fabric, top and yarn wool at $70{ }^{\circ} \mathrm{C}$

\begin{tabular}{|c|c|c|c|c|c|c|c|c|c|}
\hline \multirow{4}{*}{ days } & \multicolumn{3}{|c|}{$3.1 \mathrm{mg} \mathrm{L}^{-1} \mathrm{MGO}$ in $\mathrm{MH}$} & \multicolumn{3}{|c|}{$27.1 \mathrm{mg} \mathrm{L}^{-1} \mathrm{MGO}$ in $\mathrm{MH}$} & \multicolumn{3}{|c|}{$115.2 \mathrm{mg} \mathrm{L}^{-1} \mathrm{MGO}$ in $\mathrm{MH}$} \\
\hline & \multicolumn{3}{|c|}{$\%$ uptake } & \multicolumn{3}{|c|}{$\%$ uptake } & \multicolumn{3}{|c|}{$\%$ uptake } \\
\hline & \multicolumn{3}{|c|}{ wt uptake $\mathrm{mg} \mathrm{g}^{-1}$} & \multicolumn{3}{|c|}{ wt uptake $\mathrm{mg} \mathrm{g}^{-1}$} & \multicolumn{3}{|c|}{ wt uptake $\mathrm{mg} \mathrm{g}^{-1}$} \\
\hline & Top & Fabric & Yarn & Top & Fabric & Yarn & Top & Fabric & Yarn \\
\hline 0 & $0 \%$ & $0 \%$ & $0 \%$ & $0.0 \%$ & $0.0 \%$ & $0.0 \%$ & $0.0 \%$ & $0.0 \%$ & $0.0 \%$ \\
\hline \multirow{2}{*}{2} & $96.7 \%$ & $97.1 \%$ & $96.0 \%$ & $78.6 \%$ & $80.2 \%$ & $81.8 \%$ & $45.3 \%$ & $39.6 \%$ & $46.5 \%$ \\
\hline & 0.60 & 0.60 & 0.60 & 4.26 & 4.35 & 4.44 & 10.44 & 9.13 & 10.72 \\
\hline \multirow[b]{2}{*}{4} & - & $98.8 \%$ & $94.4 \%$ & $86.9 \%$ & $87.0 \%$ & $87.6 \%$ & $57.4 \%$ & $59.9 \%$ & $62.3 \%$ \\
\hline & 0.00 & 0.61 & 0.59 & 4.71 & 4.72 & 4.75 & 13.23 & 13.81 & 14.34 \\
\hline \multirow{2}{*}{7} & $98.4 \%$ & - & $97.2 \%$ & $88.7 \%$ & $91.7 \%$ & $90.4 \%$ & $69.0 \%$ & $59.8 \%$ & $93.1 \%$ \\
\hline & 0.61 & - & 0.60 & 4.81 & 4.97 & 4.90 & 15.89 & 13.77 & 21.46 \\
\hline
\end{tabular}

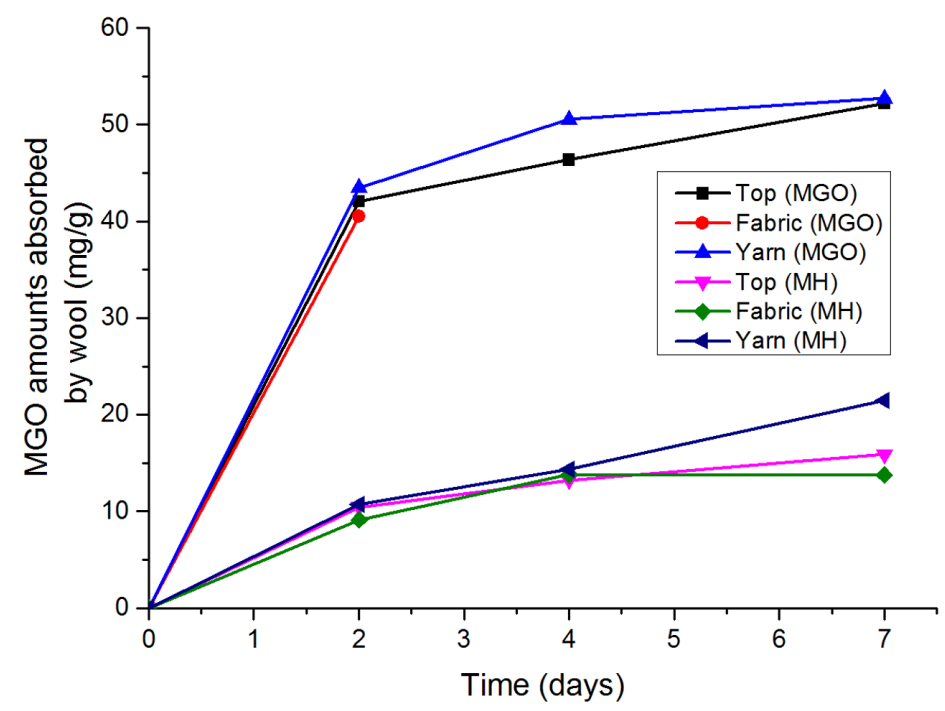

Figure 3.7: The MGO uptake of 250 and $115 \mathrm{mg} \mathrm{L}^{-1} \mathrm{MGO}$ and MGO in $\mathrm{MH}$ respectively by top, yarn and fabric wool at $70^{\circ} \mathrm{C}$ 
In summary, an increase in temperature to $70{ }^{\circ} \mathrm{C}$ for the uptake displayed a large reduction in the MGO level in all MGO and MH solutions, and hence a higher uptake by the wool. However, it was noticed that several vials had a slight reduction in solution volumes (the solution volumes dropped below the $20 \mathrm{~mL}$ marks) at this high temperature, which could affect the resulting absorptions of MGO. This reduction could be due to the absorption of the solution by the wool or some loss through the vial caps by evaporation. A higher temperature than $70{ }^{\circ} \mathrm{C}$ was investigated next to determine if the MGO uptake increased and how the solvent evaporation could be limited.

\subsubsection{Measuring the Uptake of Manuka Honey and Methylglyoxal at $80{ }^{\circ} \mathrm{C}$}

The uptake of MGO alone and in MH was determined for the three wool types using the same concentrations of the uptake solutions that were described in Section 3.2.3. Three samples were used to measure the uptake of MGO after 2, 4 and 7 days and quantifying the MGO levels in the resulting wool samples.

The HPLC results indicated there were consistently low concentrations of MGO in all MGO and MH solutions and hence suggested high uptake levels by the wool. However, the assumption could not be made that all the MGO was absorbed by the wool. It was likely that some of the MGO and $\mathrm{MH}$ was evaporated as well as being absorbed by the wool at this hot bath. Another piece of evidence was that a large number of vials had significant reductions in solution volume during the uptake process.

\subsubsection{The Methylglyoxal Uptake Using Glass Ampoules}

The higher temperature of $80^{\circ} \mathrm{C}$ for this uptake study clearly showed some evaporation of the uptake solution, which influenced the analysis. It is also possible that some evaporation took place at the low temperature of 50 and $70{ }^{\circ} \mathrm{C}$. Thus, a new methodology 
was developed to minimise any evaporation. In order to avoid this issue, wools with MGO and MH solutions were placed into open ended glass ampoules then the top of the ampoules was sealed by melting the thin top neck by the SCPS glassblower. These samples were then placed in a hot shaking water bath at 80,70 and $50{ }^{\circ} \mathrm{C}$ respectively to achieve a more controlled environment for the uptake study, as presented in the following sections.

\subsubsection{The Methylglyoxal Uptake at $80{ }^{\circ} \mathrm{C}$ In Glass Ampoules}

The MGO uptake of only 1 and $0.5 \mathrm{~g} \mathrm{~L}^{-1} \mathrm{MGO}$ solutions were studied at $80{ }^{\circ} \mathrm{C}$ using glass ampoules. There were higher MGO concentrations than previously used to determine the saturation level. Two solutions of 0.5 and $1 \mathrm{~g} \mathrm{~L}^{-1} \mathrm{MGO}$ were prepared by dilution of $40 \% \mathrm{MGO}$ to $100 \mathrm{~mL}$ with water as shown in Table 3.8. Fabric wool samples were only used as the fabric packed better into the ampoules. The extent of uptake of MGO was determined after 3, 6, 10 and 14 days for $1 \mathrm{~g} \mathrm{~L}^{-1} \mathrm{MGO}$ starting solution and after 3, 7 and 14 days for $0.5 \mathrm{~g} \mathrm{~L}^{-1}$ MGO starting solution. Also, two reference solutions ( $10 \mathrm{~mL}$ each with no fabric wool) were placed in the hot shaking water bath for 14 days to be compared with other samples. One sample of fabric wool was treated with water only and placed into the hot water bath under the same conditions for 14 days to serve as a reference for later studies by DSC and TGA, as comparison to the MGO-Wool samples (see Table 3.8). At each particular day of measuring the MGO level, as stated before, an ampoule was removed from the hot water bath and left to cool down to room temperature. Then the neck of the glass ampoule was carefully broken to enable a $1 \mathrm{~mL}$ sample of the liquid to be taken and for then the wool to be removed and left to dry at room temperature. One $\mathrm{mL}$ of each sample including the standards was diluted to $10 \mathrm{~mL}$ with water so as to be within the range of HPLC calibration curve that was determined earlier. The MGO levels from the uptake and standard solutions were determined by HPLC. The sealed ampoules showed a more controlled environment, compared to previous vials. However, there should have been only a change in the so- 
lution level due to the solution being absorbed by the wool, which should be roughly the same for all the fabric samples.

Table 3.8: Preparation of the uptake of $\mathrm{MGO}$ at $80{ }^{\circ} \mathrm{C}$ with sealed glasses

\begin{tabular}{|c|c|c|c|c|c|c|}
\hline Samples name & Total Volumes & Type of Wool & & Concentrations & Preparation & days of collecting Samples \\
\hline MGO (L) & $3 \times 20 \mathrm{~mL}$ & Fabric wool & $0.1 \mathrm{~g}$ & $500 \mathrm{mg} \mathrm{L}^{-1}$ & $\begin{array}{c}125 \mu \mathrm{L} \text { of } 40 \% \\
\mathrm{MGO} \text { in total } \\
100 \mathrm{~mL} \text { with water }\end{array}$ & $\begin{array}{c}3 \text { samples for } 3,7 \\
\text { and } 14 \text { days }\end{array}$ \\
\hline water only & $20 \mathrm{~mL}$ & Fabric wool & $0.1 \mathrm{~g}$ & none & none & 1 sample for 14 days \\
\hline MGO (L) & $4 \times 20 \mathrm{~mL}$ & Fabric wool & $0.1 \mathrm{~g}$ & \multirow[b]{2}{*}{$1 \mathrm{~g} \mathrm{~L}^{-1}$} & \multirow{2}{*}{$\begin{array}{l}250 \mu \mathrm{L} \text { of } 40 \% \text { MGO in } \\
\text { total } 100 \mathrm{~mL} \text { with water }\end{array}$} & $\begin{array}{c}4 \text { samples for } 3,6,10 \\
\text { and } 14 \mathrm{~d}\end{array}$ \\
\hline $\begin{array}{c}\text { MGO (L) } \\
\text { standard only }\end{array}$ & $10 \mathrm{~mL}$ & \multicolumn{2}{|l|}{ none } & & & 1 sample for 14 days \\
\hline
\end{tabular}

As shown in Figure 3.8 and Table 3.9, the fabric wool absorbed a large amount of MGO at $80{ }^{\circ} \mathrm{C}$ over 14 days, resulting in $180 \mathrm{mg} \mathrm{g}^{-1}$ (75.8\% uptake) uptake. The overall uptake percentages of high MGO concentrations were less than the uptake of lower MGO concentrations such as 5, 50 and $250 \mathrm{mg} \mathrm{L}^{-1}$. However, the amount of MGO absorbed by wool, from concentrated MGO, increased by 87 to 180 times of the MGO absorbed from lower MGO concentrations (see the uptake at $50{ }^{\circ} \mathrm{C}$ in Table 3.3). An increase in the initial concentrations acted as a greater driving force for the MGO uptake. This clearly showed that the low MGO uptake percentage of $250 \mathrm{mg} \mathrm{L}^{-1} \mathrm{MGO}$ in Section 3.2.2.1 was not at a saturation level, but the amount of MGO in the solution after 4 days was not enough to drive the diffusion of the MGO into the wool. This means the MGO absorption depended on the initial concentration of MGO in solution.

Figure 3.8 shows that the MGO uptakes over the 7 and 14 days of the uptake period were similar where most of the absorption was taking a place between two and four days. However, exceeding 7 days of the uptake up to 14 days led to an additional 13\% uptake (from 7 to 14 days) of MGO absorbed by the wool. This suggested a long treatment of wool with MGO was required to achieve sufficient amount of MGO per gram of wool.

The uptake in general strongly depended on the initial concentrations and temperature. Confirming this, the amount of MGO absorbed per wool unit was $0.118 \mathrm{~g} \mathrm{~g}^{-1}$ after three days of treating with $1.16 \mathrm{~g} \mathrm{~L}^{-1} \mathrm{MGO}$ starting solution, while this amount was 
absorbed after seven days with $0.695 \mathrm{~g} \mathrm{~L}^{-1} \mathrm{MGO}$ (Figure ??).

The diffusion or uptake of MGO presumably required a long period of uptake process up to 14 days. The amounts of MGO, which were absorbed increased slowly between 7 and 14 days. The peak of the absorption was likely achieved after 14 days, where small amounts of MGO were detected in the solutions by the HPLC in in the solution. These small amounts of MGO could not apply any driving force on the MGO molecules to diffuse into the wool layers.

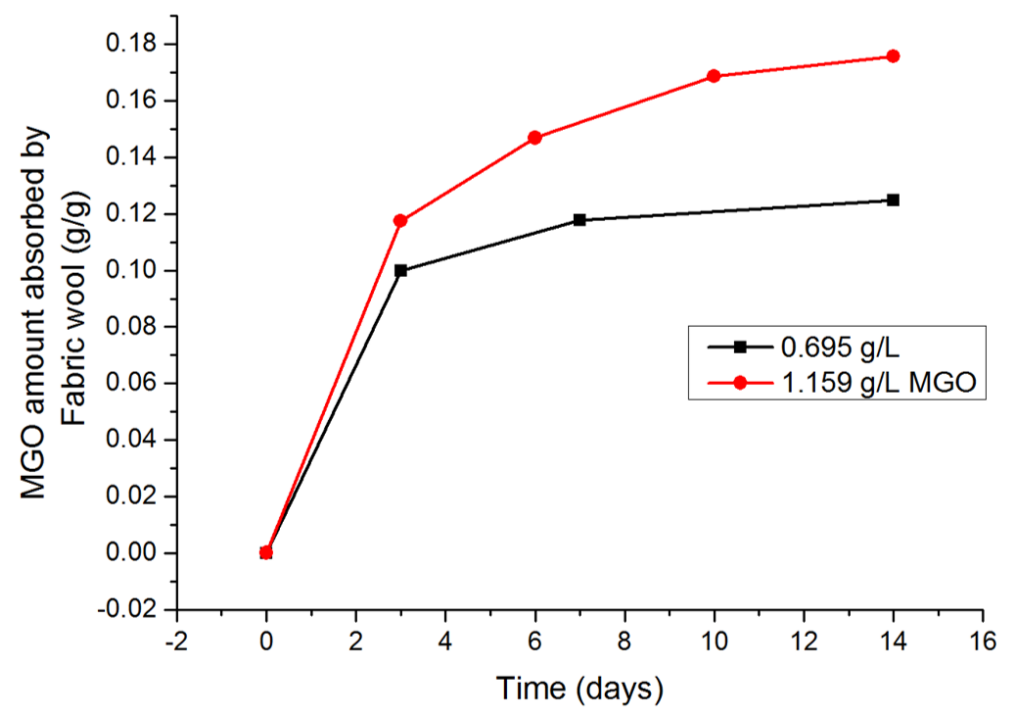

Figure 3.8: The uptake rates of 1.2 and $0.7 \mathrm{~g} \mathrm{~L}^{-1} \mathrm{MGO}$ by fabric wool at $80{ }^{\circ} \mathrm{C}$ using sealed glass ampoules

Table 3.9: The MGO uptake at $80^{\circ} \mathrm{C}$ by fabric wool.

\begin{tabular}{|c|c|c|c|c|}
\hline \multirow{3}{*}{ days } & \multicolumn{2}{|c|}{$0.695 \mathrm{~g} \mathrm{~L}^{-1} \mathrm{MGO}$} & \multicolumn{2}{|c|}{$1.159 \mathrm{~g} \mathrm{~L}^{-1} \mathrm{MGO}$} \\
\hline & \multicolumn{2}{|r|}{ Fabric } & \multicolumn{2}{|c|}{ Fabric } \\
\hline & $\%$ uptake & wt uptake $\mathrm{g} \mathrm{g}^{-1}$ & $\%$ uptake & wt uptake $\mathrm{g} \mathrm{g}^{-1}$ \\
\hline 0 & $0 \%$ & - & $0.0 \%$ & - \\
\hline 3 & $71.9 \%$ & 0.10 & $50.6 \%$ & 0.12 \\
\hline 6 & - & - & $63.4 \%$ & 0.15 \\
\hline 7 & $84.7 \%$ & 0.12 & - & - \\
\hline 10 & - & - & $72.7 \%$ & 0.17 \\
\hline 14 & $89.8 \%$ & 0.12 & $75.8 \%$ & 0.18 \\
\hline
\end{tabular}


The MGO solution only, without wool, $\left(1.2 \mathrm{~g} \mathrm{~L}^{-1}\right)$ showed a reduction of the MGO concentration by $24 \%$ (reduced to $0.9 \mathrm{~g} \mathrm{~L}^{-1}$ ) after 14 days. The high temperature of the water bath may undergo spontaneous degradation of the reactive MGO by oxidation of the aldehyde to carboxylic acids at this higher temperature.

In summary, the MGO uptake using sealed ampoules reduced the influence of any evaporation of MGO solution. The high MGO concentration resulted in absorption of a large amount of MGO (180 $\left.\mathrm{mg} \mathrm{g}^{-1}\right)$. This suggested both initial concentration and temperature affect the MGO uptake by the wool.

\subsubsection{The Methylglyoxal Uptake at $70{ }^{\circ} \mathrm{C}$ In Glass Ampoules}

In a further study of the effect of temperature and the possible loss or breakdown of MGO on the uptake of MGO and MH were similarly carried out at $70{ }^{\circ} \mathrm{C}$. Three ranges of MGO concentrations were studied: $0.5,1$ and $2 \mathrm{~g} \mathrm{~L}^{-1}$ starting solutions. The high MGO concentration $\left(2 \mathrm{~g} \mathrm{~L}^{-1}\right)$ was used to determined the maximum amount of MGO that could be absorbed by wool. These concentrations aimed to determine the MGO uptake after 4, 8 and 15 days using sealed glass ampoules. Standard solutions were placed to be collected after range of days to determine any degradation of the MGO (see Table 3.10).

Table 3.10: Preparation of MGO uptake at $70{ }^{\circ} \mathrm{C}$ with sealed glass ampoules

\begin{tabular}{|c|c|c|c|c|c|c|}
\hline Samples name & Total Volumes & \multicolumn{2}{|c|}{ Type of Wool } & Concentrations & Preparation & days of collecting Samples \\
\hline MGO (L) & $4 \times 20 \mathrm{~mL}$ & Fabric wool & $3 \times 0.1 \mathrm{~g}$ & \multirow[b]{2}{*}{$0.5 \mathrm{~g} \mathrm{~L}^{-1}$} & \multirow{2}{*}{$\begin{array}{l}125 \mu \mathrm{L} \text { of } 40 \% \text { MGO in } \\
\text { total } 100 \mathrm{~mL} \text { with water }\end{array}$} & $\begin{array}{l}3 \text { samples for } 4,8 \\
\text { and } 15 \text { days }\end{array}$ \\
\hline $\begin{array}{l}\text { MGO (L) } \\
\text { standard only }\end{array}$ & $20 \mathrm{~mL}$ & \multicolumn{2}{|l|}{ none } & & & 1 sample for 15 days \\
\hline MGO (L) & $4 \times 20 \mathrm{~mL}$ & Fabric wool & $3 \times 0.1 \mathrm{~g}$ & \multirow[b]{2}{*}{$1 \mathrm{~g} \mathrm{~L}^{-1}$} & \multirow{2}{*}{$\begin{array}{l}250 \mu \mathrm{L} \text { of } 40 \% \mathrm{MGO} \text { in } \\
\text { total } 100 \mathrm{~mL} \text { with water }\end{array}$} & $\begin{array}{l}3 \text { samples for } 4,8 \text {, } \\
\text { and } 15 \text { days }\end{array}$ \\
\hline $\begin{array}{l}\text { MGO (L) } \\
\text { standard only }\end{array}$ & $20 \mathrm{~mL}$ & \multicolumn{2}{|l|}{ none } & & & 1 sample for 8 days \\
\hline MGO (L) & $4 \times 20 \mathrm{~mL}$ & Fabric wool & $3 \times 0.1 \mathrm{~g}$ & \multirow[b]{2}{*}{$2 \mathrm{~g} \mathrm{~L}^{-1}$} & \multirow{2}{*}{$\begin{array}{l}500 \mu \mathrm{L} \text { of } 40 \% \text { MGO } \\
\text { in total } 100 \mathrm{~mL} \text { with water }\end{array}$} & $\begin{array}{l}3 \text { samples for } 4,8, \\
\text { and } 15 \text { days }\end{array}$ \\
\hline $\begin{array}{l}\text { MGO (L) } \\
\text { standard only }\end{array}$ & $20 \mathrm{~mL}$ & \multicolumn{2}{|l|}{ none } & & & 2 sample for 4 days \\
\hline
\end{tabular}




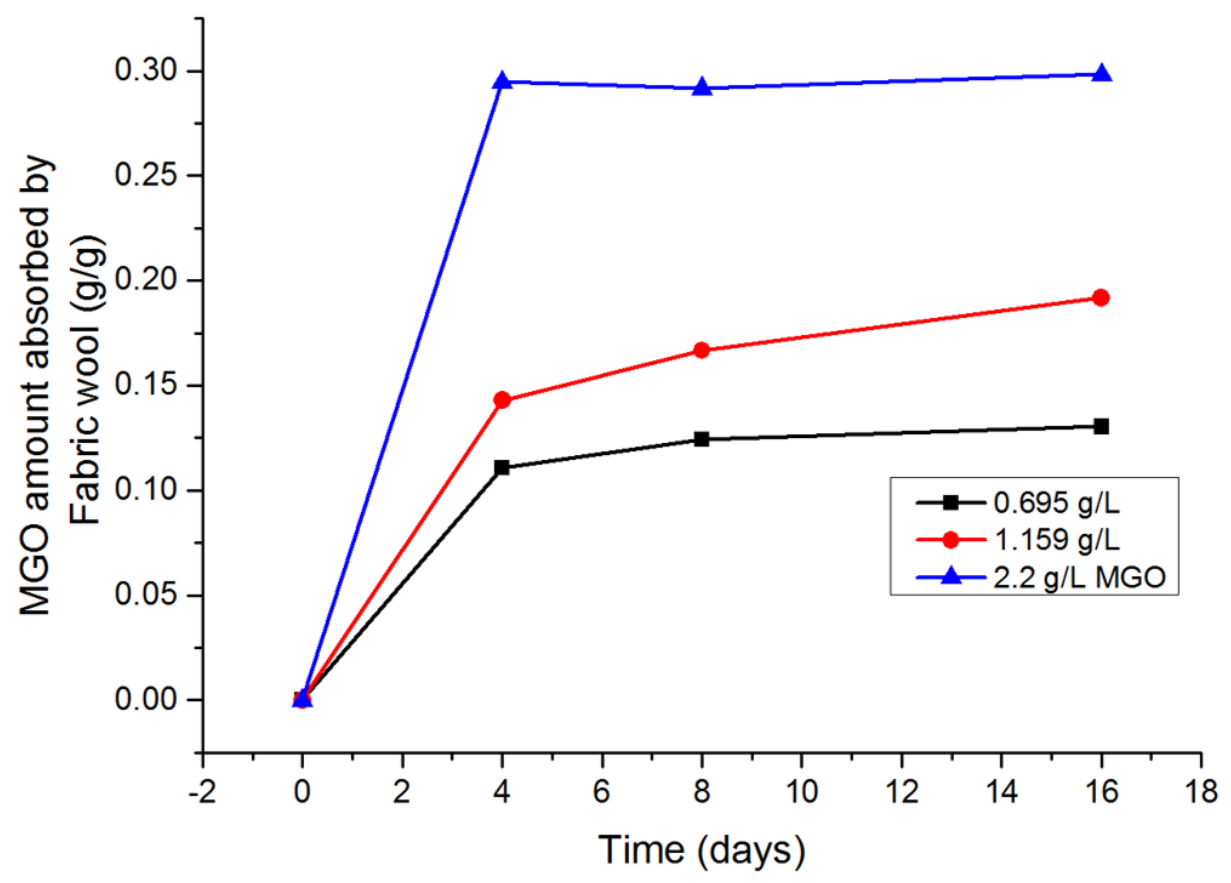

Figure 3.9: The uptake rates of 1.2 and $0.7 \mathrm{~g} \mathrm{~L}^{-1} \mathrm{MGO}$ by fabric wool at $70{ }^{\circ} \mathrm{C}$ using sealed glass ampoules

Table 3.11: The MGO uptake percentage at $70{ }^{\circ} \mathrm{C}$ using sealed ampoules

\begin{tabular}{c|ccc}
\hline \multirow{2}{*}{ days } & $0.7 \mathrm{mg} \mathrm{L}^{-1} \mathrm{MGO}$ & $1.2 \mathrm{mg} \mathrm{L}^{-1} \mathrm{MGO}$ & $2.2 \mathrm{mg} \mathrm{L}^{-1} \mathrm{MGO}$ \\
\cline { 2 - 4 } & \% uptake & \% uptake & $\%$ uptake \\
\cline { 2 - 4 } & wt uptake mg g-1 & wt uptake mg g-1 & wt uptake mg g-1 \\
\cline { 2 - 4 } & Fabric & Fabric & Fabric \\
\hline 0 & $0 \%$ & $0.0 \%$ & $0.0 \%$ \\
3 & $15.9 \%$ & $11.9 \%$ & $13.4 \%$ \\
5 & 111 & 143 & 295 \\
& $17.7 \%$ & $13.9 \%$ & $13.3 \%$ \\
16 & 124 & 167 & 292 \\
& $18.7 \%$ & $16 \%$ & $13.6 \%$ \\
& 131 & 192 & 299.00
\end{tabular}

These samples did not show any loss in the uptake amounts of the solutions. The concentration of MGO in all solutions, after treatment with wool, was slightly lower compared to the uptake at $80{ }^{\circ} \mathrm{C}$ as shown in Figure 3.9. This may suggest that exceeding the boiling point of $\mathrm{MGO}\left(72^{\circ} \mathrm{C}\right)$ might limit the extent of uptake. Also, there was higher concentration $\left(2.2 \mathrm{~g} \mathrm{~L}^{-1}\right)$ than previously used at $80{ }^{\circ} \mathrm{C}$ to investigate whether a higher amount of MGO absorption would be possible. This increase of the initial 
concentration resulted in $299 \mathrm{mg} \mathrm{g}^{-1}$ absorption with a slightly darker colour of the wool. However, Figure 3.9 shows that an increase of the initial concentration does not lead the wool to absorb double the amount of MGO at a lower temperature. In a fully proportional manner, this means treating the wool with $1 \mathrm{~g} \mathrm{~L}^{-1}$ MGO (absorption 0.19 $\mathrm{g} \mathrm{g}^{-1}$ MGO-Wool) did not absorb twice the amount of $0.6 \mathrm{~g} \mathrm{~L}^{-1}$ MGO (absorption $0.13 \mathrm{~g} \mathrm{~g}^{-1} \mathrm{MGO}-$ Wool). This result was similar to the uptake study of $2.2 \mathrm{~g} \mathrm{~L}^{-1} \mathrm{MGO}$ (absorption $0.29 \mathrm{~g} \mathrm{~g}^{-1}$ MGO-Wool).

The use of sealed glass ampoules provided a controlled environment and enabled numerous samples to be run at the same time without evaporation of the MGO containing solution. Therefore, the uptake was replicated to compare the different amounts of the MGO uptake prior and post the use of sealed ampoules ( the uptake in sealed ampoules compared to the MGO uptake using normal glasses) (see Table 3.12).

Table 3.12: Replicates for the MGO uptake at $70{ }^{\circ} \mathrm{C}$

\begin{tabular}{|c|c|c|c|c|c|c|c|}
\hline Sample Name & \multicolumn{2}{|c|}{ Total Volumes } & \multicolumn{2}{|c|}{ Type of Wool } & Concentrations & Preparation & days of collecting Samples \\
\hline \multirow{5}{*}{ MGO solutions } & $\operatorname{MGO}(\mathrm{L})$ & $2 \times 20 \mathrm{~mL}$ & Fabric wool & $2 \times 0.1 \mathrm{~g}$ & $5 \mathrm{mg} \mathrm{L}^{-1}$ & $\begin{array}{l}6.25 \mu \mathrm{L} \text { of prepared } 40 \mathrm{~g} \mathrm{~L}^{-1} \mathrm{MGO} \text { in } \\
\text { total } 50 \mathrm{~mL} \text { with water }\end{array}$ & $\begin{array}{l}2 \text { samples after } \\
3 \text { and } 7 \text { days }\end{array}$ \\
\hline & MGO (L) & $2 \times 20 \mathrm{~mL}$ & Fabric wool & $2 \times 0.1 \mathrm{~g}$ & $50 \mathrm{mg} \mathrm{L}^{-1}$ & $\begin{array}{c}62.5 \mu \mathrm{L} \text { of prepared } 40 \mathrm{~g} \mathrm{~L}^{-1} \mathrm{MGO} \text { in } \\
\text { total } 50 \mathrm{~mL} \text { with water }\end{array}$ & $\begin{array}{l}2 \text { samples after } \\
3 \text { and } 7 \text { days }\end{array}$ \\
\hline & MGO (L) & $2 \times 20 \mathrm{~mL}$ & Fabric wool & $2 \times 0.1 \mathrm{~g}$ & $250 \mathrm{mg} \mathrm{L}^{-1}$ & $\begin{array}{c}312.5 \mu \mathrm{L} \text { of prepared } 40 \mathrm{~g} \mathrm{~L}^{-1} \mathrm{MGO} \text { in } \\
\text { total } 50 \mathrm{~mL} \text { with water }\end{array}$ & $\begin{array}{l}2 \text { samples after } \\
3 \text { and } 7 \text { days }\end{array}$ \\
\hline & MGO (L) & $2 \times 20 \mathrm{~mL}$ & Fabric wool & $2 \times 0.1 \mathrm{~g}$ & $1 \mathrm{~g} \mathrm{~L}^{-1}$ & $\begin{array}{c}1.25 \mathrm{~mL} \text { of prepared } 40 \mathrm{~g} \mathrm{~L}^{-1} \mathrm{MGO} \text { in } \\
\text { total } 50 \mathrm{~mL} \text { with water }\end{array}$ & $\begin{array}{l}2 \text { samples after } \\
3 \text { and } 7 \text { days }\end{array}$ \\
\hline & MGO (L) & $2 \times 20 \mathrm{~mL}$ & Fabric wool & $2 \times 0.1 \mathrm{~g}$ & $2 \mathrm{~g} \mathrm{~L}^{-1}$ & $\begin{array}{c}2.5 \mathrm{~mL} \text { of prepared } 40 \mathrm{~g} \mathrm{~L}^{-1} \mathrm{MGO} \text { in } \\
\text { total } 50 \mathrm{~mL} \text { with water }\end{array}$ & $\begin{array}{l}2 \text { samples after } \\
3 \text { and } 7 \text { days }\end{array}$ \\
\hline
\end{tabular}

The used of the glass ampoules to replicate the MGO uptake at $70{ }^{\circ} \mathrm{C}$ of similar consecrations using non-sealed vials (in Section 3.2.3), confirmed that the amount of MGO absorption for various concentrations. The amounts of MGO absorbed by wool were slightly higher compared to similar treatment conditions using non-sealed glasses as determined using HPLC. In corresponding to the high MGO uptake, slightly darker colour of the wool was noticed using this sealed ampoules, which is probably associated with higher absorption rates of MGO. Figure 3.10 showed 94 to $99 \%$ of the MGO amounts in the solution were absorbed from 5, 52 and $284 \mathrm{mg} \mathrm{L}^{-1} \mathrm{MGO}$ solutions. Increasing the initial MGO solutions led the wool to absorb more MGO. The uptake rates of 1.15 and $2.17 \mathrm{~g} \mathrm{~L}^{-1} \mathrm{MGO}$ varied between 65 and 50\% respectively. As shown in Figure 3.10 the uptake was dependent on the initial concentration of MGO, and seemed to reach the 
saturation point. This saturation point occurred when wool was treated with 1.15 and $2.17 \mathrm{~g} \mathrm{~L}^{-1}$ MGO where the amounts of MGO absorbed by wool were 150 and $215 \mathrm{mg}$ $\mathrm{g}^{-1}$ respectively (mg MGO per $\mathrm{g}$ wool).

Overall, the uptake of MGO at $70{ }^{\circ} \mathrm{C}$ resulted in high absorptions of MGO and exceeding this temperature might limit the extent of the uptake and lead to higher oxidation level of MGO. This development of using the sealed ampoules minimised the evaporation of solution and resulted in higher uptake and in a darker colour observed in the wool. The study of various MGO concentrations showed that the amount of MGO absorbed by wool increased from $1 \mathrm{mg} \mathrm{g}^{-1}$ to $299 \mathrm{mg} \mathrm{g}^{-1}$ by increasing the initial starting solutions as shown in Table 3.11. This confirmed the finding of the MGO uptake at 80 ${ }^{\circ} \mathrm{C}$, which showed that the temperature and initial concentration are important factors dictating the MGO uptake.

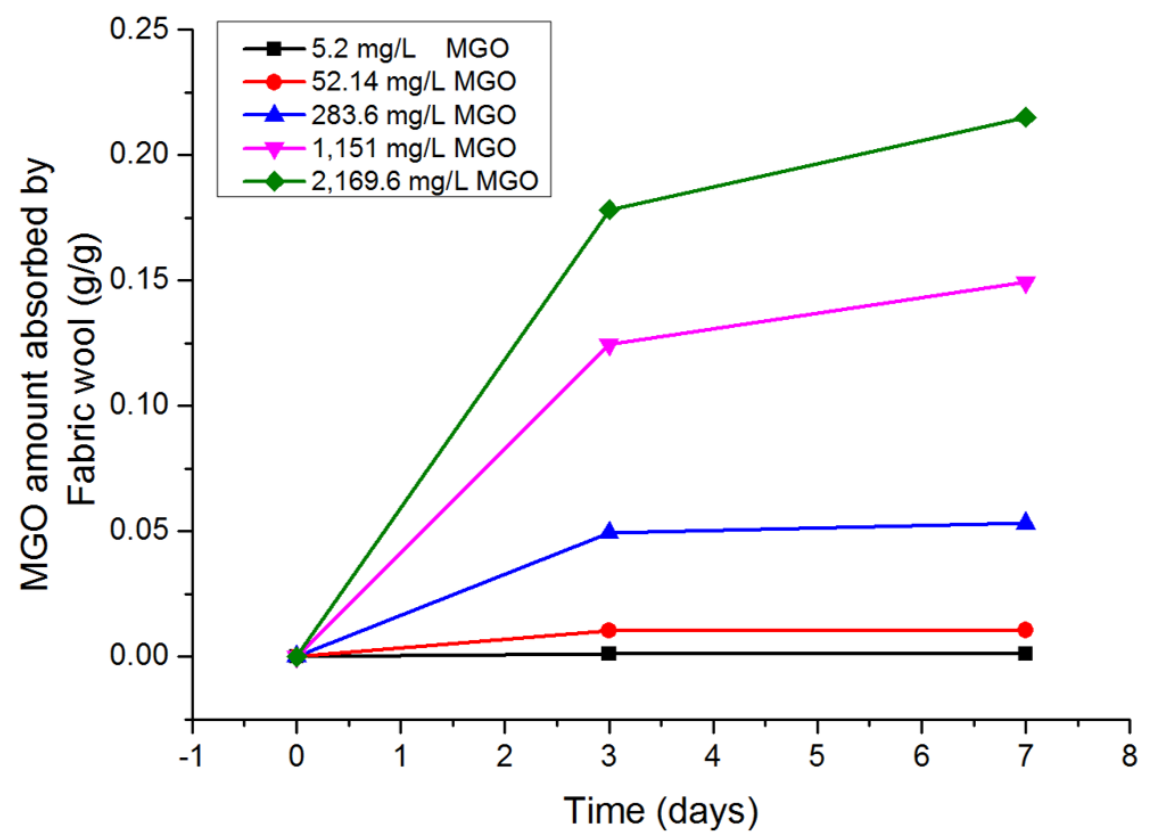

Figure 3.10: The uptakes of various MGO concentrations by fabric wool at $70{ }^{\circ} \mathrm{C}$ using sealed glass ampoules 


\subsubsection{The Methylglyoxal and Manuka Honey Uptake at $50{ }^{\circ} \mathrm{C}$ in Glass Am- poules}

The treatment of wool by MGO using sealed glass ampoules showed no loss in the uptake amounts of solution, so there was a need to replicate the first experiments at 50 ${ }^{\circ} \mathrm{C}$ that were carried out in normal vials. Because of the time constraints, finished fabric wool only were treated with various concentrations of MGO and MGO in $\mathrm{MH}$ as shown in Table 3.13 .

Table 3.14 shows that repeating the MGO uptake resulted in $10 \%$ to $12 \%$ differences of the uptake percentage between using non-ampoules and ampoules. The amounts of MGO absorbed by the wool using glass ampoules were $10 \%$ less than non-sealed ampoules. This means the MGO largely evaporated at $50{ }^{\circ} \mathrm{C}$ using normal vials. Nevertheless, this approach confirmed that the wool absorbed most of the MGO fromm the starting solutions of low MGO concentrations in the pure MGO and MH solutions. Although the uptake percentages of MGO were slightly lower from concentrated MGO (e.g. 1 and $2 \mathrm{~g} \mathrm{~L}^{-1}$ ), the amount of MGO absorbed increased with increasing the initial concentration in $\mathrm{MH}$ and MGO solutions. The MGO uptake from 1 and $2 \mathrm{~g} \mathrm{~L}^{-1} \mathrm{MGO}$ starting solutions at $50{ }^{\circ} \mathrm{C}$ was studied at this temperature for the first time

Table 3.14 shows that a decrease in temperature led to smaller amounts of MGO being absorbed by the wool compared to the uptake of MGO from similar MGO and MH concentrations at 70 and $80{ }^{\circ} \mathrm{C}$. For example, the wool absorbed $63 \mathrm{mg} \mathrm{g}^{-1}$ after 7 days at $50{ }^{\circ} \mathrm{C}$ but the absorption amount reached $167 \mathrm{mg} \mathrm{g}^{-1}$ after 5 days at $70{ }^{\circ} \mathrm{C}$ using the same MGO concentration (starting solution).

In summary, Table 3.14 shows that the maximum amount of MGO absorbed by wool at $50{ }^{\circ} \mathrm{C}$ was $80 \mathrm{mg} \mathrm{g}^{-1}$. However, at similar concentrations, the amount of MGO absorbed by wool reached $299 \mathrm{mg} \mathrm{g}^{-1}$ using similar concentrations at $70{ }^{\circ} \mathrm{C}$. This confirmed that the high temperature can act as a driving force for larger MGO uptake. 


\begin{tabular}{|c|c|c|c|c|c|c|c|c|}
\hline 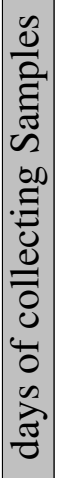 & 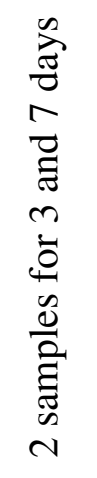 & 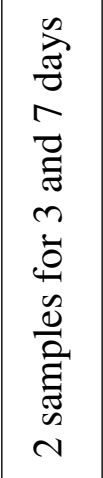 & 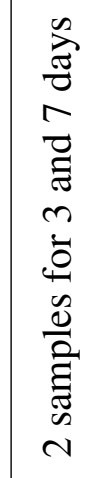 & 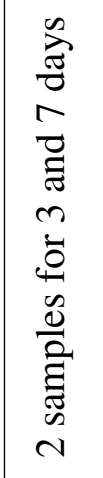 & 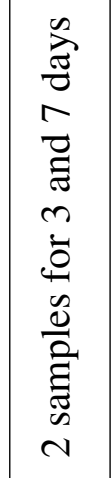 & 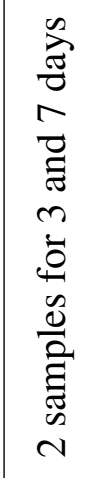 & 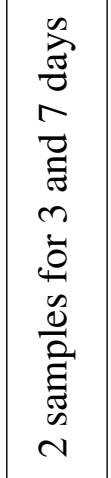 & 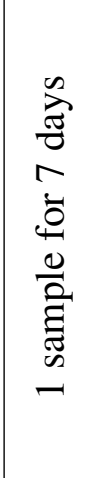 \\
\hline 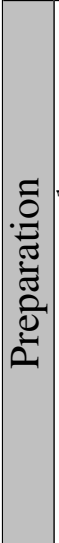 & 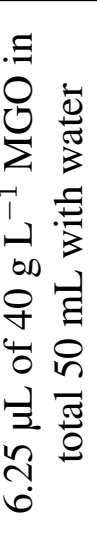 & 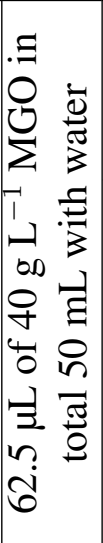 & 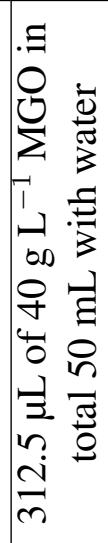 & 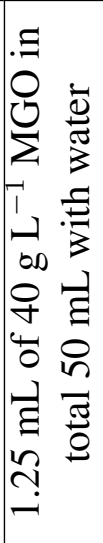 & 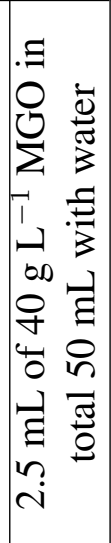 & 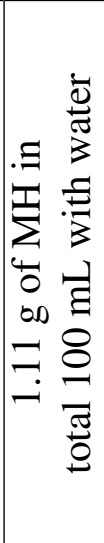 & 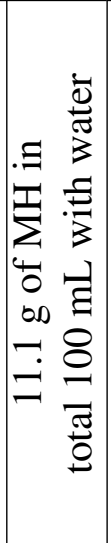 & 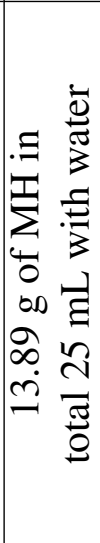 \\
\hline 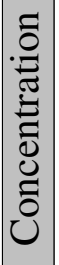 & $\begin{array}{l}\text { † } \\
\text { on } \\
\text { E } \\
n\end{array}$ & $\begin{array}{l}7 \\
1 \\
0 \\
\Xi \\
0 \\
0 \\
n\end{array}$ & $\begin{array}{l}7 \\
1 \\
00 \\
\Xi \\
0 \\
\vdots \\
\end{array}$ & ב- & 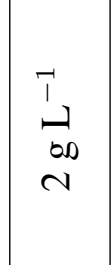 & 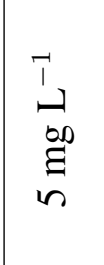 & 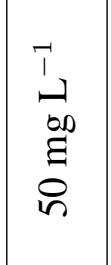 & $\begin{array}{l}1 \\
1 \\
00 \\
\Xi \\
0 \\
\\
\end{array}$ \\
\hline $\begin{array}{l}\overline{8} \\
8 \\
3\end{array}$ & \begin{tabular}{l}
00 \\
\hdashline \\
0 \\
$x$ \\
$\sim$
\end{tabular} & $\begin{array}{l}00 \\
\ddot{0} \\
\dot{x} \\
\sim\end{array}$ & $\begin{array}{l}00 \\
\ddot{0} \\
x \\
\sim\end{array}$ & $\begin{array}{l}b_{0} \\
\dot{0} \\
\dot{x} \\
\sim\end{array}$ & $\begin{array}{l}00 \\
\overrightarrow{0} \\
x \\
N\end{array}$ & $\begin{array}{l}000 \\
\overrightarrow{0} \\
x \\
i\end{array}$ & $\begin{array}{l}00 \\
\vdots \\
0 \\
x \\
i\end{array}$ & $\begin{array}{l}00 \\
\vdots \\
0 \\
x \\
-\end{array}$ \\
\hline 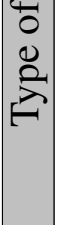 & 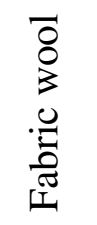 & 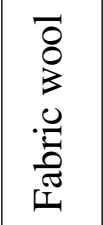 & 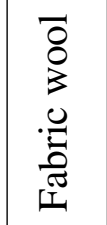 & 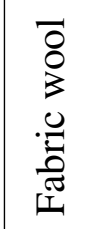 & 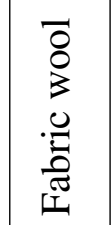 & 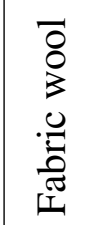 & 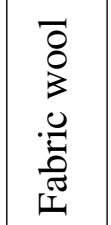 & 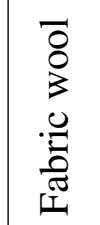 \\
\hline 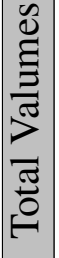 & 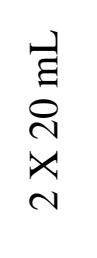 & 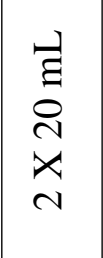 & 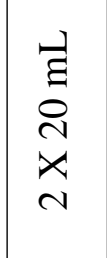 & 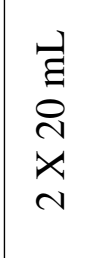 & 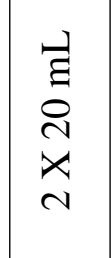 & $\begin{array}{l}\vec{\Xi} \\
\stackrel{\text { I }}{x} \\
x \\
\text { N }\end{array}$ & 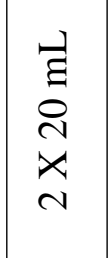 & 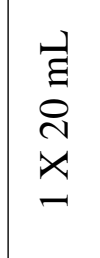 \\
\hline छ్ & $\begin{array}{l}\underset{\theta}{\ominus} \\
\stackrel{0}{\Sigma}\end{array}$ & $\begin{array}{l}త \\
0 \\
0 \\
\vdots \\
\Sigma\end{array}$ & $\begin{array}{l}త \\
0 \\
0 \\
\vdots \\
\Sigma\end{array}$ & 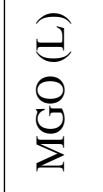 & 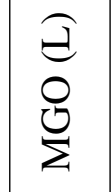 & $\begin{array}{l}\text { త্ } \\
0 \\
0 \\
\Sigma\end{array}$ & 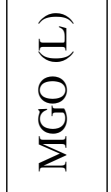 & $\begin{array}{l}\text { తి } \\
0 \\
0 \\
\Sigma\end{array}$ \\
\hline $\begin{array}{c}2 \\
\frac{0}{2} \\
\text { हี } \\
\tilde{\sim} \\
\tilde{n}\end{array}$ & \multicolumn{5}{|c|}{ 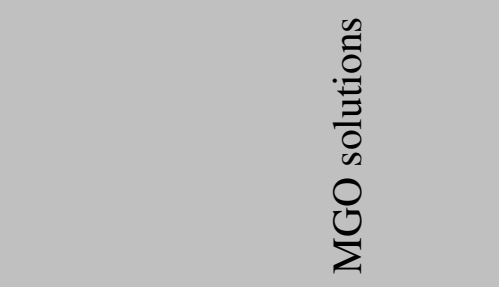 } & \multicolumn{3}{|c|}{ 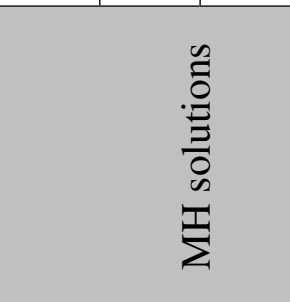 } \\
\hline
\end{tabular}


Table 3.14: The uptake percentage and weight of MGO and MGO in $\mathrm{MH}$ by wool at $50{ }^{\circ} \mathrm{C}$ using sealed glass ampoules

\begin{tabular}{|c|c|c|c|c|c|c|c|c|}
\hline \multirow[b]{2}{*}{ days } & \multicolumn{2}{|c|}{$\begin{array}{c}5 \mathrm{mg} \mathrm{L}^{-1} \mathrm{MGO} \\
\text { absorption }\end{array}$} & \multicolumn{2}{|c|}{$\begin{array}{c}50 \mathrm{mg} \mathrm{L}^{-1} \mathrm{MGO} \\
\text { absorption }\end{array}$} & \multicolumn{2}{|c|}{$\begin{array}{c}250 \mathrm{mg} \mathrm{L}^{-1} \mathrm{MGO} \\
\text { absorption }\end{array}$} & \multicolumn{2}{|c|}{$\begin{array}{l}1 \mathrm{~g} \mathrm{~L}^{-1} \mathrm{MGO} \\
\text { absorption }\end{array}$} \\
\hline & $\mathrm{mg} \mathrm{g}^{-1}$ & $\%$ & $\mathrm{mg} \mathrm{g}^{-1}$ & $\%$ & $\mathrm{mg} \mathrm{g}^{-1}$ & $\%$ & $\mathrm{mg} \mathrm{g}^{-1}$ & $\%$ \\
\hline 0 & 0.00 & $0 \%$ & 0.00 & $0 \%$ & 0.00 & $0 \%$ & 0.00 & $0 \%$ \\
\hline 3 & 0.91 & $93.28 \%$ & 6.69 & $66.66 \%$ & 19.76 & $38.10 \%$ & 51.48 & $26.68 \%$ \\
\hline \multirow[t]{2}{*}{7} & 0.97 & $98.68 \%$ & 8.41 & $83.88 \%$ & 25.81 & $49.76 \%$ & 62.93 & $32.61 \%$ \\
\hline & \multicolumn{2}{|c|}{$\begin{array}{l}2 \mathrm{~g} \mathrm{~L}^{-1} \mathrm{MGO} \\
\text { absorption }\end{array}$} & \multicolumn{2}{|c|}{$\begin{array}{c}5 \mathrm{mg} \mathrm{L}^{-1} \mathrm{MGO} \text { in } \mathrm{MH} \\
\text { absorption }\end{array}$} & \multicolumn{2}{|c|}{$\begin{array}{c}50 \mathrm{mg} \mathrm{L}^{-1} \mathrm{MGO} \text { in } \mathrm{MH} \\
\text { absorption }\end{array}$} & \multicolumn{2}{|c|}{$\begin{array}{c}250 \mathrm{mg} \mathrm{L}^{-1} \mathrm{MGO} \text { in } \mathrm{MH} \\
\text { absorption }\end{array}$} \\
\hline days & $\mathrm{mg} \mathrm{g}^{-1}$ & $\%$ & $\mathrm{mg} \mathrm{g}^{-1}$ & $\%$ & $\mathrm{mg} \mathrm{g}^{-1}$ & $\%$ & $\mathrm{mg} \mathrm{g}^{-1}$ & $\%$ \\
\hline 0 & 0.00 & $0 \%$ & 0.00 & $0 \%$ & 0.00 & $0 \%$ & 0.00 & $0 \%$ \\
\hline 3 & - & - & 0.50 & $78.08 \%$ & 2.71 & $42.76 \%$ & - & - \\
\hline 7 & 80.26 & $19.96 \%$ & 0.60 & $93.21 \%$ & 3.95 & $62.23 \%$ & 20.67 & $89.74 \%$ \\
\hline
\end{tabular}

\subsubsection{Determining the Methylglyoxal Uptake at a Larger Scale of Wool}

This study has centred on the treatments of wool with MGO and MH using $20 \mathrm{~mL}$ solutions and $0.1 \mathrm{~g} \pm 0.02$ of wool for the uptake study. However, it is important to be able to ascertain if the procedures developed and used here can be scaled up linearly as would be required for any ensuing commercial development. In order to correlate the previous study with a scaled up uptake, the MGO concentration and wool weight would be multiplied ten times with using $20 \mathrm{~mL}$ volume. Thus, two stock standards of 0.5 and $20 \mathrm{~g} \mathrm{~L}^{-1}$ MGO were prepared to treat $1 \mathrm{~g}$ wool, which is ten times scale up of 0.05 and $2 \mathrm{~g} \mathrm{~L}^{-1}$ with $0.1 \mathrm{~g}$. The uptake extent of MGO in this larger scale was determined after 3 and 7 days of immersion as used above.

This scale up experiment therefore utilised two and five times the above quantities of MGO solution and weight of wool as shown in Table 3.15. Three fabric wool samples weighing $0.5 \mathrm{~g}$ were treated with 25,250 and 1,250 $\mathrm{mg} \mathrm{L}^{-1} \mathrm{MGO}$ at $70{ }^{\circ} \mathrm{C}$ for 15 days, which are equivalent to $0.1 \mathrm{~g}$ with 5, 50 and $250 \mathrm{mg} \mathrm{L}^{-1} \mathrm{MGO}$. All these samples showed an efficient uptake compared to previous study at $70 \mathrm{C}$ for seven days. It is seen that the MGO absorption rates increased from 1 to $8 \%$ between 7 and 14 days treatments, which is similar to 7 and 14 days absorptions in Table 3.15. The higher concentration MGO solutions: 1,2 and $4 \mathrm{~g} \mathrm{~L}^{-1}$ MGO with $0.2 \mathrm{~g}$ fabric wool were equivalent to using $0.1 \mathrm{~g}$ fabric wool with $0.5,1$ and $2 \mathrm{~g} \mathrm{~L}^{-1} \mathrm{MGO}$ respectively at the 
Table 3.15: An illustration of the MGO uptakes per wool weight at 70 ${ }^{\circ} \mathrm{C}$ (MGO wool ${ }^{-1} \mathrm{~g} \mathrm{~g}^{-1}$ ). The scale up process validates the consistent absorption of MGO per a particular wool weight at every concentration of MGO. The table is showing the MGO absorption $(\mathrm{g})$ per wool $(\mathrm{g})\left(\mathrm{g} \mathrm{g}^{-1}\right)$.

\begin{tabular}{|c|c|c|c|c|}
\hline \multirow{2}{*}{ dave } & $5 \mathrm{mg} \mathrm{L}^{-1}$ & $25 \mathrm{mg} \mathrm{L}^{-1}$ & $50 \mathrm{mg} \mathrm{L}^{-1}$ & $250 \mathrm{mg} \mathrm{L}^{-1}$ \\
\hline & $0.1 \mathrm{~g}$ wool & $0.5 \mathrm{~g}$ wool & $0.1 \mathrm{~g}$ wool & $0.5 \mathrm{~g}$ wool \\
\hline 0 & 0 & 0 & 0 & 0 \\
\hline 7 & 0.001 & - & 0.010 & - \\
\hline 15 & - & 0.001 & - & 0.010 \\
\hline \multirow{2}{*}{ davic } & $500 \mathrm{mg} \mathrm{L}^{-1}$ & $1,000 \mathrm{mg} \mathrm{L}^{-1}$ & $1,000 \mathrm{mg} \mathrm{L}^{-1}$ & $2,000 \mathrm{mg} \mathrm{L}^{-1}$ \\
\hline & $0.1 \mathrm{~g}$ wool & $0.2 \mathrm{~g}$ wool & $0.1 \mathrm{~g}$ wool & $0.2 \mathrm{~g}$ wool \\
\hline 0 & 0 & 0 & 0 & 0 \\
\hline 15 & 0.126 & 0.084 & 0.179 & 0.239 \\
\hline \multirow{2}{*}{ dovic } & $250 \mathrm{mg} \mathrm{L}^{-1}$ & $1250 \mathrm{mg} \mathrm{L}^{-1}$ & $2,000 \mathrm{mg} \mathrm{L}^{-1}$ & $4,000 \mathrm{mg} \mathrm{L}^{-1}$ \\
\hline & $0.1 \mathrm{~g}$ wool & $0.5 \mathrm{~g}$ wool & $0.1 \mathrm{~g}$ wool & $0.2 \mathrm{~g}$ wool \\
\hline 0 & 0 & 0 & 0 & 0 \\
\hline 7 & 0.052 & - & - & - \\
\hline 15 & - & 0.054 & 0.298 & 0.350 \\
\hline
\end{tabular}


comparable temperatures. The results showed that there were some small variations in the MGO uptake amounts for the scale up methods because the initial solutions differed slightly compared to previous analysis, which resulted in a higher uptake per unit (g of wool).

Overall, the increase of both weight of wool and concentrations of MGO, respectively resulted in a similar extent of uptake compared with the smaller scale examples. This confirms the extent of MGO uptake per unit weight of wool is essentially independent of the scale of the operation. It suggests that larger scale productions of MGO-Wool composites are most likely to have an efficiency of the amounts of MGO are required per unit weight of wool, which was achieved at smaller scale.

\subsection{Summary of the Temperature Influence on the Methyl- glyoxal and Manuka Honey Uptake by Wool}

All different forms of wool have been treated with MGO and MH solutions. The uptake study showed a relatively higher uptake rate with loose top fibres, which is due to the larger accessible surface area. A range of temperatures was investigated to quantify the effects of temperature on the MGO and $\mathrm{MH}$ absorption rates. At room temperature, the diffusion rate was very slow, which resulted in minimal uptake of MH and MGO after 24 hours treatment. This was consistent with the uptake studies of a range of concentrations at low temperatures. The effects of increasing the temperature from $\sim$ 20 to $80{ }^{\circ} \mathrm{C}$ significantly accelerated the absorption and diffusion rates into the fibres and hence the uptake, which increased the total amount of MGO by itself in solution and as a component in MH solution that was absorbed by the wool. In general, a long treatment time from 7 and 14 days and higher temperature up to $80{ }^{\circ} \mathrm{C}$ increased the amount of MGO and MH absorbed by wool and resulted in a significant colour change. It was found that the high temperatures have not resulted in any colour change of the 
wool with the absence of MGO. As the amount of MGO absorbed was increased, the colour changed from light to dark brown. These colour changes were consistent with the amount of MGO that absorbed and diffused into the wool (see Figure 3.11).

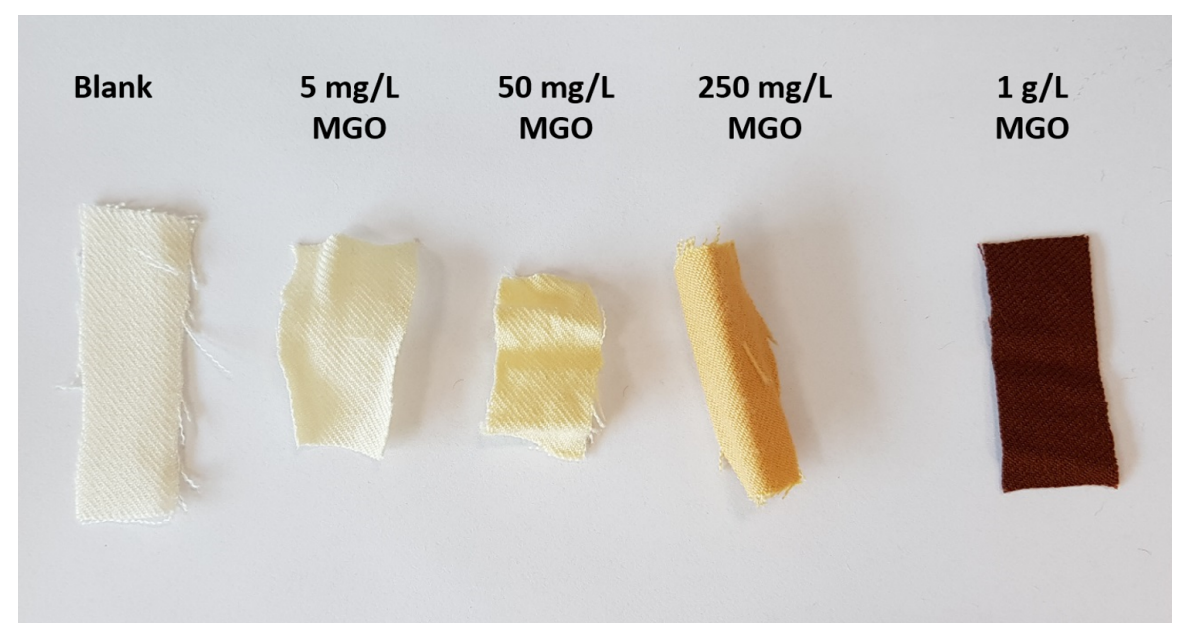

Figure 3.11: The effect of MGO concentrations on the colour of wool after 15 days treatment at $70{ }^{\circ} \mathrm{C}$. The wool tends to become darker when HPLC results show a large amount of MGO absorbed by wool

Figure 3.12 shows how the uptake and diffusion of MGO into wool fabric increases from $90 \mathrm{mg} \mathrm{g}^{-1}$ at $50{ }^{\circ} \mathrm{C}$ to $176 \mathrm{mg} \mathrm{g}^{-1}$ at $70{ }^{\circ} \mathrm{C}$. There is also an increase in the MGO uptake as the concentration of MGO is increased from 0.7 to $1.1 \mathrm{~g} \mathrm{~L}^{-1}$ at $70{ }^{\circ} \mathrm{C}$. Washing these treated samples resulted in a negligible leaching of the MGO absorbed suggesting a chemical bonding between MGO and wool. The MGO molecules are considered to diffuse intercellularly between the wool's cuticles into the bulk fibre (see Figure 3.13 ). The diffusion and hence the uptake of MGO is essentially first order (exponential) in nature and therefore dependent on the initial concentration of MGO and the temperature as well as the diffusivity. A long period of treatments was required to reach saturation absorption under a particular set of conditions. 


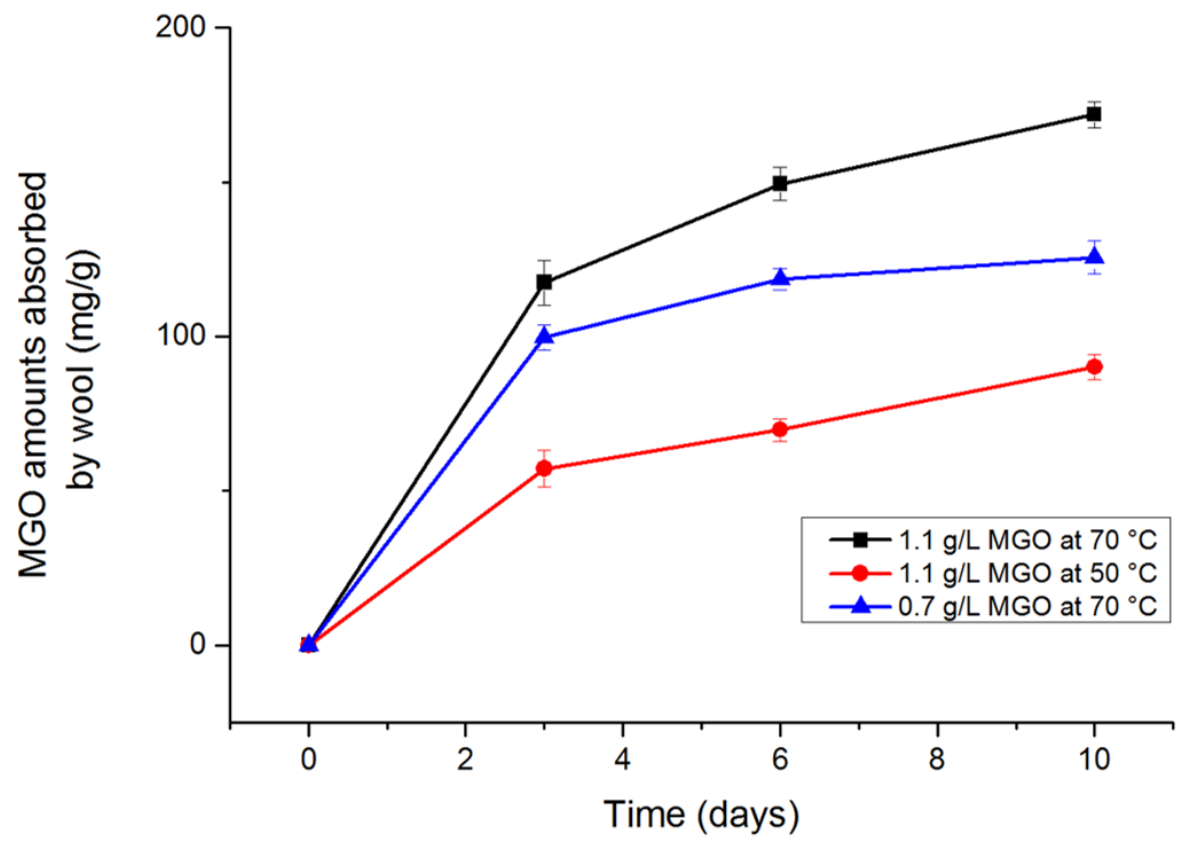

Figure 3.12: The effects of temperature on the amount of MGO absorbed by wool

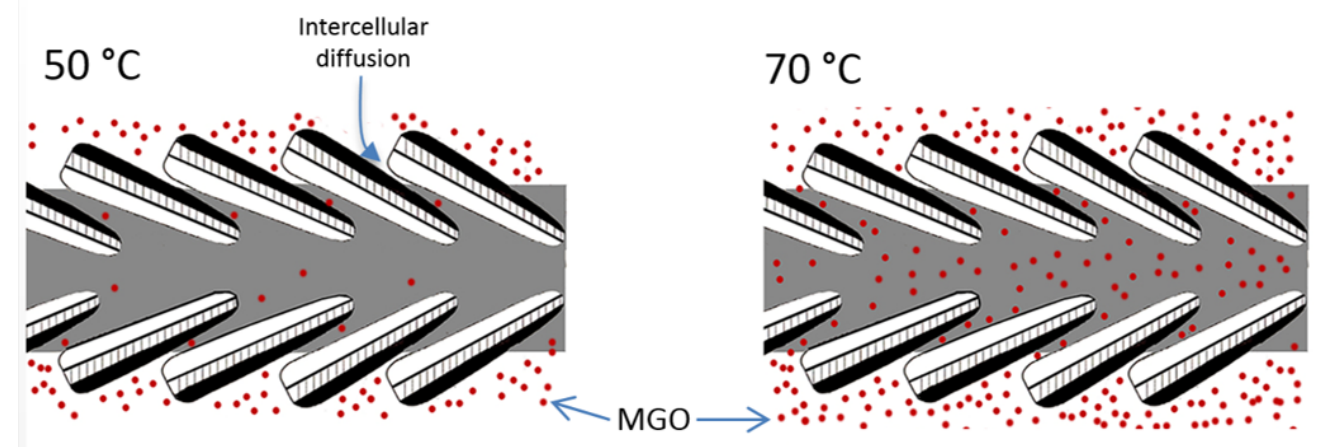

Figure 3.13: The effects of high temperatures on the MGO diffusion rates into wool fibres. The intercellular diffusion occurs between the gaps between cuticle cells into cell membrane complex.

\subsection{Degradation of Methylglyoxal}

It is recognised that the MGO concentration in solution could be affected by increased temperatures as Nemet et al. ${ }^{65}$ reported, but Weigel et al. ${ }^{63}$ observed no effect on MGO concentration upon $\mathrm{MH}$ storage between 35 and $45{ }^{\circ} \mathrm{C}$. The interest here was to investigate any change in MGO concentration during the storage of the solution after the 
uptake study and prior the HPLC analysis. Also, it was important to determine the effect of the elevated temperatures used for the uptake process on the MGO concentrations.

Thus, two wool samples were treated with two solutions $(20 \mathrm{~mL})$ of $5 \mathrm{mg} \mathrm{L}^{-1}$ of MGO and MGO in $\mathrm{MH}$ for a day at $90{ }^{\circ} \mathrm{C}$. After that $1 \mathrm{~mL}$ of each solution was collected after 24 hours and stored in the fridge at $4{ }^{\circ} \mathrm{C}$ for a week before it was derivatised with OPD. Additionally, $1 \mathrm{~mL}$ of the same solution was collected at the same time but after being kept in the dark at room temperature for a week. Finally, all samples were derivatised with OPD and analysed to quantify if there was an effect of the storage condition on the concentration.

The HPLC analysis showed that the MGO concentration in MH was approximately 4\% higher during storage in the fridge than at the room temperature suggesting a small amount of degradation had taken place at the higher temperature. The MGO solutions themselves had a similar higher concentration of $3.6 \%$ during storage at room temperature compared to storage in the refrigerator. It is, therefore, possible that the extent of uptake of MGO measured here by the wool is overstated by up to $4 \%$. However, it is still clear that the majority of the reduction of MGO in solution in the uptake studies is actually due to the absorption of MGO by the wool.

Over a long period of six months, it was observed that the MGO in the MH batch reduced by $8.6 \%$ during the storage at room temperature reduced by $8.6 \%$. This percentage was confirmed by preparing equivalent concentrations of MH solutions and several HPLC analyses during the uptake study.

In conclusion, an increase in temperature slightly affects the level of MGO in $\mathrm{MH}$ and MGO solutions. Also the MGO concentration in the honey batch reduced by $8.6 \%$ over six months of storage. 


\subsection{Leaching Test of Methylglyoxal}

The amount of MGO and MH absorbed by wool has determined in the above studies. It is now important to understand how MGO is likely to be bound to the wool and how strong this bonding is. This test is significant as it is desirable that as little MGO is leached out of the treated wool by washing. To ascertain this, the wool samples treated with MGO and MH were immersed into $20 \mathrm{~mL}$ distilled water and placed into a hot shaking bath at $50{ }^{\circ} \mathrm{C}$ for 24 hours. Then the amounts of MGO in residual solutions were determined by HPLC.

These leaching tests confirmed that MGO alone and that in $\mathrm{MH}$ were strongly and likely chemically bound to the wool. It was demonstrated that only very small amounts of MGO leached from the MGO-Wool and MH-Wool after 24 hours (see Table 3.16). The MGO leached into the water was likely only weakly bonded to the wool surface. It was found that the amount of MGO in $\mathrm{MH}$ leached was slightly higher than that from the MGO-Wool only, which was likely because of a viscous layer of MH on the wool surface that might capture MGO (note: one sample was washed with distilled water after the uptake and another was not washed before carrying out the leaching test).

\subsection{FT-IR Spectroscopy of Methylglyoxal and Wool Com- posites}

The MGO has both aldehyde and ketone carbonyl groups present and it was reported that the more reactive aldehyde carbonyl group is more likely to be hydrated than the ketonic carbonyl in water. The FTIR spectrum of MGO solution (40\%) as shown in Figure 3.14 was obtained and showed a ketonic carbonyl stretching band at $1,639 \mathrm{~cm}^{-1}$ and an aldehyde carbonyl stretching band at $1,723 \mathrm{~cm}^{-1}$. The peak at $3,360 \mathrm{~cm}^{-1}$ corresponds to the $\mathrm{OH}$ stretching from water. The $\mathrm{CH}$ stretching mode is observed at approximately 
Table 3.16: The MGO leached from the MGO-Wool and MH-wool composites. MGO uptake was determined first then the same samples were tested for leaching test.

\begin{tabular}{ccc}
\hline & The uptake study \\
\hline Temperature ${ }^{\circ} \mathrm{C}$ & $\begin{array}{c}\text { MGO absorbed } \\
\mathrm{mg} \mathrm{g}^{-1}\end{array}$ & $\begin{array}{c}\text { \% absorbed from } \\
\text { initial solution }\end{array}$ \\
\hline 80 & 1.2 & 100 \\
50 & 2.4 & 91 \\
\hline Temperature ${ }^{\circ} \mathrm{C}$ & MGO in MH absorbed $^{\mathrm{mg} \mathrm{g}^{-1}}$ & $\begin{array}{c}\text { \% absorbed from } \\
\text { initial solution }\end{array}$ \\
\hline 80 & 0.7 & 75 \\
50 & 0.8 & 95
\end{tabular}

\begin{tabular}{ccc}
\hline \multicolumn{2}{c}{ Leaching test } \\
\hline Temperature ${ }^{\circ} \mathrm{C}$ & $\begin{array}{c}\text { Amount of MGO Leached } \\
\mathrm{mg} \mathrm{L}^{-1}\end{array}$ & \% leached from MGO-Wool \\
\hline 50 & 0.043 & $0.74 \%$ \\
50 & 0.046 & $0.38 \%$
\end{tabular}

\begin{tabular}{ccc}
\hline Temperature ${ }^{\circ} \mathrm{C}$ & $\begin{array}{c}\text { Amount of MGO in MH Leached } \\
\mathrm{mg} \mathrm{L}^{-1}\end{array}$ & \% leached from MGO-Wool \\
\hline 50 & 0.05 & $1.53 \%$ \\
50 & 0.082 & $1.98 \%$
\end{tabular}

$2,850 \mathrm{~cm}^{-1}$, which is seen as small peak overlapping with a broad peak of water $(\mathrm{OH})$. There are three medium $\mathrm{C}-\mathrm{C}-\mathrm{C}$ asymmetric stretches at $1,361 \mathrm{~cm}^{-1}$, the $\mathrm{CH}$ bend at $1,385 \mathrm{~cm}^{-1}$ and the $\mathrm{CH}_{3}$ bends at $1,415 \mathrm{~cm}^{-1}$. There is a strong absorbance band at $1,082 \mathrm{~cm}^{-1}$, which corresponds to $\mathrm{C}-\mathrm{O}$ stretching in MGO. The $\mathrm{CH}_{3}$ has rocking modes at 939 and $1,008 \mathrm{~cm}^{-1}$. Axson et al. ${ }^{102}$ investigated the water addition effects on MGO in the gas-phase that result in distinct vibrational modes between 1,050 and $1,500 \mathrm{~cm}^{-1}$ and influencing the $\mathrm{C}-\mathrm{O}$ stretching. Axson's study and others similarly confirmed the FT-IR spectrum of MGO discussed above ${ }^{103-106}$. 


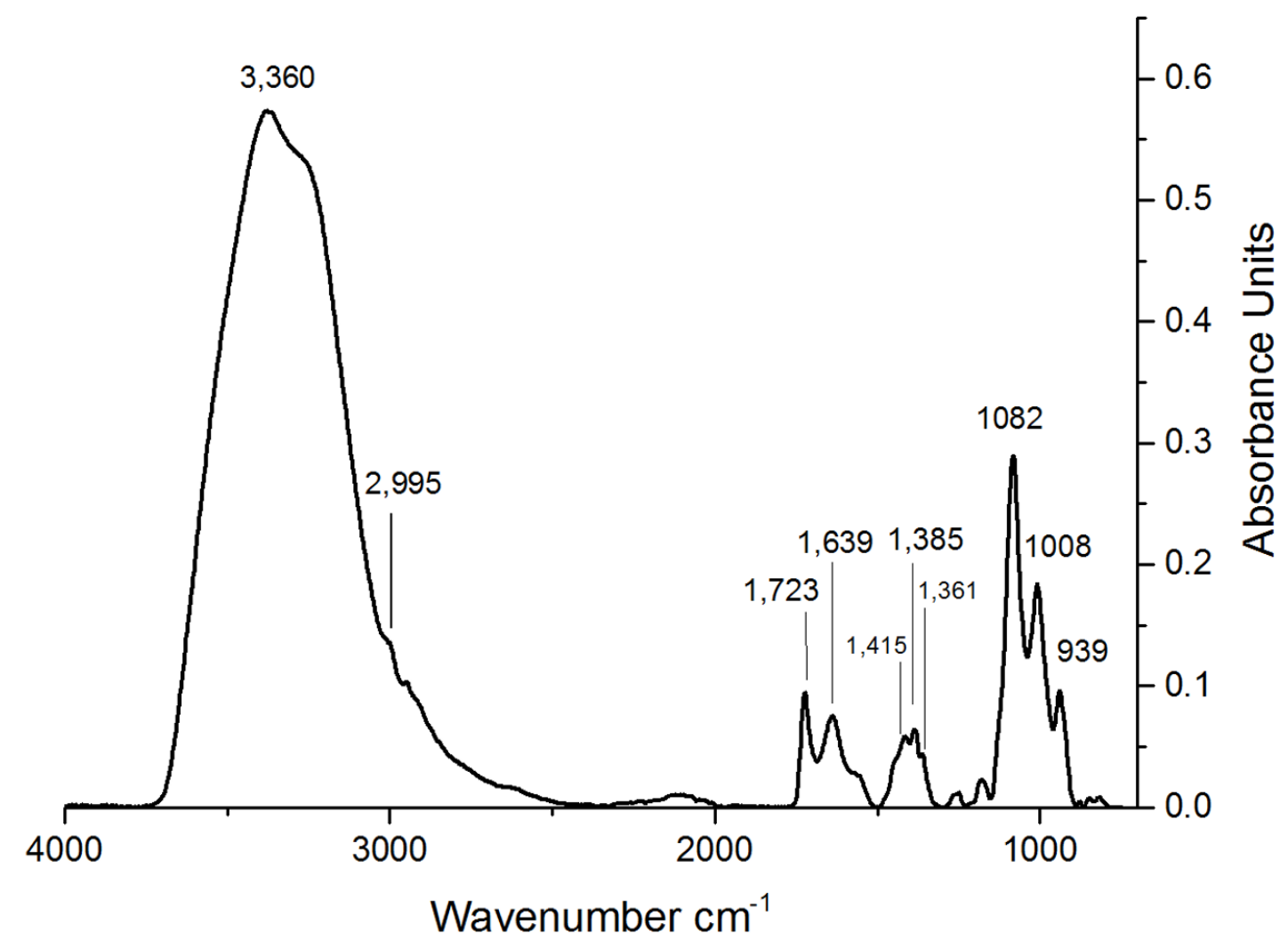

Figure 3.14: The FT-IR spectra of $40 \%$ MGO.

Figure 3.15 shows the FT-IR spectra of the non-treated wool with absorption bands between 4,000 and 2,800 $\mathrm{cm}^{-1}$ corresponding to Amide I at 3,270 $\mathrm{cm}^{-1}$ and Amide II at $3,066 \mathrm{~cm}^{-1}$. These peaks are due to the $\mathrm{N}-\mathrm{H}$ stretching vibration, which has a strong absorption in this region. The keratin absorptions occur in the 1,200-1,650 $\mathrm{cm}^{-1}$ region that result from all three amide groups and the $\mathrm{C}-\mathrm{O}$ stretching vibration can be seen at $1,230 \mathrm{~cm}^{-1}$. These observations are in agreement with the information reported by Tonin et al. ${ }^{107}$. It is important to clarify that the intensity of wool absorption might differ because the limitation of the FT-IR set up and the complexity of getting an identical amount of sample on the sample window between various samples for comparison purpose.

Figure 3.15 also compares the FT-IR spectra of the non-treated wool (red colour) and the MGO-Wool composite (blue colour). The MGO-Wool was a result of wool treatment with $1 \mathrm{~g} \mathrm{~L}^{-1} \mathrm{MGO}$ for 15 days at $70{ }^{\circ} \mathrm{C}$. The $\mathrm{MGO}$ in the wool at most occupied 


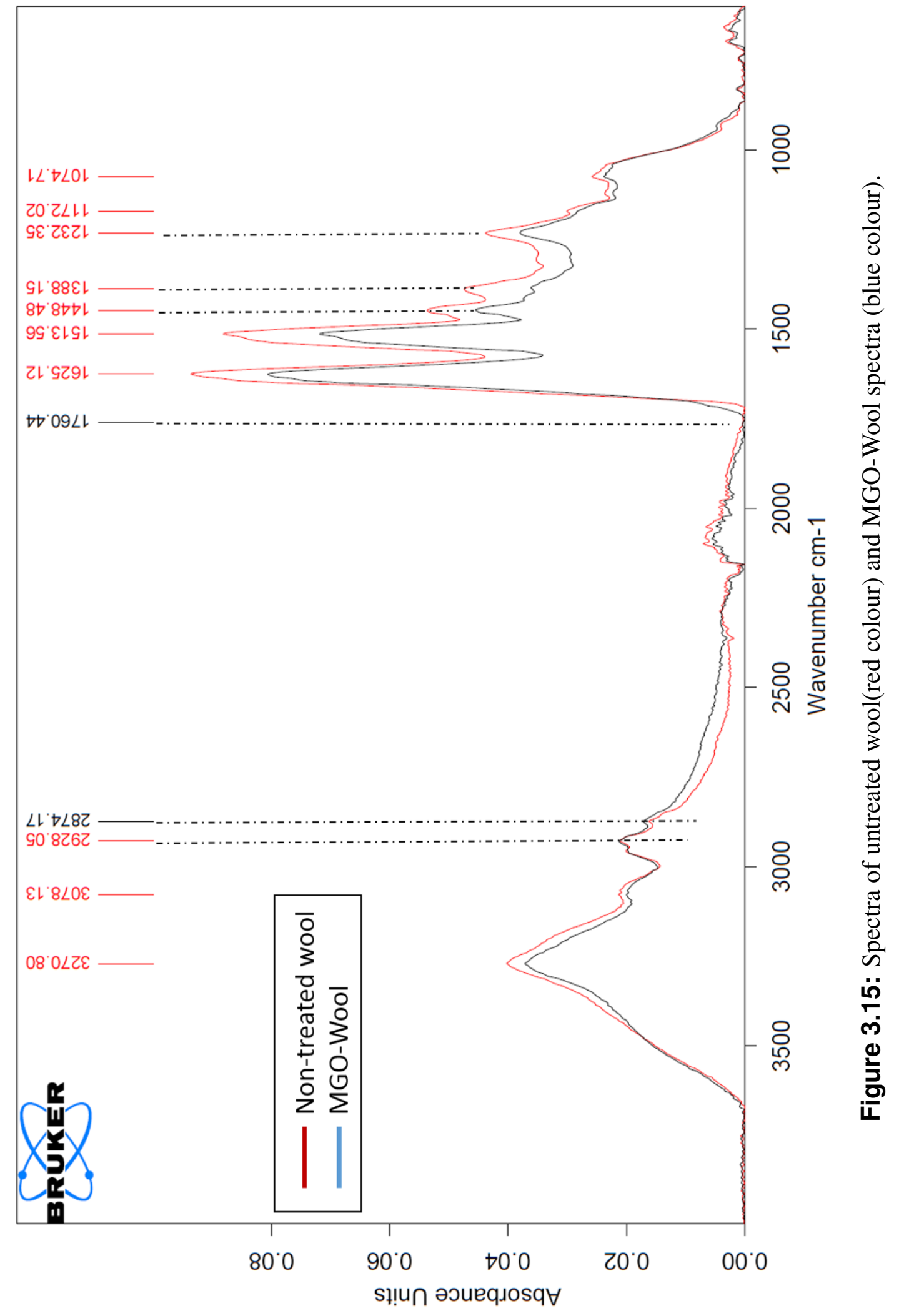


approximately $19 \%$ of the wool-MGO composite at the maximum absorption rate. The spectra show noticeable differences in the $1,000-1,800 \mathrm{~cm}^{-1}$ region after the MGO absorption as shown in more detail in Figure 3.16 on scaling the spectra for more detail. The scaling up of the intensity of the MGO-Wool for a better comparison, shows a reduction in the $\mathrm{C}-\mathrm{O}$ stretching peak intensity. In addition, two peaks had mostly disappeared $\left(1,384 \mathrm{~cm}^{-1}\right)$ or have been reduced in intensity $\left(1,447 \mathrm{~cm}^{-1}\right)$, which are typical of the wool proteins. This provides evidence of an interaction between MGO and the wool proteins. The intensity of the peak at $1,627 \mathrm{~cm}^{-1}$ increased after MGO addition showing an alteration in the MGO ketonic carbonyl on MGO uptake into the wool. A small shoulder is present at $1,760 \mathrm{~cm}^{-1}$ corresponding to a MGO derived aldehyde but it is not a distinct peak in the MGO-Wool spectrum. The amide II peak at $3,066 \mathrm{~cm}^{-1}$ was altered after the MGO absorption where MGO itself has no peak at this wavelength. The differences in the protein regions due to the MGO treatment indeed suggest some chemical bonding between wool and MGO and this interaction probably occurs through hydrogen bonding.

Overall, the FT-IR spectra of non-treated wool and MGO-Wool confirm the interaction of MGO with the wool proteins suggesting hydrogen bonding occurs in MGO-Wool composites. The nature of chemical interaction here supports the leaching test result where a negligible amount of MGO was leached from washing the MGO-Wool at elevated temperature (see Section 3.5). 


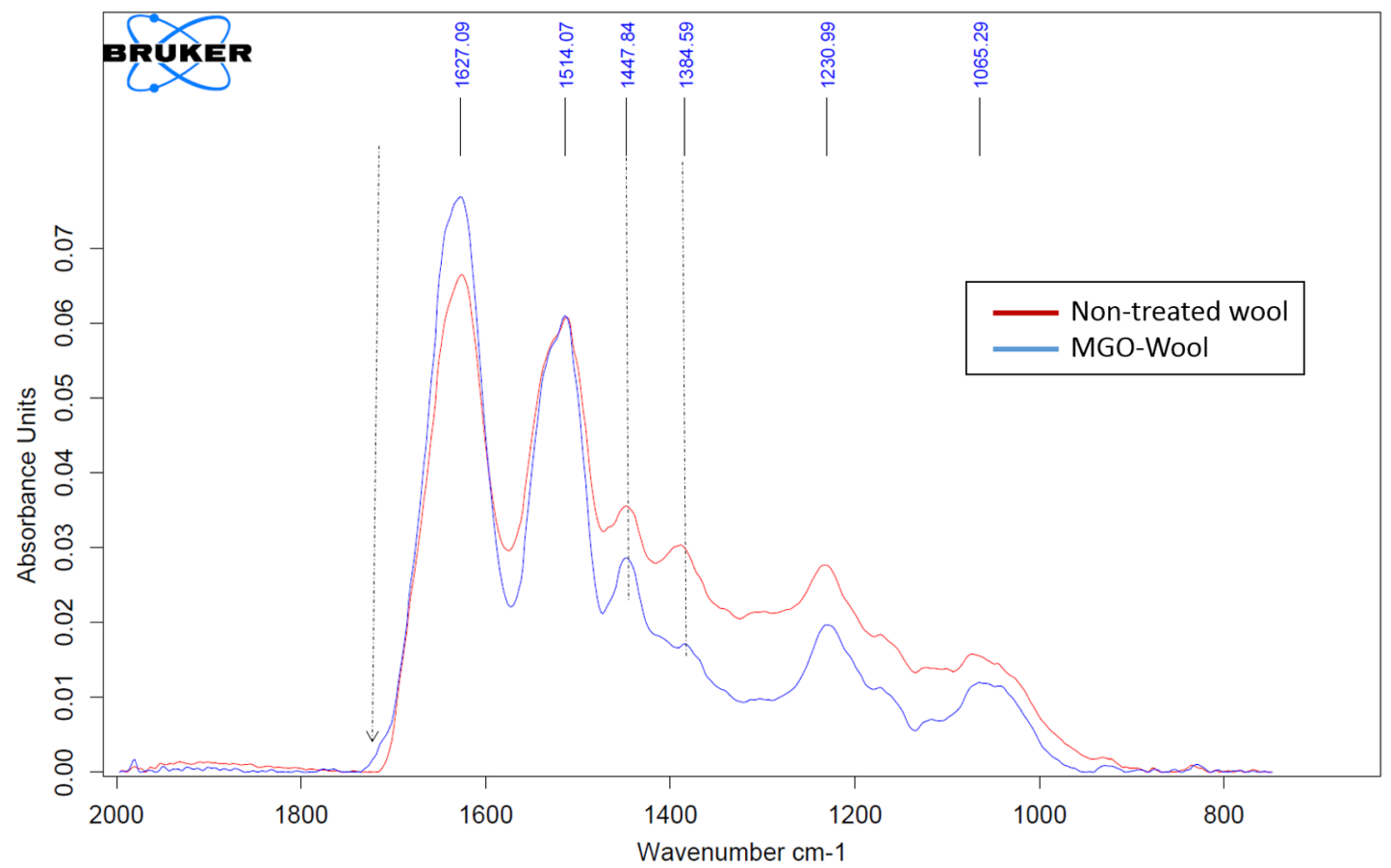

Figure 3.16: Scale up spectra of untreated wool(red colour) and MGOWool spectra (blue colour) in order to distinguish the MGO interactions with the wool.

\subsection{Thermogravimetric Analysis (TGA) of Wool Com- posites}

Typical TGA curves of the wool only and MGO-Wool materials are presented in Figure

3.17. Firstly, it is important to note that all samples were dried between 25 and $30{ }^{\circ} \mathrm{C}$ for three days to minimise the moisture quantity prior to the TGA analysis. Figure 3.17 shows that non-treated wool had a $12.12 \%$ mass loss after heating the sample up to 200 ${ }^{\circ} \mathrm{C}$. This suggests that the mass loss of wool corresponds to the bound water on the wool surface or inside the fibre ${ }^{108}$. The treatment of wool with low concentrated MGO (50 $\mathrm{mg} \mathrm{L}^{-1}$ ) shows the composite material loses higher mass than wool only. It is likely the MGO replaced some of the bound water and the low concentration of MGO did not provide a sufficient concentration gradient to drive the MGO to diffuse into the wool bulk. Therefore, the rate of weight loss differed significantly by having a fast mass loss 
between 40 and $100{ }^{\circ} \mathrm{C}$, resulting in $13.6 \%$ total mass loss for the composites. As the wool absorbed more MGO ( $1 \mathrm{~g} \mathrm{~L}^{-1} \mathrm{MGO}$ at $70{ }^{\circ} \mathrm{C}$ over 14 days $)$, the MGO replaces the bound water forming hydrogen bonds, which reduced the rate of weight loss and the total amount of weight loss of the wool. This is correlated to a slight mass loss in the higher MGO-Wool of 7.2\%, suggesting a chemical bonding of MGO to the wool.

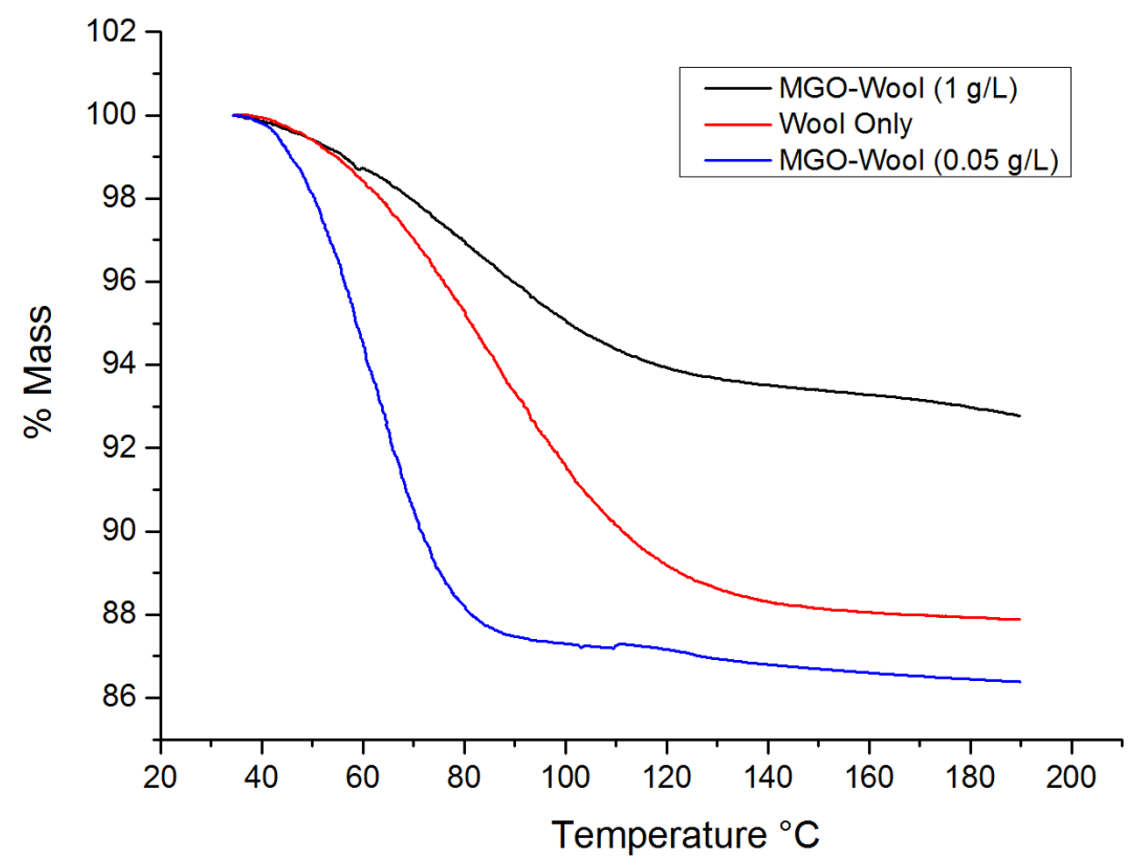

Figure 3.17: TGA traces for non-treated wool, MGO-Wool $\left(1 \mathrm{~g} \mathrm{~L}^{-1} \mathrm{MGO}\right.$ at $\left.70{ }^{\circ} \mathrm{C}\right)$ and $\mathrm{MGO}-\mathrm{Wool}\left(5 \mathrm{mg} \mathrm{L}{ }^{-1} \mathrm{MGO}\right.$ at $\left.70^{\circ} \mathrm{C}\right)$ with $12.1,7.2$ and 13.6 $\%$ mass loss respectively.

In summary, untreated wool showed a weight loss of $12.1 \%$, which relates to the bound water on the wool fibres. The small amount of MGO uptake resulted in significantly fast mass loss with a weight loss of $13.6 \%$. This small amount of MGO replaced some of the bound water, but this concentration was not sufficient to cause diffusion of MGO into the wool. The uptake of a large amount of MGO formed hydrogen bond and stabilised the thermal properties of the wool, resulting in only a $7.2 \%$ mass loss. 


\subsection{Differential Scanning Calorimetry (DSC) Analysis of Wool Composites}

The DSC curves of fabric wool and treated wool by MGO are shown in Figure 3.18. As wool fabric is hydrophilic with consequent hydrogen bonding of the water to the wool surface and bulk the DSC peak shows a broader evaporation peak of water up to $120{ }^{\circ} \mathrm{C}$. Although water evaporation begins about $60{ }^{\circ} \mathrm{C}$ an endothermic peak is seen between $200{ }^{\circ} \mathrm{C}$ and $240{ }^{\circ} \mathrm{C}$ in wool only, which corresponds to thermal degradation of $\alpha$-keratin ${ }^{109-111}$. As discussed above in the TGA results, the MGO absorption appears to result in hydrogen bonding between the MGO and wool proteins. The DSC curve of the MGO-Wool shows the endothermic property of wool was altered by the MGO, resulting in a shift of the temperature peak from $234.6{ }^{\circ} \mathrm{C}$ to $236.6{ }^{\circ} \mathrm{C}$ and the endothermic reaction is greater for the MGO-Wool. This shift was likely due to the formation of hydrogen bonds between the MGO and with protein amide groups in the MGO-Wool composites, which are not present in the untreated wool ${ }^{112}$. The onset of the vaporisation peak of water occurs at about $100{ }^{\circ} \mathrm{C}$. The vaporisation peak observable in the treated wool is shifted to a lower temperature $\left(83^{\circ} \mathrm{C}\right)$, which relates to the low boiling point of MGO. This again demonstrates that the MGO compound was successfully incorporated into the wool.

In summary, the DSC curves show that the endothermic properties of non-treated wool changed when the MGO was absorbed by the wool. These changes can be seen in the onset peak at $100{ }^{\circ} \mathrm{C}$, corresponds to the water removal, which shifted to a lower peak at $83{ }^{\circ} \mathrm{C}$ when the MGO was absorbed by the wool as the boiling point of MGO boiling point is lower than that of water. Also the thermal degradation reaction of the $\alpha$-keratin present in non-treated wool at $235{ }^{\circ} \mathrm{C}$ was detected, but the formation of hydrogen bonding between the MGO and wool changed this degradation step and shifted this peak to $237^{\circ} \mathrm{C}$. The DSC analysis confirmed the success of incorporating the MGO into the wool and also confirmed the effect of the chemical bonding between the MGO 
and wool.

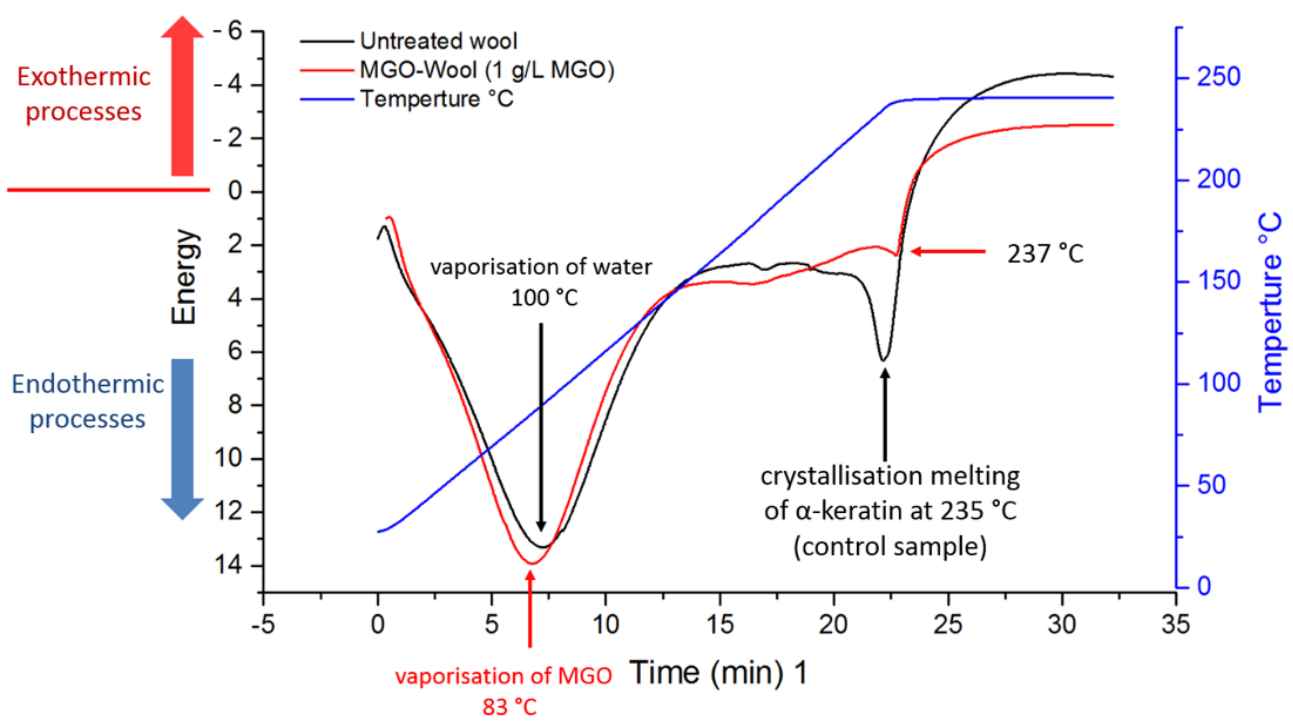

Figure 3.18: DSC curves of (A) non-treated wool and (B) MGO-Wool composites (from the uptake of $1 \mathrm{~g} \mathrm{~L}^{-1} \mathrm{MGO}$ at $70{ }^{\circ} \mathrm{C}$ over 15 days) with holding time at $240{ }^{\circ} \mathrm{C}$ for ten minutes.

\subsection{Contact Angle Measurement of Wool Treatment}

The contact angle on the control fabric wool surface for a water droplet was $130.1^{\circ}$. The subsequent chemical modification with MGO absorption in combination with the surface active hydrophobic agent Dynasylan ${ }^{\circledR}$ showed the contact angle of wool increased by about $1.4^{\circ}$ and $7.5^{\circ}$ for treatment with 0.25 and $1 \mathrm{~g} \mathrm{~L}^{-1} \mathrm{MGO}$ respectively. Although the standard deviation value of $1 \mathrm{~g} \mathrm{~L}^{-1}$ MGO treated overlapped with the control sample, wool treatments with MGO showed some evidence of a trend (see Table 3.17). Higher numbers of replicates could not be fully investigated due to lack of time.

Overall, the MGO absorption and treatment with Dynasylan ${ }^{\circledR}$ confirmed the effects of the MGO on the hydrophobicity of the wool and there is evidence of a trend. However, a further study with replicates is required to confirm trends. 
Table 3.17: The contact angle of blank wool and treated wool with MGO at MGO concentrations of 0.25 and $1 \mathrm{~g} \mathrm{~L}^{-1}$.

\begin{tabular}{|c|c|c|}
\hline Sample & Average contact angle & Standard deviation \\
\hline Wool only & $130.1^{\circ}$ & $3.9^{\circ}$ \\
\hline MGO-Wool & $131.5^{\circ}$ & $5.5^{\circ}$ \\
$\left(0.25 \mathrm{~g} \mathrm{~L}^{-1} \mathrm{MGO}\right)$ & & \\
\hline $\mathrm{MGO}-$ Wool $^{\circ}$ & $137.6^{\circ}$ & $8.0^{\circ}$ \\
\hline$\left(1 \mathrm{~g} \mathrm{~L}^{-1} \mathrm{MGO}\right)$ & & \\
\hline
\end{tabular}

\subsection{Antimicrobial Performance of MGO-Textile Com- posites}

It is known that MGO has antibacterial activity, mainly against Gram-positive bacteria (Bacillus subtilis and Staphylococcus aureus (S. aureus) with a minimum inhibitory concentration (MIC) of 0.8 and $1.2 \mathrm{mM}$ ) and Gram-negative (Pseudomonas aeruginosa and Escherichia coli (E. coli) at MIC 1.0 and $1.2 \mathrm{mM}$ ). This activity has been reported at equivalent concentrations in $\mathrm{MH}$ and synthetic $\mathrm{MGO}^{53,113}$. The MGO totally inhibits bacterial growth at these levels using an agar plate assay based on methodology reported by Sherlock et al ${ }^{114}$.

With this knowledge of the antimicrobial activity of MGO in solutions, the next step in the current study was to investigate the antimicrobial effectiveness of the MGO-Wool composites. This experiment was carried out at the School of Biological Sciences at Victoria University of Wellington. A few tests for some of the MGO-Wool composites were also done at Wellington Southern Community Laboratories.

The antimicrobial activity of textile fibres dip coated with MGO and $\mathrm{MH}$, known as a physical surface coating, has been reported ${ }^{82}$. However, in this method the textile was immersed into MGO and MH solutions for ten minutes then dried and tested for their 
antimicrobial activity. This method is unlikely to have any durable bonding of MGO to the fibres as the MGO and MH solutions were simply dried into the surface of the fibres at room temperature. This study shows there is essentially no uptake of the $\mathrm{MH}$ or MGO by the wool fibres at room temperature.

S. aureus

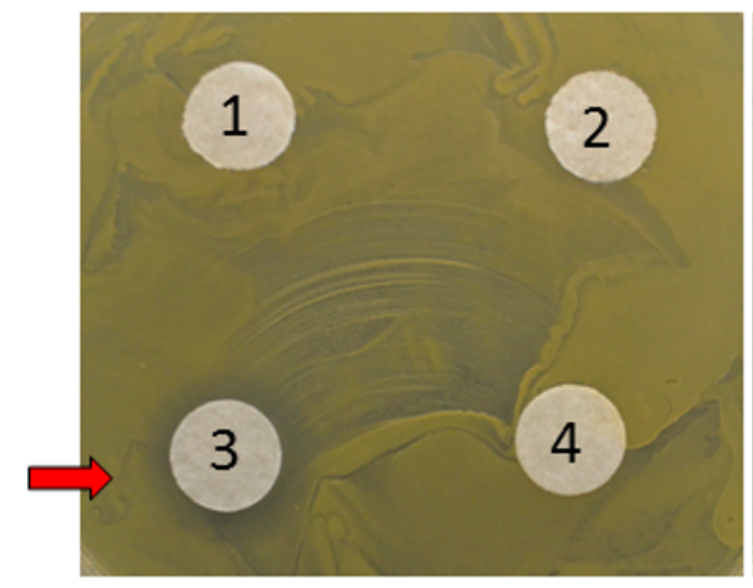

E. coli

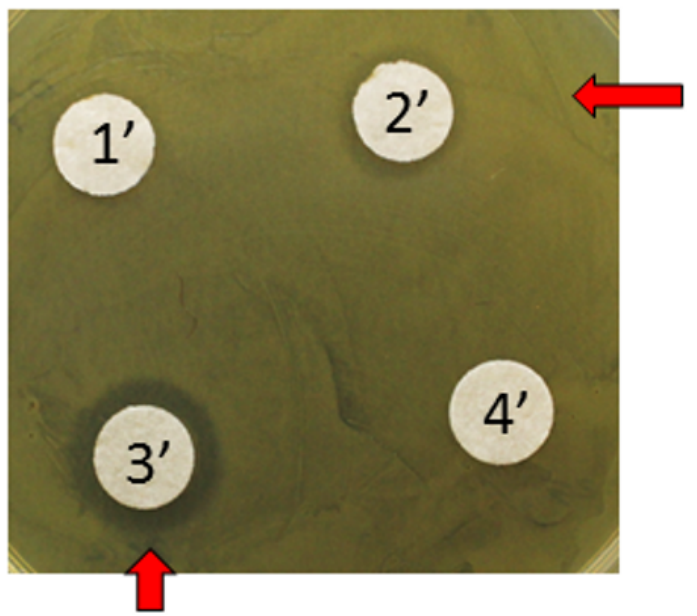

Figure 3.19: The zone of inhibition of paper coated with MGO solutions at: 1, 1') $0.5 \mathrm{~g} \mathrm{~L}^{-1} \mathrm{MGO} 2$, 2') $1 \mathrm{~g} \mathrm{~L}^{-1} \mathrm{MGO} 3$, 3') $2 \mathrm{~g} \mathrm{~L}^{-1} \mathrm{MGO} 4$, 4') $0.25 \mathrm{~g} \mathrm{~L}^{-1} \mathrm{MGO}$ against S.aureus and E.coli. Note: arrows show the zone of inhibition.

In a parallel test, paper samples dip coated with MGO was studied similarly to determine the MGO bonding when applied as a physical surface coating. Here the paper sheet was immersed into MGO solutions of various concentrations for ten minutes then dried at room temperature before the zone of inhibition test. The paper coated with MGO was tested against Gram-negative E. coli and Gram-positive S. aureus at varying MGO concentrations as shown in Figure 3.19. White-yellow cloudy areas in Figure 3.19 indicate bacterial growth, where clear areas surrounding some samples indicate the bacteria free region and hence the bioactivity of the sample. The MGO-Paper sample (3 and 3') (2 $\left.\mathrm{g} \mathrm{L}^{-1} \mathrm{MGO}\right)$ inhibited 2.1 and $2.8 \mathrm{~mm}$ of a clear inhibition zone area toward S. aureus and E. coli respectively. Although the sample (3) had a zone of inhibition against $S$. aureus, this sample did not show a clear edge or a clear zone of inhibition as sample (3'). It suggests that the MGO-Paper here inhibited a larger area of E. coli growth than the growth of $S$. aureus. The MGO-Paper (2) $\left(1 \mathrm{~g} \mathrm{~L}^{-1} \mathrm{MGO}\right)$ had a zone 
of $1.1 \mathrm{~mm}$ against E. coli and none for S. aureus. Other MGO-Paper samples treated with lower MGO concentrations showed no zone of inhibition including 1, 1', 4 and 4'. However, all the samples showed no growth of microbes under the samples. The lack of a zone of inhibition suggests the samples do not exhibit antimicrobial activity (kill microbes distant from the surface). However, as there was no growth of the microbes on the surface, it exhibits bacteriostatic properties better than antimicrobial properties.

As an important evaluation of the physical coating onto a textile, it was important to identify if MGO bonds to the textile and how likely it was to be washed off. Thus, paper sheets were immersed into various MGO concentrations for ten minutes then dried at room temperature similar to what was doen in Bulman's method ${ }^{82}$. Then, this method was repeated using paper sheets at the same MGO concentration, but the treated papers were rinsed with water for two minutes then dried and tested against $E$. coli and S. aureus microbes as shown in Figure 3.20.

It was observed that washing the treated MGO-paper samples with water prior to this antimicrobial testing resulted in a reduction of the zone of inhibition size (see Figure 3.20). The sample (5) treated with $2 \mathrm{~g} \mathrm{~L}^{-1} \mathrm{MGO}$ and tested against $S$. aureus, resulted in a $2.3 \mathrm{~mm}$ zone of inhibition. On the other hand, washing the treated paper (with $2 \mathrm{~g}$ $\mathrm{L}^{-1} \mathrm{MGO}$ ) with water (5) reduced the amount of MGO on the paper surface where it inhibited only $1.6 \mathrm{~mm}$ against $S$. aureus. The MGO-Paper (2 $\left.\mathrm{g} \mathrm{L}^{-1} \mathrm{MGO}\right)(9)$ had a 2.1 mm zone of inhibition against E. coli, but after washing with water (9') this zone was observed to be $<1.8 \mathrm{~mm}$. Also, the treated paper with $0.5 \mathrm{~g} \mathrm{~L}^{-1} \mathrm{MGO}$ (10) showed $<$ $1.3 \mathrm{~mm}$ of an inhibition zone area toward E. coli, but washing the paper (10') resulted in MGO removal from the paper surface hence no zone of inhibition. This clearly demonstrates that this immersion method causes MGO to be only weakly bonded to the paper surface. This is presumably the same for MGO-Wool dried textiles as stated previously. (Note there is a variation in the zone of inhibition's diameter in Figure 3.20 because the size of papers was not consistent). 
S. aureus

Without rinsing

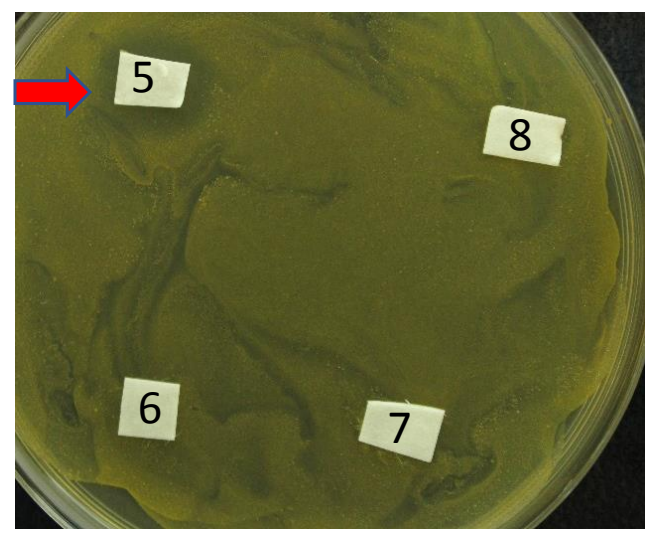

E. coli

Without rinsing

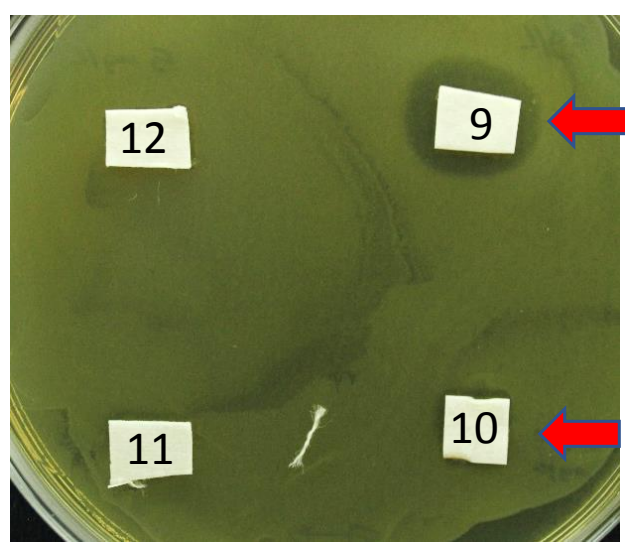

S. aureus

After rinsing the samples

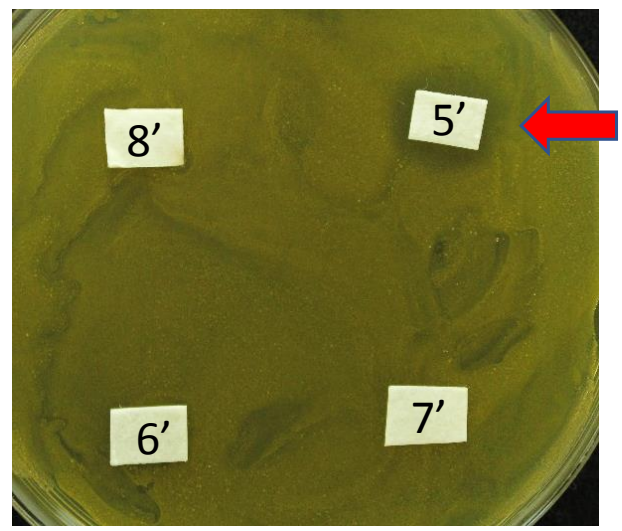

E. coli

After rinsing the samples

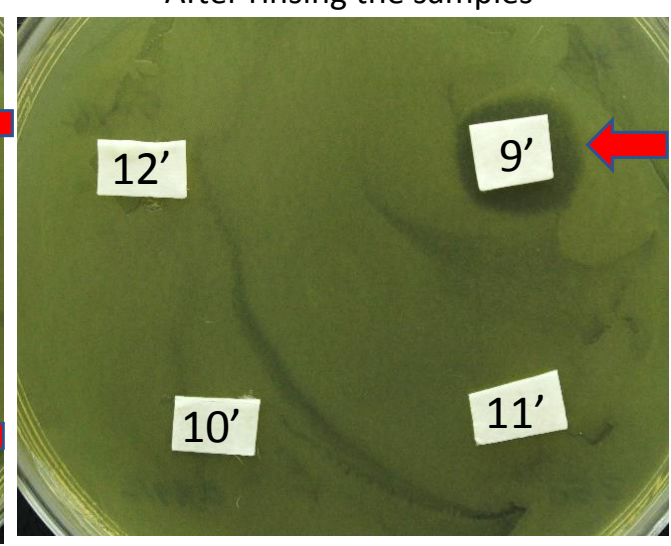

Figure 3.20: Paper coated with MGO solutions for ten minutes at: 5, 9) $2 \mathrm{~g} \mathrm{~L}^{-1}$ MGO 6, 10) $0.5 \mathrm{~g} \mathrm{~L}^{-1}$ MGO 7, 11) $0.25 \mathrm{~g} \mathrm{~L}^{-1}$ MGO 8, 12) 0.005 $\mathrm{g} \mathrm{L}^{-1} \mathrm{MGO}$ against S.aureus and E.coli. The samples differed in their activity after being washed with water as follows: 5', 9') $2 \mathrm{~g} \mathrm{~L}^{-1} \mathrm{MGO}$ 6', 10') $0.5 \mathrm{~g} \mathrm{~L}^{-1} \mathrm{MGO} 7$ ', 11') $0.25 \mathrm{~g} \mathrm{~L}^{-1} \mathrm{MGO} 8^{\prime}, 12$ ') $0.005 \mathrm{~g} \mathrm{~L}^{-1} \mathrm{MGO}$, suggesting that MGO is likely to be washed off the surface. Note: arrows show the zone of inhibition.

The MGO-Wool samples produced here through the uptake studies were tested against E.coli and S.aureus at varying MGO concentrations as shown in Figure 3.21. The MGO-Wool sample (13) with $0.4 \mathrm{~g} \mathrm{~g}^{-1}$ MGO per wool, after an uptake using $2 \mathrm{~g}$ $\mathrm{L}^{-1} \mathrm{MGO}$ at $70{ }^{\circ} \mathrm{C}$ for 15 days, inhibited $>2 \mathrm{~mm}$ of a clear inhibition zone area toward S.aureus and none for E.coli (13'). This result demonstrates for the first time that the antimicrobial effectiveness as compared to bacteriostatic effectivess of MGO-Wool 
composites toward S.aureus was greater than against E. coli (13'). It has been reported that MGO kills both S.aureus and E. coli bacteria with MIC of $1.1 \mathrm{mM}^{115}$, but incorporating the MGO into the wool textiles might limit its activity. The MGO-Wool samples (14) and (14') with $0.16 \mathrm{mg} \mathrm{g}^{-1} \mathrm{MGO}$ (uptake of $1 \mathrm{~g} \mathrm{~L}^{-1} \mathrm{MGO}$ ) had no zone of inhibition against $S$. aureus and E. coli. However, there was no growth observed under the samples suggesting bacteriostatic activity. Also, it was necessary to investigate how the durability of MGO bonding to the wool after a long period of completing the treatment. Therefore, MGO-Wool samples were treated with $1 \mathrm{~g} \mathrm{~L}^{-1}$ MGO (absorbed $0.16 \mathrm{mg}$ $\mathrm{g}^{-1}$ ) tested after 70 days of determining the uptake toward S. aureus (15) and E. coli (15'). Although the samples (15) and (15') showed no zone of inhibition, both samples had tendencies.

The reduction of the MGO antimicrobial activities in the MGO-Wool composites may relate to the diffusion rate of $\mathrm{MGO}$ from the treated wool into the bacteria agar. Also, the antimicrobial activity of the MGO could be held by the textile substrate, which might be varied or modified through the interaction with the fibre. It was suggested through the FT-IR, DSC and TGA measurements that the MGO is likely to form a hydrogen bound to the wool proteins. This clearly might affect and restrict the MGO diffusion as the MGO does not show any zone of inhibition. Interestingly, Bulman ${ }^{82}$ reported that for MGO-Wool, approximately $0.5 \mathrm{~g} \mathrm{~g}^{-1}$ MGO per sample (paper), showed no zone of inhibition. However, the MGO containing sample showed 100\% reduction colony forming units ${ }^{82}$. This clearly confirmed that coating wool with MGO would inhibit antimicrobial activities. 
S. aureus

$2 \mathrm{~g} \mathrm{~L}^{-1} \mathrm{MGO}$ (A day old sample)

(13)

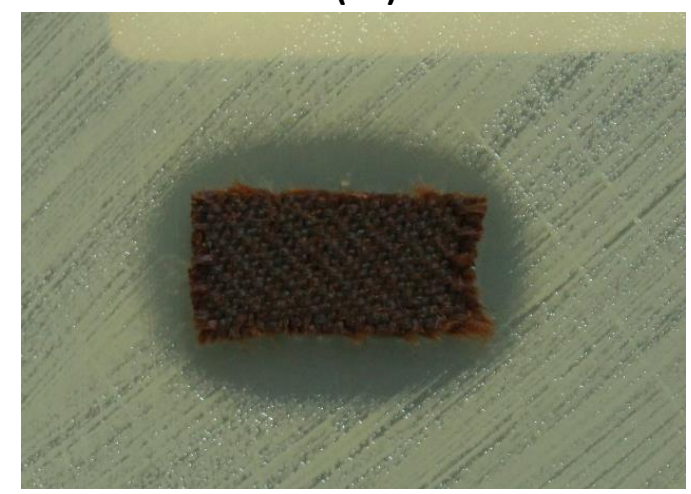

S. aureus

$1 \mathrm{~g} \mathrm{~L}^{-1} \mathrm{MGO}$ (A day old sample)

(14)

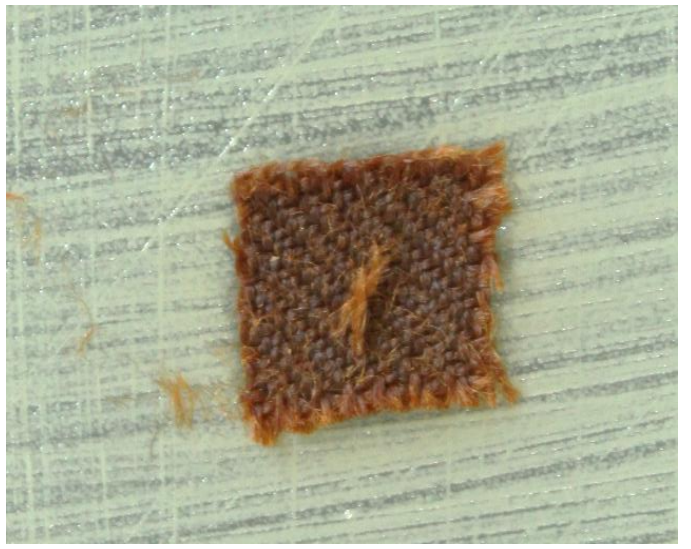

S. aureus

$1 \mathrm{~g} \mathrm{~L}^{-1} \mathrm{MGO}$ (70 days old sample)

(15)

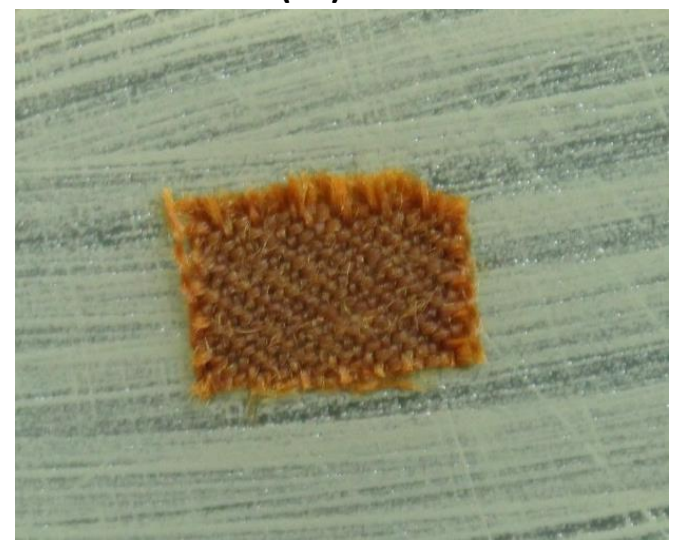

E. coli

$2 \mathrm{~g} \mathrm{~L}^{-1} \mathrm{MGO}$ (A day old sample)

(13')

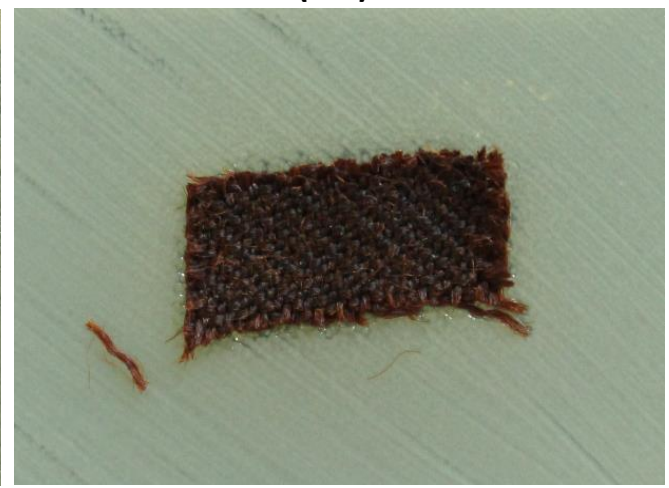

E. coli

$1 \mathrm{~g} \mathrm{~L}^{-1} \mathrm{MGO}$ (A day old sample)

(14')

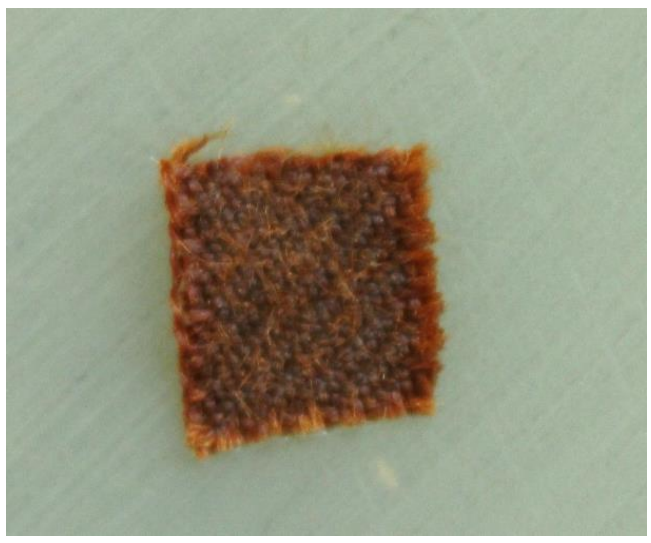

E. coli

$1 \mathrm{~g} \mathrm{~L}^{-1} \mathrm{MGO}$ (70 days old sample)

(15')

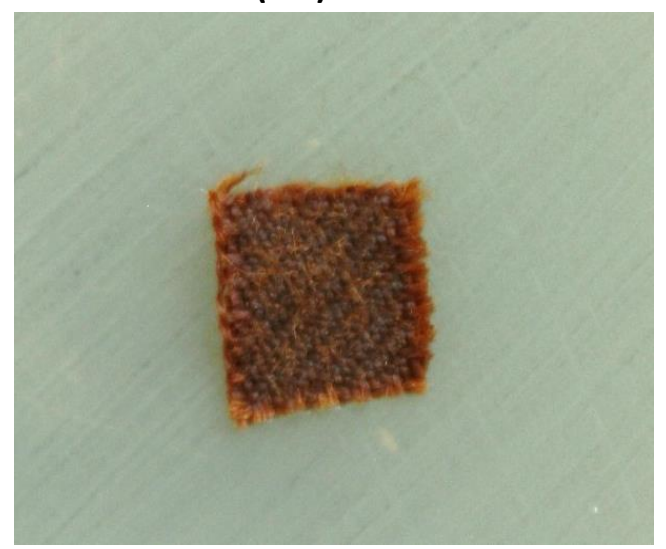

Figure 3.21: Zone of inhibition of treated fabric wool by various MGO concentrations against S.aureus and E.coli. The samples 13, 13', 14 and 14 ' were tested for their antibacterial activity after one day of finishing the uptake. The last two samples were tested after 70 days of the uptake and being kept at room temperature 
It was significant that the MGO-Wool composites showed different amounts of bacterial growth on the underside of the samples, which depended on the MGO concentrations in the wool. Table 3.18 shows the effects of MGO concentrations on the growth of bacteria under the samples where MGO inhibited mostly S.aureus growth. The MGOWool, treated with $2 \mathrm{~g} \mathrm{~L}^{-1}$ did not show a zone of inhibition against $E$. coli but there was no bacterial growth underneath of the sample, which showed an effect of this MGO concentration against $E$. coli. The MGO-Wool, treated with $1 \mathrm{~g} \mathrm{~L}^{-1}$, inhibited some of the S.aureus growth even though this sample was three months old after being synthesised, but there was a heavy bacteria growth underside of the sample for E. coli. The MGO-Wool, treated with low MGO concentration $0.25 \mathrm{~g} \mathrm{~L}^{-1}$, inhibited some of the S.aureus growth under the sample but none for E. coli. It all suggested that the active MGO slightly diffuses into the bacteria agar and inhibited the bacteria growth underside of the samples even at low MGO concentration. It confirmed the excellent efficiency of MGO against these bacteria and the success of incorporating MGO into the wool fibres.

Table 3.18: Effect of MGO concentrations on the growth of both $S$. aureus and E. coli for MGO-Wool composites after determining the uptake of MGO.

\begin{tabular}{|c|c|c|c|c|}
\hline \multirow{4}{*}{$\begin{array}{c}\text { Initial MGO } \\
\text { concentration } \\
\qquad\left(\mathrm{g} \mathrm{L}^{-1}\right)\end{array}$} & \multirow{4}{*}{$\begin{array}{l}\text { Time between } \\
\text { the treatement } \\
\text { and the test }\end{array}$} & \multirow{4}{*}{$\begin{array}{c}\text { MGO } \\
\text { concentration } \\
\left(\mathrm{mg} \mathrm{g}^{-1}\right)\end{array}$} & S. aureus & E. coli \\
\hline & & & Observed growth & Observed growth \\
\hline & & & under & under \\
\hline & & & sample & sample \\
\hline 2 & 1 day & 298 & no growth & very slight \\
\hline 1 & 1 day & 191 & no growth & medium-heavy \\
\hline 1 & 70 days & 191 & medium & heavy \\
\hline 0.25 & 1 day & 50 & medium & heavy \\
\hline
\end{tabular}

In summary, the MGO coating was tested against $S$. aureus and E. coli and showed antimicrobial activity in paper and wool. The antimicrobial test of the physical coating of MGO showed that MGO could be washed easily. However, the MGO-Wool synthesised 
by the uptake study showed excellent durability on washing and successfully inhibited the bacterial growth. This clearly confirm that this protocol of the MGO and MH uptake can only be used to achieve the desire antimicrobial property of treated wool, in compare with padding method. Also, incorporating a low amount of MGO into wool fibres resulted in a significant reduction of bacterial growth.

\subsection{Future Work}

This study shows a successful approach to incorporate the MGO into the wool fibres. The characterization techniques confirmed the formation of MGO-Wool composites and how MGO is likely bound to the wool. The antimicrobial test showed a significant effectiveness of the MGO-Wool against a bacterial growth and the goal of this study was achieved. However, for numerical quantifications of the antimicrobial effectiveness, further testing is required that utilises colony counting as a parameter. This was outside the time frame of this project.

Another approach that might be interesting to explore is the attachment of a metal to MGO. This metal hopefully would act as a tracer and facilitate the understanding of where and how MGO is distributed in the wool, which can be confirmed by SEM-EDS measurements. Also, the use of a metal might lead to determining the uptake without the HPLC and would confirm the chemical interaction between the MGO-Metal and the wool. 


\section{Chapter 4}

\section{Polymeric Materials with}

\section{Methylglyoxal}

In the final part of this research, it was decided that due to the complexity of wool's structure and morphology and its interaction with $\mathrm{MH}$ and MGO, it would be interesting to examine a less complex polymer system, to see how MGO might interact with such polymers. The polymeric materials used were polymethyl methacrylate (PMMA) and polyurethane (PU).

\subsection{Preparation of Polymeric Materials with Methylgly- oxal}

\subsubsection{NeoCryl $^{\circledR}$ XK-98}

A commercial resin known as NeoCryl ${ }^{\circledR}$ XK-98 (abbreviated as NeoCryl) was provided by The Polymer Group Ltd (see Section chemical and materials). This resin is formed from an acrylic emulsion and is a colourless and a high gloss polymer. The NeoCryl is 
approximately $45 \%$ suspended solids and the exact chemical composition of the commercial NeoCryl is not available due to it being proprietary knowledge.

The NeoCryl was functionalised with MGO by the following simple aqueous methods. NeoCryl (6 or $9 \mathrm{~mL})$ was mixed with various concentrations of MGO $(1 \mathrm{~mL})$, as detailed in Section (2.3.3), to give the final ratio of NeoCryl:MGO 6:1 or 9:1. The MGO was added dropwise to NeoCryl under high stirring to mix the MGO with the polymer. The samples then were left on a shaking machine for a day. The addition of 15 to $40 \%$ MGO to 6 or $9 \mathrm{~mL}$ NeoCryl resulted in an immediate formation of a strong resin. This could be evidence of the MGO cross-linking with the ester functionality. The mixture of NeoCryl with 8 to $13 \%$ MGO showed a formation of a thick copolymer, but it was observed that the mixture polymerised after a week into a cured resin with a separated yellow liquid. Similarly, 5, 6 and 7\% MGO (1 mL with 6 or $9 \mathrm{~mL}$ NeoCryl) polymerised or partially polymerised after two to four weeks from being mixed together. In the coating process, the polymer seemed to crack when NeoCryl was diluted more than 10\%, which means the ratio 6:1 NeoCryl:MGO was not favoured when dried at room temperature. On the other hand, 9:1 NeoCryl:MGO cracked slightly between 3 to $8 \%$ MGO and no cracking was observed using less than 3\% MGO $(1 \mathrm{~mL})$. The drying of the samples at $50{ }^{\circ} \mathrm{C}$ led to a thick yellow-brown layer and this drying process reduced the cracking up to of $8 \%$ MGO with NeoCryl. The MGO concentrations had an effect on the polymer colour where it became slight yellow-brown colour for low MGO and brown at high MGO concentrations (see Figure 4.1). 


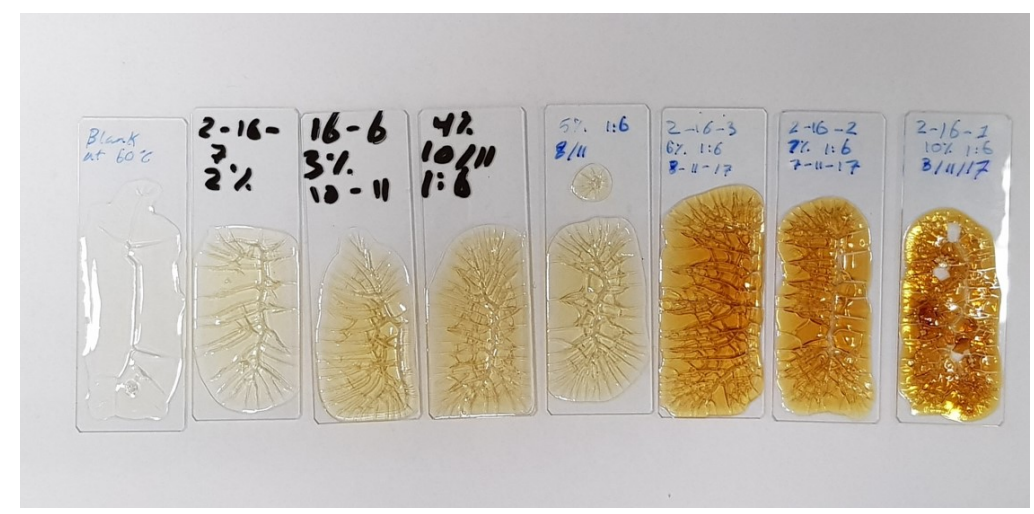

Figure 4.1: The effects of increasing MGO concentrations on the NeoCryl's colour. The colour of NeoCryl changes from colouress, yellowbrown to a brown colour with increasing the amount of MGO.

The concentrating of the MGO level via water removal led to the formation of a thick dried layer of the mixture and less cured resin was formed compared to the addition of MGO solution. However, the high concentrations of MGO in liquid or dried forms resulted in formation of a cured resin. This means that the MGO probably initiates cross-linking with NeoCryl. Low concentrations between 1\%-5\% MGO showed a partial polymerization of the NeoCryl.

Overall, concentrated MGO resulted in a noticeable interaction with NeoCryl, suggesting a cross-linking between the MGO and the polymer. It is important to note that the commercial NeoCryl contains additional composites that might complicate the nature of MGO interaction with PMMA in NeoCryl and then the identification of this interaction.

\subsubsection{Fourier Transform Infrared Spectroscopy (FTIR) Analysis of Methylglyoxal with Poly(methyl methacrylate)}

FT-IR analysis was used for a mixture of NeoCryl and MGO. Drops of the samples were placed onto glass slides and dried at room temperature or $50{ }^{\circ} \mathrm{C}$ for the FTIR characterisation. The FTIR analysis confirmed that the NeoCryl was PMMA. In the FTIR spectra (Figure 4.2), there is a distinct absorption band of the acrylate carboxyl 
group at $1,727 \mathrm{~cm}^{-1}$ and two absorption bands of the $\mathrm{C}-\mathrm{O}-\mathrm{C}$ stretching at 1,148 and $1,238 \mathrm{~cm}^{-1}$. The $\alpha$-methyl vibrations of PMMA can be seen at 750 and $1,385 \mathrm{~cm}^{-1}$. $\mathrm{C}-\mathrm{H}$ bond stretching vibrations of the $\mathrm{CH}_{3}$ and $\mathrm{CH}_{2}$ are seen at 2,956 and 2,934 $\mathrm{cm}^{-1}$ respectively, and a $\mathrm{C}-\mathrm{H}$ bending mode is assigned to a peak at $1,449 \mathrm{~cm}^{-1}$ as shown in Figure $4.2^{116}$.

In a comparison with the FTIR spectra of untreated NeoCryl and treated NeoCryl with $20 \%$ MGO, a few changes in the intensity of polymer absorption peaks between 1,660 and $750 \mathrm{~cm}^{-1}$ region were observed. A distinct increase in the intensity occurred at the PMMA peak intensity and $\mathrm{C}-\mathrm{O}-\mathrm{C}$ of the polymer at 1,064 and $750 \mathrm{~cm}^{-1}$ (for PMMA) and 1,238 and $1,148 \mathrm{~cm}^{-1}(\mathrm{C}-\mathrm{O}-\mathrm{C})$. The $\mathrm{C}-\mathrm{H}$ stretching intensity of $\mathrm{CH}_{3}$ and $\mathrm{CH}_{2}$ were reduced for the 2,956 and 2,934 $\mathrm{cm}^{-1}$ respectively. The FTIR spectra show there is an interaction between the MGO and PMMA, which might lead to cleavage of the ester group or hydrogen bonding with the polymer. However, there is no real evidence to support this mechanism and a further investigation is required. In general, FITR showed there is possibility of crosslinking between the MGO and NeoCryl and this is supported by the DSC analysis. 


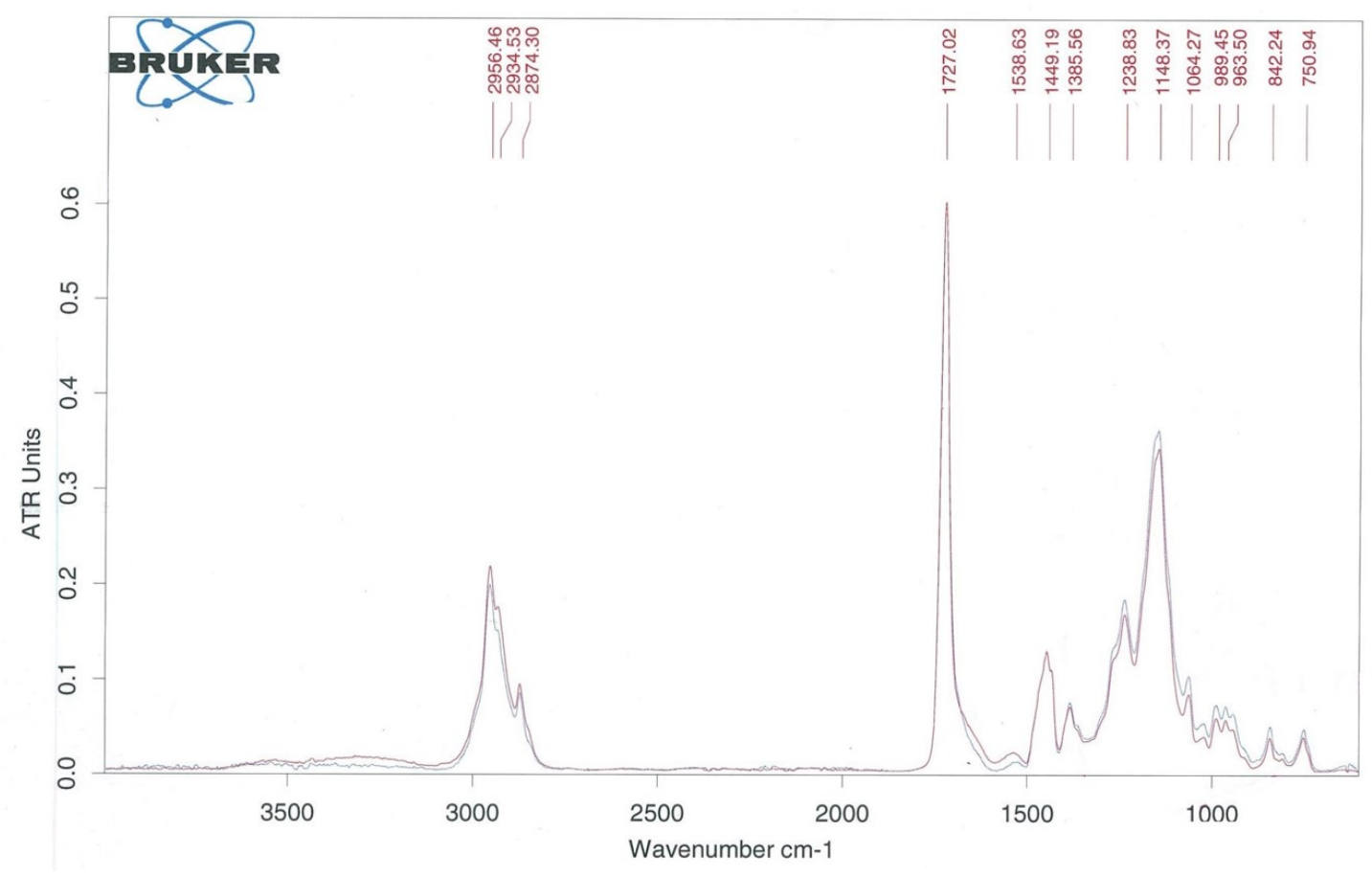

Figure 4.2: The FTIR spectra of NeoCryl ${ }^{\circledR}$ XK-98 (red colour) and treatment $\mathrm{NeoCryl}^{\circledR}$ XK-98 with 20\% MGO (blue colour) at ratio 9:1 NeoCryl:MGO

\subsubsection{Differential Scanning Calorimetry Analysis of NeoCryl ${ }^{\circledR}$ XK- 98 Polymer with Methylglyoxal}

The effect of heating rate on NeoCryl only and Neocryl with MGO was investigated through the DSC using a heating rate of $5{ }^{\circ} \mathrm{C} \min ^{-1}$. The glass transition temperature (Tg) of NeoCryl was $107.1{ }^{\circ} \mathrm{C}$, which was attributed to the Tg of pure PMMA. It was clear that Figure (4.3) the Tg increased, as MGO was added to the matrix, to $108.5^{\circ} \mathrm{C}$. The increase of $\mathrm{Tg}$ value is due to a restriction of the mobility of polymer chains in the cross-linking between MGO and NeoCryl. The addition of MGO to NeoCryl resulted in a greater thermal stability of NeoCryl matrix than for NeoCryl only ${ }^{117}$. Also, the DSC curve of MGO-NeoCryl composite shows a small endothermic peak between 30 and $75{ }^{\circ} \mathrm{C}$ with an onset peak at $70{ }^{\circ} \mathrm{C}$. This peak likely corresponds to some of the MGO evaporation as the MGO boiling point is $71{ }^{\circ} \mathrm{C}$. 
In summary, the DSC analysis confirmed the interaction between MGO and NeoCryl. MGO changed some endothermic transitions associated with NeoCryl resulting in a shift of NeoCryl's Tg peak with a new small peak being observed at $70{ }^{\circ} \mathrm{C}$. These clearly suggest that the MGO most likely interacted with NeoCryl through hydrogen bonding or other means.

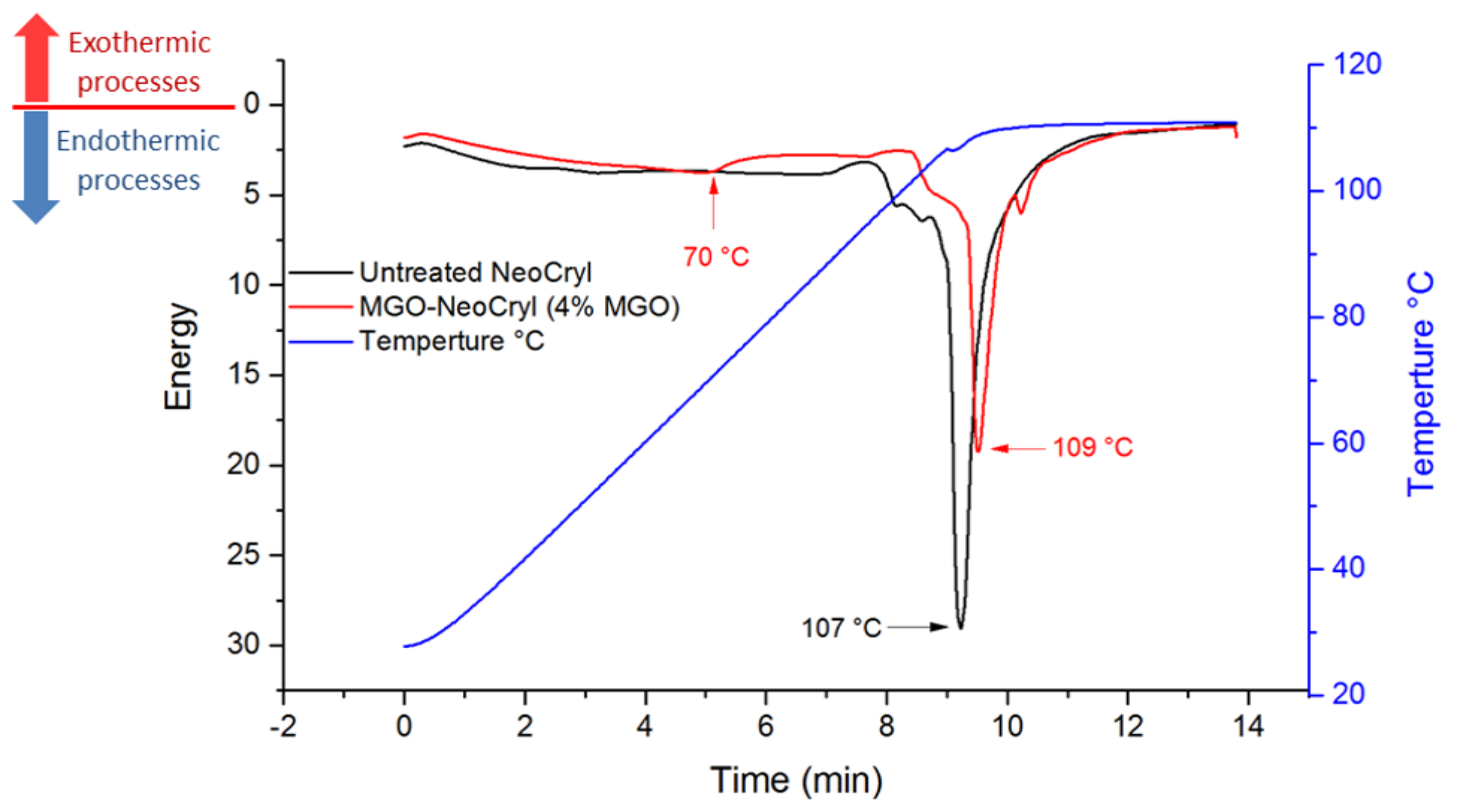

Figure 4.3: DSC curves of (A) non-treated NeoCryl (B) MGO-NeoCryl composites ( $\left.1 \mathrm{~g} \mathrm{~L}^{-1} \mathrm{MGO}\right)$ with holding time at $240{ }^{\circ} \mathrm{C}$ for ten minutes.

\subsubsection{The Contact Angles of NeoCryl ${ }^{\circledR}$ XK-98 with Methylglyoxal}

The contact angle (CA) data of the water on the solid surface of MGO-NeoCryl composites are shown in Table 4.1. The chemical modification of NeoCryl with MGO and then Dynasylan ${ }^{\circledR}$ F8815 altered the the surface energy of NeoCryl. Thus, the CA data of NeoCryl reached $75.6 \pm 5.6$, which was slightly higher than what has been reported in a literature review of PMMA ${ }^{118-120}$. The MGO additions to NeoCryl showed an increase in the CA. this means the MGO modified the properties of NeoCryl and showed an increase in the hydrophobicity of the NeoCryl. The concentrated MGO between 10 to $60 \mathrm{mg}$ with $6 \mathrm{~g}$ PMMA (6 g PMMA in $10 \mathrm{~mL}$ of NeoCryl) increased the CA from $75.6^{\circ}$ to $78.9^{\circ}$ and $83^{\circ}$ at the ratio 0.01:6 and 0.06:6 (g) MGO:NeoCryl respectively. 
However, the addition of $70 \mathrm{mg}$ MGO to NeoCryl showed an increase of $1^{\circ}$ compared to the blank sample. This sample did not have a coherent surface to measure the CA due to cracks on the sample surface after the addition of concentrated MGO at this ratio. Thus there was insufficient evidence of MGO effects on surface hydrophobicity on NeoCryl at this concentration.

Another approach was used to determine the MGO effects on NeoCryl's properties. 1 $\mathrm{mL}$ of $4 \%$ aqueous MGO, in water, was mixed with $10 \mathrm{~mL}$ NeoCryl then treated with Dynasylan ${ }^{\circledR}$ F8815. The aqueous MGO achieved high CA suggesting an effect of the solvent on NeoCryl. Also a higher ratio 0.1:9 (g) MGO:NeoCryl was obtained and the CA was similar to that measured using aqueous MGO with NeoCryl $\left(87.5^{\circ}\right)$.

Overall, it was observed that enhancing the hydrophobic properties of NeoCryl could be achieved by the addition of low concentrations of MGO and then treatment with Dynasylan ${ }^{\circledR}$ F8815. The aqueous MGO addition resulted in a significant modification of the polymer surface. However, the cracks posed an interference to this measurement. Further experiments need to be conducted to minimise the cracking of the polymer, while being dried on glass microscope slide in order to measure the CA of concentrated MGO with NeoCryl.

Table 4.1: The contact angle of NeoCryl and MGO-NeoCryl composites treated with Dynasylan ${ }^{\circledR}$ F8815.

\begin{tabular}{|c|c|c|c|}
\hline Sample name & Ratio & Average CA & Standard Deviation \\
\hline Blank NeoCryl X-98 & - & $75.6^{\circ}$ & $5.6^{\circ}$ \\
\hline NeoCryl with 10 mg MGO & $0.01: 6(\mathrm{~g})$ MGO:NeoCryl & $78.9^{\circ}$ & $4.1^{\circ}$ \\
\hline NeoCryl with 60 mg MGO & $0.06: 6(\mathrm{~g})$ MGO:NeoCryl & $83^{\circ}$ & $4.98^{\circ}$ \\
\hline NeoCryl with 70 mg MGO & $0.07: 6(\mathrm{~g})$ MGO:NeoCryl & $76^{\circ}$ & $5.94^{\circ}$ \\
\hline NeoCryl with 1 ml 4\% MGO & $1: 10(\mathrm{~mL})$ MGO:NeoCryl & $87.9^{\circ}$ & $4.96^{\circ}$ \\
\hline NeoCryl with 100 mg MGO & $0.1: 9(\mathrm{~g})$ MGO:NeoCryl & $87.5^{\circ}$ & $6.6^{\circ}$ \\
\hline
\end{tabular}




\subsubsection{Leaching Test of Methylglyoxal from Methylglyoxal-NeoCryl composites}

It was now important to understand how MGO is likely to bond or cross link with NeoCryl when the mixture is dried or coated. In this leaching study, $1 \mathrm{~mL}$ of either $6 \%$ and $7 \%$ was mixed with $9 \mathrm{~mL}$ NeoCryl as stated before. Then $5 \mathrm{~mL}$ of the mixture was dried on a glass microscope slide at room temperature. It is important to note that the mixtures were dried within a day of adding MGO to the NeoCryl. Then the sample slide was placed into $20 \mathrm{~mL}$ water and placed in hot water bath at $50{ }^{\circ} \mathrm{C}$ for three days. The amounts of MGO in solution were determined by HPLC.

These leaching test confirmed that the amounts of MGO leached out were 0.5 and 0.9 $\mathrm{mg} \mathrm{L}^{-1}$ for the $6 \%$ and $7 \%$ MGO:NeoCryl, respectively. These levels were below the detection limit of HPLC, which means there were negligibly small amounts of MGO has leached from the MGO-NeoCryl. This confirmed the cross linking or hydrogen bond between the NeoCryl and MGO has occurred and bonded the bioactive MGO into the polymer. This is a way that might be used in coating applications to prevent any microbial growth on the polymer surface.

\subsubsection{Antimicrobial Performance of Methylglyoxal-NeoCryl com- posites}

The antimicrobial properties of MGO constitute a promising feature to be incorporated in the NeoCryl polymer. The MGO-Wool composites inhibited the growth of E. coli and S. aureus. Next, it was evaluated whether MGO inhibits antimicrobial effects after being added to NeoCryl. Figure 4.4 shows that the non treated NeoCryl had on average a 2.5 mm zone of inhibition against E. coli, which was likely due to detergents in NeoCryl. Although some of the non treated NeoCryl did not show a zone of inhibition against $S$. aureus (as shown in Figure 4.4 in the top left image), blank NeoCryl had a smaller zone 
of inhibition with S. aureus compared to E. coli.

The addition of aqueous MGO to NeoCryl slightly decreased the size of the zone of inhibition. Figure 4.4, top images, shows that the zone of inhibition's size decreased slightly after adding aqueous MGO when compared to the control sample. The crosslinking of MGO with NeoCryl might limit the MGO diffusion into the agar plat. 3\% and $10 \%$ MGO had an average of 1.5 and $1.1 \mathrm{~mm}$ of zone of inhibition, respectively against $E$. coli but none for S. aureus. However, 5\% MGO inhibited a larger area of approximately $2.8 \mathrm{~mm}$ against $E$. coli and $<1.1 \mathrm{~mm}$ for $S$. aureus. It is important to note here that the concentrated MGO $>6 \%$ undergo phase separation processes, when the mixture was in an aqueous phase during the storage, between an hour to a few days. On the other hand, the MGO separation required a longer period when 5\% MGO was mixed with NeoCryl. This might be associated with the zone of inhibition size and the MGO diffusion into the agar plate.

It can be concluded that the antimicrobial properties of MGO were imparted to the polymer bas,e NeoCryl. The MGO-NeoCryl composites inhibited the growth of both S. aureus and E. coli. The concentrated MGO (0.07 $\mathrm{g}$ and $10 \%)$ showed a smaller zone of inhibition compared to $0.05 \mathrm{~g}$ and $5 \%$ MGO using the Kirby-Bauer test. However, this qualitative method of inhibiting microbial growth cannot be certain in the case of the antimicrobial agent MGO staying affixed to the polymer. Thus, a further study is needed to investigate measuring colony forming units to gain a better understanding of antimicrobial properties of MGO-NeoCryl composites. 

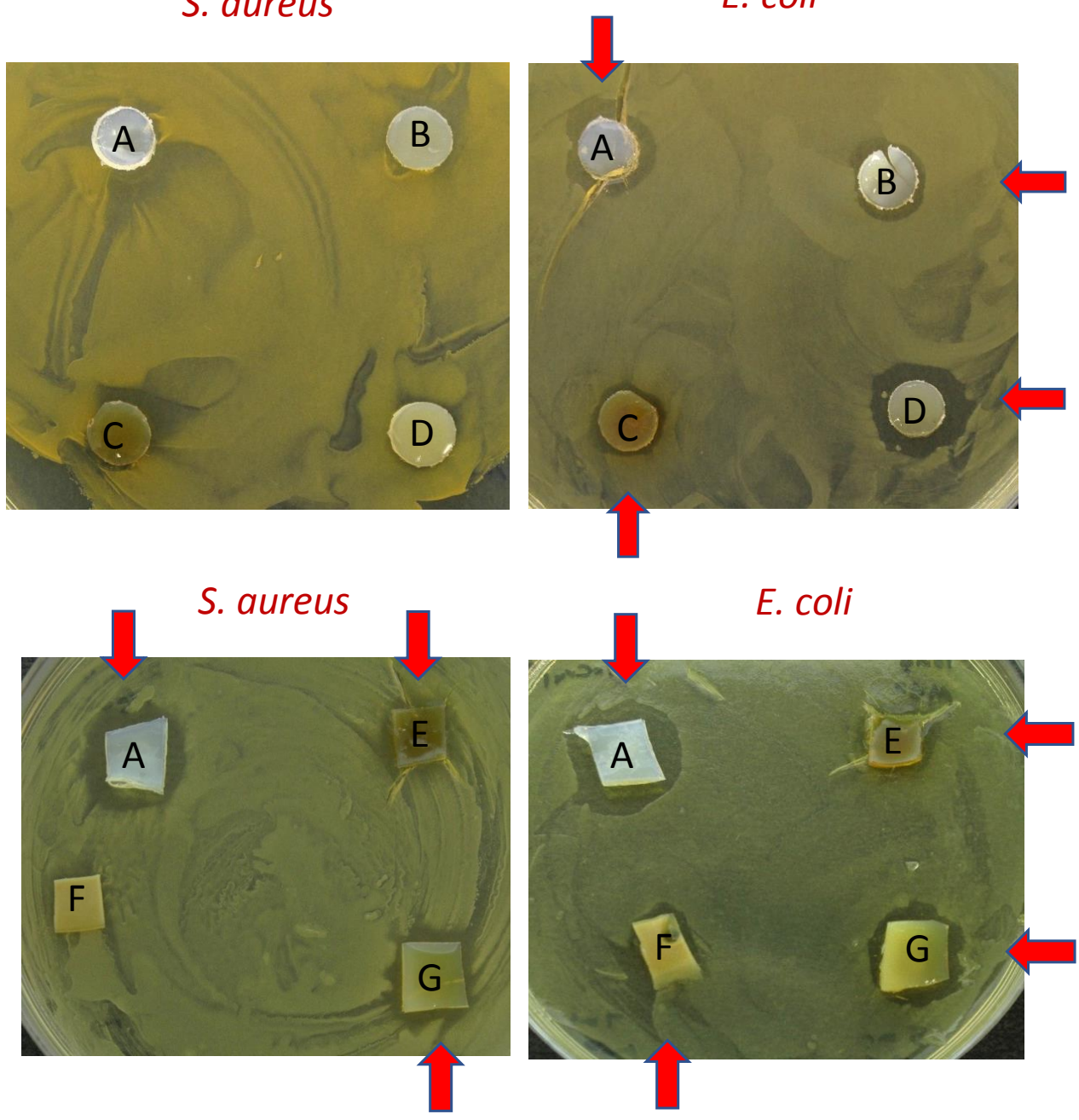

Figure 4.4: NeoCryl $^{\circledR}$ XK-98 with MGO: A) Blank B) 1:10 (mL) 3\% MGO:NeoCryl C) 1:10 (mL) 10\% MGO:NeoCryl D) 1:10 (mL) 5\% MGO:NeoCryl E) 0.1:6 (g) MGO:NeoCryl F) 0.07:6 (g) MGO:NeoCryl G) 0.05:6 (g) MGO:NeoCryl against S.aureus and E.coli. Note: arrows show the zone of inhibition.

\subsection{Kamthane K-5000 (Polyurethane)}

Kamthane K5000(K5000) polyurethane was provided by The Polymer Group Ltd, which is a self-crosslinking, clear, water based and colourless polymer. The functionalisation of K5000 with MGO was achieved using a similar method to that of NeoCryl and MGO. The K5000 showed a slight similarity with the NeoCryl:MGO in terms of forming a 
cured resin after the addition of concentrated MGO liquid. This was found when $8 \%$ MGO or more mixed with K5000. In addition, the use of higher temperatures (up to 60 ${ }^{\circ} \mathrm{C}$ ) led to a thick and uniform coating layer of K5000:MGO on use of the same MGO concentrations that were used with NeoCryl. The MGO is likely to interact with the $\mathrm{N}-\mathrm{H}$ group similarly to the MGO-Wool composites.

\subsubsection{Fourier Transform Infrared Spectroscopy (FTIR) Analysis of Methylglyoxal with Polyurethane}

The FT-IR spectra of untreated K5000 showed polyurethane (PU) characteristic bands. The PU showed two main features of the spectra at 1,728 and $1,160 \mathrm{~cm}^{-1}$, which were identified to be the $\mathrm{C}=\mathrm{O}$ and $\mathrm{C}-\mathrm{O}-\mathrm{C}$ stretching of the $\mathrm{PU}$, respectively. The two absorption bands at 1,537 and $1,236 \mathrm{~cm}^{-1}$ were due to the $\mathrm{C}-\mathrm{N}$ stretching and $\mathrm{N}-\mathrm{H}$ bending vibrations of amide II of the PU. There was a shoulder peak at around 1,670 $\mathrm{cm}^{-1}$ that can be identified as the $\mathrm{C}=\mathrm{O}$ peak of amide $\mathrm{I}$ in an urethane linkage. $\mathrm{C}-\mathrm{H}$ bond stretching peaks are seen between 2,950-2,930 $\mathrm{cm}^{-1}$ and $1,449 \mathrm{~cm}^{-1}$ region ${ }^{121,122}$.

In a comparison of the FTIR spectra of untreated and treated K5000 as shown in Figure 4.5 and Figure 4.6, there are three largest reductions in the intensity of $\mathrm{C}=\mathrm{O}$ at 1,728 $\mathrm{cm}^{-1}, \mathrm{C}-\mathrm{O}-\mathrm{C}$ at $1,160 \mathrm{~cm}^{-1}$ and $\mathrm{C}-\mathrm{H}$ stretching at $1,449 \mathrm{~cm}^{-1}$. In addition, there is a slight decrease of the intensity and shifting of the position of $\mathrm{N}-\mathrm{H}$ bending and $\mathrm{C}-\mathrm{N}$ stretching between 1,536 and $1,236 \mathrm{~cm}^{-1}$. There is a prominent absorption peak at $3,440 \mathrm{~cm}^{-1}$ after the treatment of $\mathrm{K} 5000$ with $\mathrm{MGO}$, which is either another $\mathrm{N}-\mathrm{H}$ stretching vibrational peak or a new $\mathrm{O}-\mathrm{H}$ stretching peak after the MGO addition. 

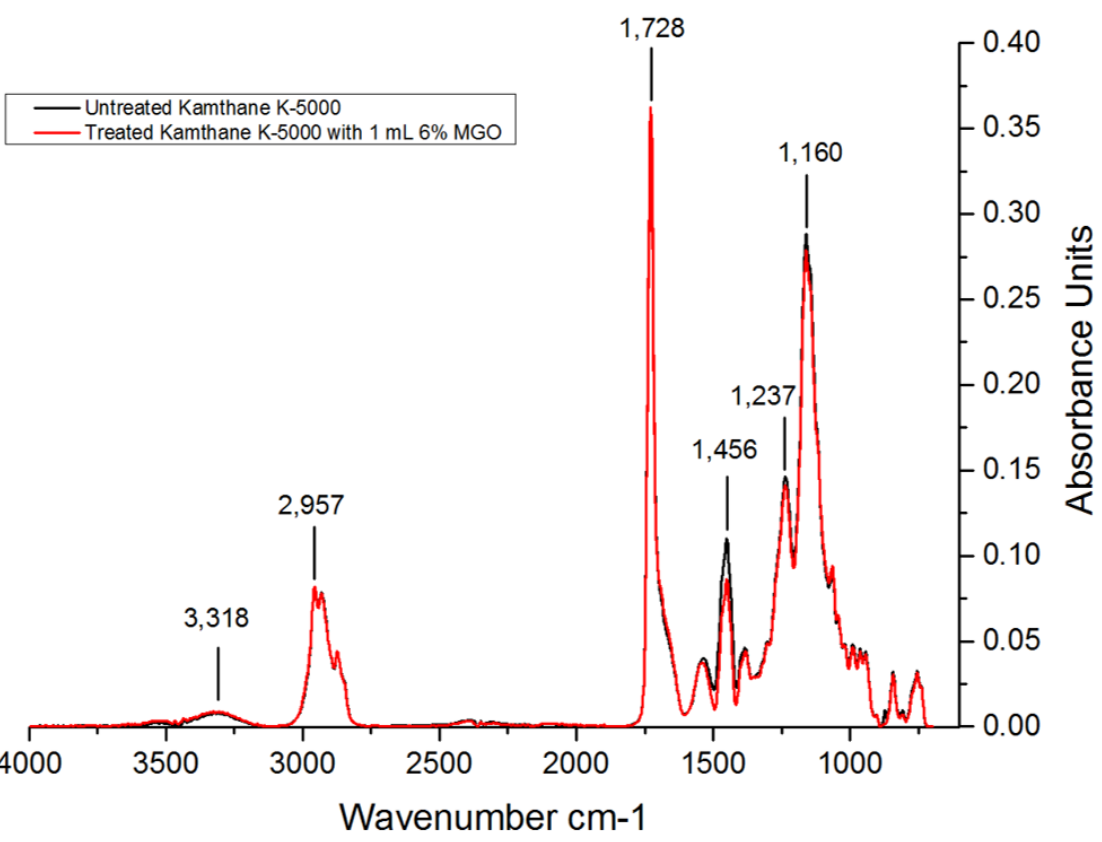

Figure 4.5: The FTIR spectra of untreated Kamthane K-5000 (black colour line) and treatment Kamthane K-5000 with 6\% MGO (red colour line) at a ratio of 9:1 Kamthane:MGO

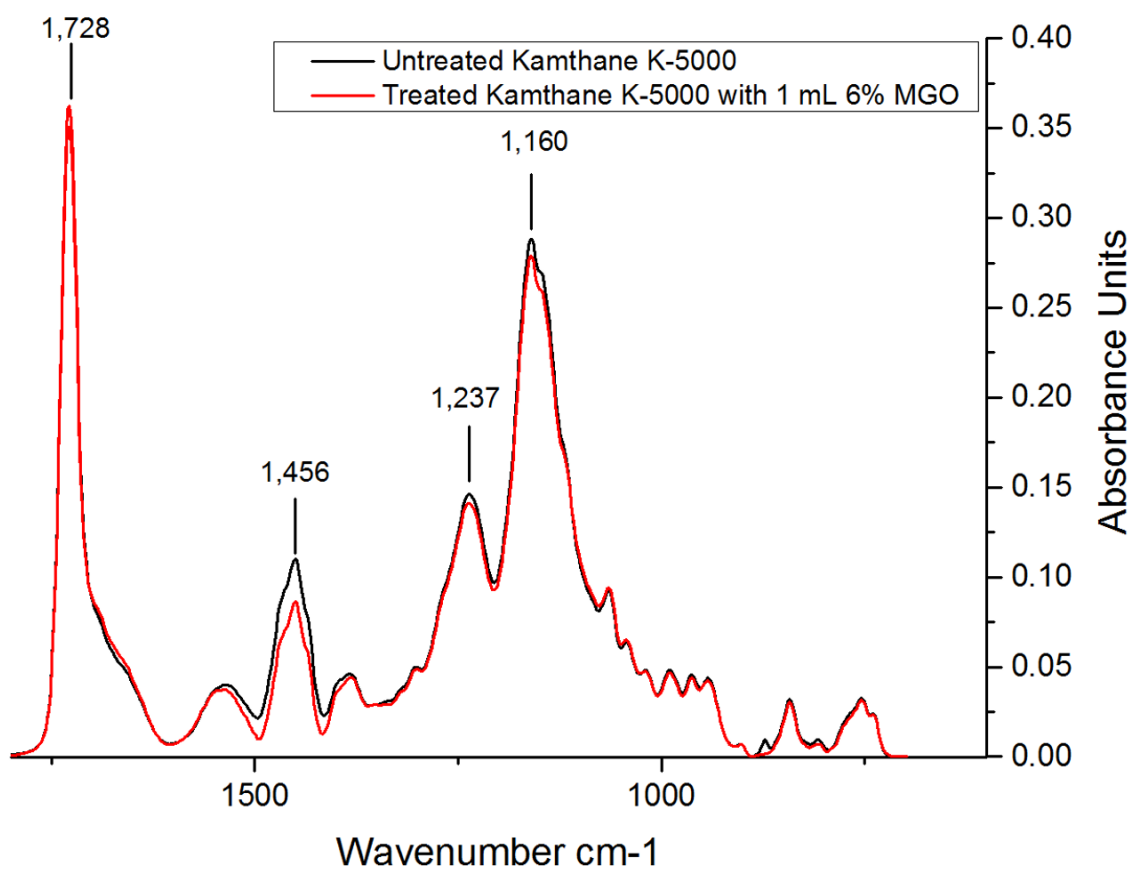

Figure 4.6: Zoomed FTIR spectra of untreated Kamthane K-5000 (black colour line) and treatment Kamthane K-5000 with 6\% MGO (red colour line) at ratio 9:1 Kamthane:MGO 


\subsubsection{Differential Scanning Calorimetry Analysis of Kamthane K- 5000 polymer with Methylglyoxal}

The DSC curves of Kamthane polyurethane with water and MGO are shown in Figure 4.7. The Kamthane was blended with water to determine the effect of being in a similar environment to MGO. There are two temperature stages in each DSC curve. The Kamthane with water showed an endothermic peak region 1 between $30-100{ }^{\circ} \mathrm{C}$ with an onset at $63{ }^{\circ} \mathrm{C}$. The DSC of Kamthane with water demonstrates a strong endothermic peak at $107.5^{\circ} \mathrm{C}$, which might correspond to the water evaporating from the PU polymer chains. The introduction of MGO into the polymer resulted in a decrease in the endothermic peaks, which is probably due to cross-linking or hydrogen bonding of MGO. However, there is no a distinct shift or a new peak compared to what was observed in the MGO-Wool and MGO-NeoCryl samples previously.

Overall, the DSC curves showed that incorporating MGO with Kamthane resulted in an interaction between the MGO and Kamthane. This interaction changed the endothermic transitions in Kamthane slightly. It suggests that the MGO might form a hydrogen bond with Kamthane. This confirmed the observation of a cured resin being formed after the addition of the highly concentrated MGO as showen by FT-IR and DSC results.

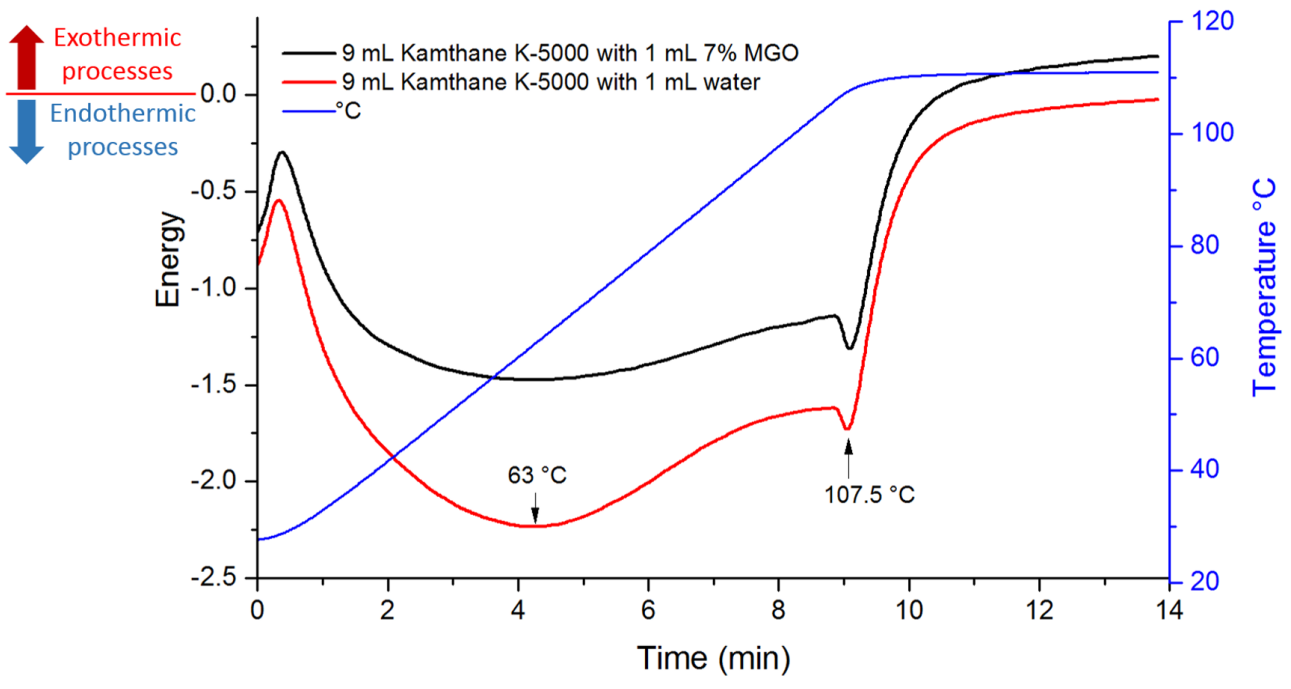

Figure 4.7: The DSC analysis of $9 \mathrm{~mL}$ Kamthane with $1 \mathrm{~mL}$ water (red curve) and $9 \mathrm{~mL}$ Kamthane with $1 \mathrm{~mL} 6 \%$ MGO (black curve). 


\subsubsection{Antimicrobial Performance of Methylglyoxal-Kamthane Com- posites}

MGO was found to exhibit antimicrobial properties in testing the MGO-Wool and MGO-NeoCryl composites, so it was of interest to determine its antimicrobial activity in Kamthane. The zone of inhibition test is shown in Figure 4.8. The blank Kamthane (A) showed no zone of inhibition against either S. aureus and E. coli, but a moist appearance (cloudiness) and slight bacterial growth on the blank sample were observed. Various concentrations of MGO were incorporated into the Kamthane to test their antimicrobial performance (no MGO solution with Kamthane was tested for their antimicrobial properties). The sample (B) 0.05:9 g MGO:Kamthane showed no zone of inhibition for $S$. aureus and E. coli, but the sample showed bacteriostatic properties against E. coli. The sample (C) 0.03:9 g MGO:Kamthane similarly with the sample (B) had bacteriostatic surface against $E$. coli, but a moist appearance and slight bacterial growth were observed against $S$. aureus. The low MGO concentration (sample (D)) had a slight growth inhibition against $E$. coli and there was no effect of MGO was observed against S. aureus.

S. aureus

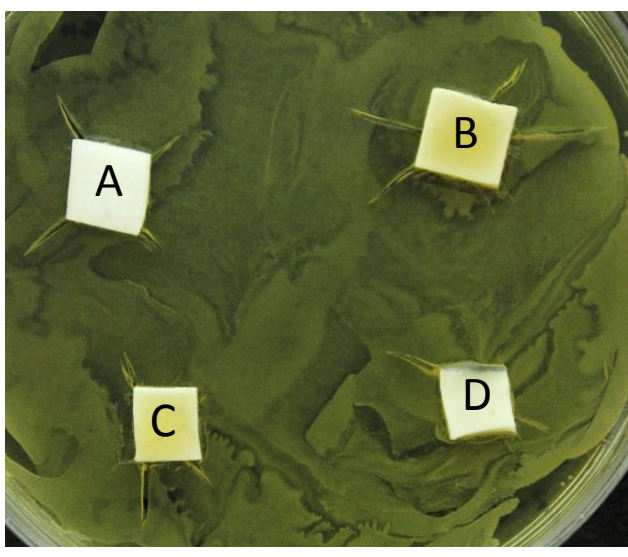

E. coli

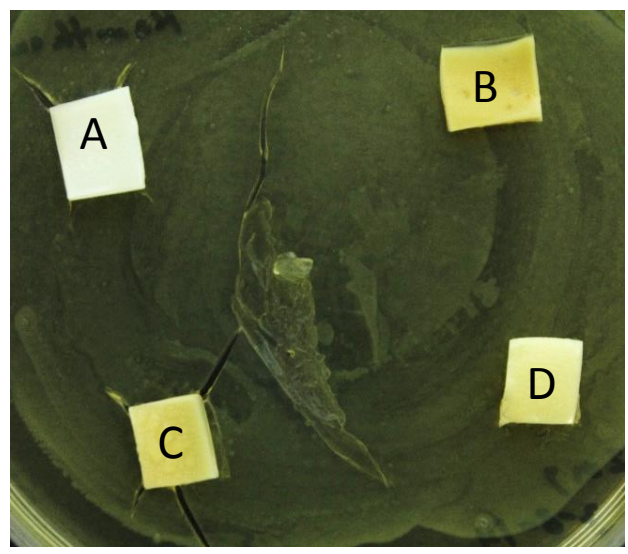

Figure 4.8: The zone of inhibition test of blank Kamthane and MGOKamthane (A) Blank Kamthane (B) 0.05:9 (g) MGO:Kamthane (C) 0.03:9 (g) MGO:Kamthane (D) 0.02:9 (g) MGO:Kamthane. 
It can be reasonably concluded that the MGO at these concentrations inhibited slight antimicrobial efficiency against $E$. coli and bacteriostatic properties against both $E$. coli and $S$. aureus. However, this performance was not very significant. This low level of antimicrobial efficiency could be due to the MGO being captured within the polymer matrix during the curing and hydrogen bonding with the Kamthane. Also, MGO could react with amide groups in the Kamthane. Thus the MGO might not diffuse from the MGO:Kamthane composites freely into the agar and display antimicrobial properties. Also, it is important to investigate two aspects: blending higher MGO concentrations with the Kamthane for antimicrobial testing and determining a colony forming unit assay for the antimicrobial test.

\subsection{Future Work}

This study showed that MGO imparted a low level of antimicrobial activity to the polymers. The characterization techniques showed an interaction between the MGO and polymers possibly through hydrogen bonding or formation of a new bond. However, the exact mechanism of this interaction needs to be confirmed using pure PMMA and polyurethane. Although the antimicrobial test showed a small positive result, more investigation is needed. It is suggested that the microbial colony counting method could provide quantitative antimicrobial efficiency results for the MGO activity in the polymers. 


\section{Chapter 5}

\section{Conclusion}

This thesis has been concerned with the incorporation and use of $\mathrm{MH}$ and MGO into wool textiles and polymers and an assessment of the antimicrobial properties of the resulting composites.

\subsection{The Uptake of Manuka Honey and Methylglyoxal by the Wool}

The innovative development of MGO-Wool and $\mathrm{MH}$-Wool composites has been successfully achieved. This methodology focused on incorporating MGO in the forms of both $\mathrm{MH}$ and isolated synthetic compound into wool fibres and chemically bonding it to the wool fibres. This approach determined the extent of uptake of $\mathrm{MH}$, based on its MGO concentrations, and MGO into wool fibres. The MH and MGO uptake was quantitatively analysed by HPLC post derivatisation with OPD using a modified method designed by Weigel et $\mathrm{al}^{63}$. This uptake studied the MGO absorption by different forms of wool over a range of $\mathrm{MH}$ and MGO concentrations and temperatures. The loose top wool absorbed a slightly higher amount of MGO compared to other forms due to the 
more accessible surface of the wool. An increase of the temperature from room temperature to $80{ }^{\circ} \mathrm{C}$ resulted in a significant increase in the amount of MGO absorbed by the wool. This effect was seen clearly between 50 and $80{ }^{\circ} \mathrm{C}$, but a larger amount of MGO absorbed at $70{ }^{\circ} \mathrm{C}$. A larger amount of MGO was oxidised by $15 \%$ after exceeding the boiling point during the uptake at $80{ }^{\circ} \mathrm{C}$. Also, higher concentrations of the initial MGO and $\mathrm{MH}$ solution increased the diffusion rate of MGO into the wool and hence the uptake amount. The relatively slow diffusion rate of MGO into the wool required a long period of time, up to 14 days, for the particular uptake to generally reach the saturation level. A higher MGO uptake resulted consistently in significant colour changes to the wool from light to dark brown. This was another indication of the amount of MGO diffused into the wool. The MH and MGO uptake clearly depended on the temperature and initial concentrations, which acted as a driving force on the MGO diffusion into the wool leading to larger amount of MGO absorption. The maximum amount of $\mathrm{MH}$ and MGO that were incorporated into the wool were $21.2 \mathrm{mg} \mathrm{g}^{-1}$ and $299 \mathrm{mg} \mathrm{g}^{-1}$ respectively.

\subsubsection{The Characterisation Techniques of MGO-Wool and MH-Wool}

The chemical interaction between MGO and the wool in MGO-Wool composites was characterised by FT-IR, DSC and TGA. The FT-IR spectra of MGO-Wool composites showed that the MGO changed the absorption peaks of wool. In particular, MGO changed the intensity of the absorption bands of Amide I, Amide II and Amide III of the wool proteins between $2,000 \mathrm{~cm}^{-1}$ and $700 \mathrm{~cm}^{-1}$ and $\mathrm{NH}$ stretching at $3,270 \mathrm{~cm}^{-1}$. The TGA and DSC analyses showed the thermal stability of the wool including less break down of the $\alpha$-keratin after the MGO absorption. This thermal behaviour is likely due to the formation of a new, probably a hydrogen, bond between the MGO and the wool. Confirming these results, the MGO-Wool and MH-Wool showed an excellent durability against leaching in water, where less than $1 \%$ of MGO that was absorbed, leached out. These all suggest that the MGO is chemically bound to the wool fibres. The CA 
measurement showed that MGO slightly increased the hydrophobicity of the wool and that there was evidence of a trend.

\subsubsection{The Antimicrobial Properties of Coated MGO Samples}

The coated MGO samples were tested against Gram-positive S. aureus and Gramnegative E. coli bacteria at a range of MGO concentrations. The physical coating of a paper sheet with MGO exhibited a significant zone of inhibition against $S$. aureus and E. coli. However, it was observed that washing the samples produced in this treatment resulted in a reduction of the zone of inhibition. It clearly suggested that the MGO is weakly absorbed by the paper sheet in this methodology. On the other hand, the MGOWool composites used in this uptake study were tested against the same bacteria. The MGO-Wool composites exhibited a significant zone of inhibition. Also, all MGO-Wool composites showed bacteriostatic properties even after three months of being synthesised. This approach confirmed that the MGO was successfully incorporated into the wool fibres and had a strong chemical bond between the MGO and the wool. This suggests potential applications in the use of MH and MGO in antimicrobial woollen apparel, medical textiles and bandages.

\subsection{Methylglyoxal with Polymeric Materials}

The MGO was also incorporated into samples of NeoCryl ${ }^{\circledR}$ XK-98 and Kamthane K5000 polymer resins. This approach investigated the addition of various concentrations of MGO at different ratios of the polymers. It was observed that the addition of between $15 \%$ and $40 \%$ MGO formed a set polymer, indicating a high cross-linking. However, between $14 \%$ and $6 \%$ MGO resulted in less polymerisation, but a cured resin was found a few days after the MGO addition. 5\% MGO or less showed that less polymerisation was taken place. 


\subsubsection{The Characterisation Techniques of MGO-Polymer}

The interaction of MGO with these polymers resulted in a similar hydrogen bonding between MGO and the polymers. The FT-IR and DSC showed that hydrogen bonding was confirmed at high MGO concentrations by the the presence of a new endothermic transition peak in the DSC. Also, the MGO-Polymer showed a resistance to MGO leaching, suggesting the formation of a strong bond. The CA measurement showed that MGO modified the polymer surface and formed a higher hydrophobic surface with an increased water droplet CA of $87.5^{\circ}$.

\subsubsection{The Antimicrobial Properties of Methylglyoxal with Polymeric Materials}

The MGO-Polymer composites were successfully tested against Gram-positive $S$. aureus and Gram-negative E. coli. The new polymer composites were shown to exhibit antimicrobial properties. 


\section{Bibliography}

1. Harvey, A. Drug Discovery Today 2000, 5, 294-300.

2. Harvey, A. L. Drug Discovery Today 2008, 13, 894-901.

3. Butler, M. S. Natural Product Reports 2008, 25, 475.

4. Koehn, F. E.; Carter, G. T. Nature Reviews Drug Discovery 2005, 4, 206-220.

5. Bhatnagar, I.; Kim, S. K. Marine Drugs 2010, 8, 2673-2701.

6. Hayek, S. A.; Gyawali, R.; Ibrahim, S. A. Formatex.Info 2013, 910-921.

7. Salim, A.; Chin, Y.; Kinghorn, A. Bioactive Molecules and Medicinal Plants 2008, 1-25.

8. Jones, A. W. Drug Testing and Analysis 2011, 3, 337-344.

9. Sneader, W. Drug Discovery: A History; 2006; pp 1-468.

10. Eteraf-Oskouei, T.; Najafi, M. Iranian Journal of Basic Medical Sciences 2013, $16,731-742$.

11. Siddiqui, A. A.; Iram, F.; Siddiqui, S.; Sahu, K. International Journal of Drug Development and Research 2014, 6, 172-204.

12. Alvarez-Suarez, J. M. Bee Products - Chemical and Biological Properties; 2017; pp 1-306.

13. Aminov, R. Biochemical Pharmacology 2017, 133, 4-19.

14. Genilloud, O., Vicente, F., Eds. Drug Discovery from Natural Products; RSC Drug Discovery; The Royal Society of Chemistry, 2012; pp FP001-416.

15. Calcagno, C.; Lobatto, M. E.; Robson, P. M.; Millon, A. Diagn Microbiol Infect Dis. 2016, 28, 1304-1314.

16. Moloney, M. G. Trends in Pharmacological Sciences 2016, 37, 689-701.

17. Ajikumar, P. K.; Xiao, W. H.; Tyo, K. E.; Wang, Y.; Simeon, F.; Leonard, E.; Mucha, O.; Phon, T. H.; Pfeifer, B.; Stephanopoulos, G. Science 2010, 330, 7074.

18. Takahashi, T.; Tsukamoto, H.; Yamada, H. Bioorganic and Medicinal Chemistry Letters 1998, 8, 113-116. 
19. Wani, M. C.; Taylor, H. L.; Wall, M. E.; Coggon, P.; Mcphail, A. T. Journal of the American Chemical Society 1971, 93, 2325-2327.

20. Guénard, D.; Guéritte-Voegelein, F.; Potier, P. Accounts of Chemical Research 1993, 26, 160-167.

21. Chavan, S. P.; Chavan, P. N.; Khairnar, L. B. RSC Adv. 2014, 4, 11417-11419.

22. Bailey, C. J.; Day, C. Practical Diabetes International 2004, 21, 115-117.

23. Compean, K. L.; Ynalvez, R. A. Research Journal of Medicinal Plant 2014, 8, 204-213.

24. Cowan, M. M. Clinical microbiology reviews 1999, 12, 564-82.

25. Bahar, A. A.; Ren, D. Pharmaceuticals 2013, 6, 1543-1575.

26. Wright, G. D. Advanced Drug Delivery Reviews 2005, 57, 1451-1470.

27. Moore, B. S.; Carter, G. T.; Brönstrup, M. Nat. Prod. Rep. 2017, 34, 685-686.

28. Da Silva, P. M.; Gauche, C.; Gonzaga, L. V.; Costa, A. C. O.; Fett, R. Food Chemistry 2016, 196, 309-323.

29. Elijah,; Imohiosen, O.; Lamidi,; Umar, International Journal of Pharmaceutical Science Invention ISSN (Online 2015, 4, 2319-6718.

30. Molan, P. C. Bee World 1992, 73, 5-28.

31. Singh, V.; Pal, U.; Singh, R.; Soni, N. National Journal of Maxillofacial Surgery 2014, 5, 31 .

32. Sackett, W. G. The agricultural Experiment Station of the Colorado Agricultural College 1919, 1-18.

33. Ayesha, F.; Ayesha, N.; Dsouza, M. Journal of Chemical and Pharmaceutical Research 2016, 8, 1027-1034.

34. Meda, A.; Lamien, C. E.; Romito, M.; Millogo, J.; Nacoulma, O. G. Food Chemistry 2005, 91, 571-577.

35. Ciulu, M.; Solinas, S.; Floris, I.; Panzanelli, A.; Pilo, M. I.; Piu, P. C.; Spano, N.; Sanna, G. Talanta 2011, 83, 924-929.

36. Quideau, S. Angewandte Chemie International Edition; 2006; Vol. 45; pp 67866787.

37. Pía, M.; Barra, G.; Ponce-Díaz, M. C.; Venegas-Gallegos, C. Chilean Journal of Agricultural Research 2010, 70, 75-84.

38. Manyi-Loh, C. E.; Ndip, R. N.; Clarke, A. M. International Journal of Molecular Sciences 2011, 12, 9514-9532.

39. Grainger, M. N. C.; Manley-harris, M.; Lane, J. R.; Field, R. J. Food Chemistry 2016, 202, 500-506. 
40. Mato, I.; Huidobro, J. F.; Simal-Lozano, J.; Sancho, M. T. Journal of Agricultural and Food Chemistry 2006, 54, 1541-1550.

41. Bang, L. M.; Buntting, C.; Molan, P. Journal of Alternative \& Complementary Medicine 2003, 9, 267-273.

42. Beretta, G.; Granata, P.; Ferrero, M.; Orioli, M.; Facino, R. M. Analytica Chimica Acta 2005, 533, 185-191.

43. Kishore, R. K.; Halim, A. S.; Syazana, M. S.; Sirajudeen, K. N. Nutrition Research 2011, 31, 322-325.

44. Chua, L. S.; Rahaman, N. L. A.; Adnan, N. A.; Eddie Tan, T. T. Journal of Analytical Methods in Chemistry 2013, 2013.

45. Rao, P. V.; Krishnan, K. T.; Salleh, N.; Gan, S. H. Brazilian Journal of Pharmacognosy 2016, 26, 657-664.

46. Ahmed, S.; Sulaiman, S. A.; Baig, A. A.; Ibrahim, M.; Liaqat, S.; Fatima, S.; Jabeen, S.; Shamim, N.; Othman, N. H. 2018,

47. Schramm, D. D.; Karim, M.; Schrader, H. R.; Holt, R. R.; Cardetti, M.; Keen, C. L. Journal of Agricultural and Food Chemistry 2003, 51, 1732-1735.

48. Roshan, N.; Rippers, T.; Locher, C.; Hammer, K. A. Archives of Microbiology 2017, 199, 347-355.

49. G Vallianou, N. General Medicine: Open Access 2014, 02.

50. Adams, C. J.; Boult, C. H.; Deadman, B. J.; Farr, J. M.; Grainger, M. N.; ManleyHarris, M.; Snow, M. J. Carbohydrate Research 2008, 343, 651-659.

51. Donarski, J. A.; Roberts, D. P. T.; Charlton, A. J. Analytical Methods 2010, 2, 1479.

52. Russell, K. M.; Molan, P. C.; Wilkins, A. L.; Holland, P. T. Journal of Agricultural and Food Chemistry 1990, 38, 10-13.

53. Mavric, E.; Wittmann, S.; Barth, G.; Henle, T. Molecular Nutrition and Food Research 2008, 52, 483-489.

54. Adams, C. J.; Manley-Harris, M.; Molan, P. C. Carbohydrate Research 2009, 344, $1050-1053$.

55. Packer, J. M.; Irish, J.; Herbert, B. R.; Hill, C.; Padula, M.; Blair, S. E.; Carter, D. A.; Harry, E. J. International Journal of Antimicrobial Agents 2012, $40,43-50$.

56. Cooper, R. A.; Molan, P. C.; Harding, K. G. Journal of the Royal Society of Medicine 1999, 92, 283-285.

57. Kwakman, P. H.; Zaat, S. A. IUBMB Life 2012, 64, 48-55. 
58. Bang, L. M.; Buntting, C.; Molan, P. Journal of Alternative \& Complementary Medicine 2003, 9, 267-273.

59. Brudzynski, K.; Abubaker, K.; St-Martin, L.; Castle, A. Frontiers in Microbiology 2011, 2, 1-9.

60. Casteels-Josson, K.; Zhang, W.; Capaci, T.; Casteels, P.; Tempst, P. Journal of Biological Chemistry 1994, 269, 28569-28575.

61. Lusby, P. E.; Coombes, A.; Wilkinson, J. M. Journal of wound, ostomy, and continence nursing : official publication of The Wound, Ostomy and Continence Nurses Society / WOCN 2002, 29, 295-300.

62. Mandal, M. D.; Mandal, S. Asian Pacific Journal of Tropical Biomedicine 2011, $1,154-160$.

63. Weigel, K. U.; Opitz, T.; Henle, T. European Food Research and Technology 2004, 218, 147-151.

64. Wren, S. N.; Gordon, B. P.; Valley, N. A.; McWilliams, L. E.; Richmond, G. L. Journal of Physical Chemistry A 2015, 119, 6391-6403.

65. Nemet, I.; Vikić-Topić, D.; Varga-Defterdarović, L. Bioorganic Chemistry 2004, $32,560-570$.

66. Molan, P. Wound Practice and Research 2011, 19, 204-220.

67. Tang, B.; Wang, J.; Xu, S.; Afrin, T.; Xu, W.; Sun, L.; Wang, X. Journal of Colloid and Interface Science 2011, 356, 513-518.

68. Wang, Q.; Fan, X.; Hu, Y.; Yuan, J.; Cui, L.; Wang, P. Bioprocess and Biosystems Engineering 2009, 32, 633-639.

69. Gao, Y.; Cranston, R. Textile Research Journal 2008, 78, 60-72.

70. Simoncic, B.; Tomsic, B. Textile Research Journal 2010, 80, 1721-1737.

71. Yuan Gao,; Cranston, R. Textile Research Journal 2008, 78, 60-72.

72. Wang, T.; Zhu, X.-K.; Xue, X.-T.; Wu, D.-Y. Carbohydrate Polymers 2012, 88, $75-83$.

73. S.H., A.-F.; E.M., E.-K. 2012, 16, 42-48.

74. Kelly, F. M.; Johnston, J. H. ACS Applied Materials and Interfaces 2011, 3, 10831092.

75. Moore, O. A.; Smith, L. A.; Campbell, F.; Seers, K.; McQuay, H. J.; Moore, R. A. BMC Complementary and Alternative Medicine 2001, 1 .

76. Molan, P. C. Bee World 1992, 73, 59-76.

77. Molan, P.; Rhodes, T. Wounds : a compendium of clinical research and practice 2015, 27, 141. 
78. Madhumathi, K.; Sudheesh Kumar, P. T.; Abhilash, S.; Sreeja, V.; Tamura, H.; Manzoor, K.; Nair, S. V.; Jayakumar, R. Journal of Materials Science: Materials in Medicine 2010, 21, 807-813.

79. Krishna, K. A.; Pawan, A. R.; Babu, B. N.; Gorantla, N. 2015, 4, 38-42.

80. Bulman, S. E.; Goswami, P.; Tronci, G.; Russell, S. J.; Carr, C. Journal of Biomaterials Applications 2015, 29, 1193-1200.

81. Ghosh, S.; Chakraborty, P.; Chakrabarti, A.; Ghosh, M.; Mandal, A.; Saha, P.; Mukherjee, A.; Acharya, S.; Ray, M. RSC Adv. 2016, 6, 6631-6642.

82. Bulman, S. E. L.; Tronci, G.; Goswami, P.; Carr, C.; Russell, S. J. Materials 2017, 10,954 .

83. Oksman, K.; Skrifvars, M.; Selin, J. F. Composites Science and Technology 2003, $63,1317-1324$.

84. Eisenbau Krämer, European Ail \& Gas 2008, 115-117.

85. Simpson, W. S.; Crawshaw, G. H.; Textile Institute (Manchester, E. Wool : science and technology; CRC Press, 2002; p 368.

86. Zahn, H.; Wortmann, F.-J.; Höcker, H. Chemie in Unserer Zeit 1997, 31, 280-290.

87. Leon, N. H. Journal of the Society of Cosmetic Chemists 1972, 23, 427-445.

88. Wortmann, F. J.; Phan, K. H. Textile Research Journal 1999, 69, 139-144.

89. Lewis, D. M. D. M.; ; Colourists, S. o. D. Wool dyeing / edited by D.M. Lewis.; Bradford, West Yorkshire : Society of Dyers and Colourists: Bradford, West Yorkshire, 1992.

90. Mercer, E. H.; Golden, R. L.; Jeffries, E. B. Textile Research Journal 1954, 24, 615-618.

91. Ehrenstein, G. W. In Polymeric materials : structure, properties, applications / Gottfried W. Ehrenstein; Theriault, R. P., Ed.; Munich : Hanser ; Cincinnati, OH : Hanser Gardner Publications: Munich : Cincinnati, OH, 2001.

92. Xu, X.; He, L.; Zhu, B.; Li, J.; Li, J. Polym. Chem. 2017, 8, 807-823.

93. Carraher, C. Polymer Chemistry 2003, 850.

94. Radheshkumar, C.; Münstedt, H. Materials Letters 2005, 59, 1949-1953.

95. Muñoz-Bonilla, A.; Fernández-García, M. Progress in Polymer Science (Oxford) 2012, 37, 281-339.

96. Tanaka, T.; Yokoyama, T. Polymer 1968, 6, 2137-2152.

97. Brunette, C. M.; Hsu, S. L.; MacKnight, W. J. Macromolecules 1982, 15, 71-77.

98. Mattia, J.; Painter, P. Macromolecules 2007, 40, 1546-1554. 
99. Wong, C. S.; Badri, K. H. Materials Sciences and Applications 2012, 03, 78-86.

100. Stalder, A. F.; Kulik, G.; Sage, D.; Barbieri, L.; Hoffmann, P. Colloids and Surfaces A: Physicochemical and Engineering Aspects 2006, 286, 92-103.

101. Stalder, A. F.; Melchior, T.; Müller, M.; Sage, D.; Blu, T.; Unser, M. Colloids and Surfaces A: Physicochemical and Engineering Aspects 2010, 364, 72-81.

102. Axson, J. L.; Takahashi, K.; De Haan, D. O.; Vaida, V. Proceedings of the National Academy of Sciences 2010, 107, 6687-6692.

103. Loeffler, K. W.; Koehler, C. A.; Paul, N. M.; De Haan, D. O. Environmental Science and Technology 2006, 40, 6318-6323.

104. Zhou, S.; Barnes, I.; Zhu, T.; Bejan, J.; Albu, M.; Benter, T. Environmental Science \& Technology 2008, 42, 7905-7910.

105. Plath, K. L.; Takahashi, K.; Skodje, R. T.; Vaida, V. Journal of Physical Chemistry A 2009, 113, 7294-7303.

106. Profeta, L. T.; Sams, R. L.; Johnson, T. J.; Williams, S. D. Journal of Physical Chemistry A 2011, 115, 9886-9900.

107. Tonin, C.; Zoccola, M.; Aluigi, A.; Varesano, A.; Montarsolo, A.; Vineis, C.; Zimbardi, F. Biomacromolecules 2006, 7, 3499-3504.

108. Hassan, M. M.; Schiermeister, L.; Staiger, M. P. RSC Adv. 2015, 5, 55353-55362.

109. Ranjbar-Mohammadi, M.; Arami, M.; Bahrami, H.; Mazaheri, F.; Mahmoodi, N. M. Colloids and Surfaces B: Biointerfaces 2010, 76, 397-403.

110. Hsieh, S. H.; Huang, Z. K.; Huang, Z. Z.; Tseng, Z. S. Journal of Applied Polymer Science 2004, 94, 1999-2007.

111. Zargarkazemi, A.; Sadeghi-Kiakhani, M.; Arami, M.; Bahrami, S. H. Journal of the Textile Institute 2015, 106, 80-89.

112. Martí, M.; Ramírez, R.; Manich, A. M.; Coderch, L.; Parra, J. L. Journal of Applied Polymer Science 2007, 104, 545-551.

113. Talukdar, D.; Chaudhuri, B. S.; Ray, M.; Ray, S. Biochemistry (Moscow) 2009, 74, 1059-1069.

114. Sherlock, O.; Dolan, A.; Athman, R.; Power, A.; Gethin, G.; Cowman, S.; Humphreys, H. BMC Complement Altern Med 2010, 10, 47.

115. Rabie, E.; Serem, J. C.; Oberholzer, H. M.; Gaspar, A. R. M.; Bester, M. J. Ultrastructural Pathology 2016, 40, 107-111.

116. Duan, G.; Zhang, C.; Li, A.; Yang, X.; Lu, L.; Wang, X. Nanoscale Research Letters 2008, 3, 118-122.

117. Agarwal, S.; Saraswat, V. Material Science Research India 2014, 11, 168-172. 
118. Briggs, D.; Hearn, M. J.; Chan, H.; McBriar, D. I.; Munro, H. S. Langmuir 1990, $6,420-424$.

119. Ma, Y.; Cao, X.; Feng, X.; Ma, Y.; Zou, H. Polymer 2007, 48, 7455-7460.

120. Kwok, D. Y.; Leung, a.; Li, a.; Lam, C. N. C.; Wu, R.; Neumann, a. W. Colloid \& Polymer Science 1998, 276, 459-469.

121. Charpentier, P. A.; Burgess, K.; Wang, L.; Chowdhury, R. R.; Lotus, A. F.; Moula, G. Nanotechnology 2012, 23.

122. Chiono, V.; Mozetic, P.; Boffito, M.; Sartori, S.; Gioffredi, E.; Silvestri, A.; Rainer, A.; Giannitelli, S. M.; Trombetta, M.; Nurzynska, D.; Di Meglio, F.; Castaldo, C.; Miraglia, R.; Montagnani, S.; Ciardelli, G. Interface Focus 2013, 4, 20130045-20130045. 